\title{
Investigating Feeding Omega-3 Polyunsaturated Fatty Acids and/ or Soy Protein Isolate to Female pck Rats on Polycystic Kidney Disease and Related Complications
}

\author{
Kaitlin Hope Maditz \\ West Virginia University
}

Follow this and additional works at: https://researchrepository.wvu.edu/etd

\section{Recommended Citation \\ Maditz, Kaitlin Hope, "Investigating Feeding Omega-3 Polyunsaturated Fatty Acids and/or Soy Protein Isolate to Female pck Rats on Polycystic Kidney Disease and Related Complications" (2014). Graduate Theses, Dissertations, and Problem Reports. 169. \\ https://researchrepository.wvu.edu/etd/169}

This Dissertation is protected by copyright and/or related rights. It has been brought to you by the The Research Repository @ WVU with permission from the rights-holder(s). You are free to use this Dissertation in any way that is permitted by the copyright and related rights legislation that applies to your use. For other uses you must obtain permission from the rights-holder(s) directly, unless additional rights are indicated by a Creative Commons license in the record and/ or on the work itself. This Dissertation has been accepted for inclusion in WVU Graduate Theses, Dissertations, and Problem Reports collection by an authorized administrator of The Research Repository @ WVU. For more information, please contact researchrepository@mail.wvu.edu. 


\title{
Investigating Feeding Omega-3 Polyunsaturated Fatty Acids and/or Soy Protein Isolate to Female pck Rats on Polycystic Kidney Disease and Related Complications
}

\author{
Kaitlin Hope Maditz \\ Doctor of Philosophy \\ in \\ Animal and Food Sciences \\ Approved by \\ Janet C. Tou, PhD., Chair \\ Vagner Benedito, PhD. \\ Brett Kenney, PhD. \\ Joseph Moritz, PhD. \\ Jianbo Yao, PhD.
}

Dissertation submitted to the Davis College of Agriculture, Natural Resources and Design in partial fulfillment of the requirements for a degree of

Division of Animal and Nutritional Sciences

West Virginia University

Morgantown, West Virginia

2014

Keywords: soy protein, omega-3 fatty acids, kidney, polycystic kidney disease 


\title{
ABSTRACT \\ Investigating Feeding Omega-3 Polyunsaturated Fatty Acids and/or Soy Protein Isolate to Female pck Rats on Polycystic Kidney Disease and Related Complications
}

\begin{abstract}
Kaitlin Hope Maditz
Polycystic kidney disease (PKD) is a genetic disorder characterized by multiple benign cysts along the epithelial lining of the kidneys. As PKD progresses, cyst growth increases kidney volume, decreases renal function, and may eventually lead to end stage renal disease. In addition to renal manifestations, PKD patients are at risk of complications that include bone loss and polycystic liver disease (PLD). Currently, no genetic therapy or effective pharmacological treatments exist. Therefore, dietary intervention offers a potentially efficacious, cost-effective, and safe therapeutic option for PKD and PKD-related complications. Offering dietary treatment to attenuate PKD disease progression has the potential to improve renal function, preserve bone health, and to prevent PLD. Dietary soy protein has been shown to reduce cyst proliferation and growth and to enhance bone mass. Dietary omega-3 polyunsaturated fatty acids (n-3 PUFA's) have anti-inflammatory properties. Dietary n-3 PUFAs have been shown to reduce PKD severity and may attenuate bone loss and PLD severity. Therefore, the objectives of this thesis was to investigate the role of dietary soy protein and/or n-3 PUFAs on PKD progression and severity and related complications of bone loss, and PLD using a pck rat model. Young (age $28 \mathrm{~d}$ ) female pck rats were randomly assigned $(n=12$ /group) to diets consisting of casein + corn oil $($ Casein $+\mathrm{CO})$, casein + soybean oil $($ Casein $+\mathrm{SO}), \mathrm{SPI}+$ soybean oil $(\mathrm{SPI}+\mathrm{SO})$ or $\mathrm{SPI}+1: 1$ soybean/salmon oil $(\mathrm{SPI}+\mathrm{SB})$ for 12-weeks. Histological evaluation showed that all rats had renal and hepatic cysts regardless of the dietary group. Rats fed SPI+ SB diet had the highest $(\mathrm{P}=0.03)$ renal and hepatic cortical cyst obstruction. Although, rats fed SPI+SB diet had the highest $(\mathrm{P}<$ $0.001)$ renal docosahexaenoic acid (DHA) and highest $(\mathrm{P}<0.001)$ hepatic eicosapentaenoic acid (EPA) and DHA content, this did not reduce inflammation. Gene expression of various transcription factors and inflammatory genes in the kidneys and liver was not significantly different among the dietary treatment groups. Histological evaluation of hepatic and renal fibrosis and gene expression of fibrosis were also not significantly different among the dietary treatment groups. However, rats fed SPI + SB diet had the highest $(\mathrm{P}<0.01)$ serum blood urea nitrogen levels indicating reduced renal function. Rats fed SPI + SB diet also had the highest liver total lipid $(\mathrm{P}<0.001)$ and steatosis $(\mathrm{P}=0.003)$ suggesting disordered lipid metabolism. Rats fed SPI+SB diet had higher $(\mathrm{P}=0.01)$ calcium $(\mathrm{Ca})$ and phosphorus $(\mathrm{P})$ retention, but there were no significant differences in bone $\mathrm{Ca}, \mathrm{P}$, bone mass, bone microarchitecture or strength among the diet groups. Based on the results, dietary soy protein and/or n-3 PUFAs did not attenuate PKD progression and severity or related complications of bone loss and PLD in the female pck rat model of PKD. Furthermore, feeding SPI + SB diet was potentially detrimental on kidney function and liver metabolism in female pck rats.
\end{abstract}




\section{Acknowledgements}

While completing this work, I have been so very blessed by so many people.

First, I would like to thank the Davis College for giving me the opportunity to earn my doctorate degree in such a wonderful environment. I am so thankful for all of the people/professors that work in the college that have helped me out along the way. I am also eternally grateful to my fellow graduate students and lab members. I would like to especially thank Chris Oldaker for his continued friendship and support throughout this process.

I am also very thankful for my friends and family. Without the constant love and support of my parents, Robert and Susan, and fiancé, Jack Dehlin, I certainly would not be where I am today. Thank you so much for you love, patience, and kindness during some of the most enlightening, difficult, and prosperous years of my life thus far. I would also like to thank my sweet puppy, Lola, for keeping me laughing and smiling throughout this process. I am so grateful for all they have done to keep me motivated and focused on my goal.

Also, I would like to thank my committee. I can honestly say that I have been blessed with some of the very best researchers to mentor me during my schooling. I am so grateful for each of you. I would like to especially thank Dr. Benedito for his constant mentorship and support. Both in science and in character, he will always go down as 'one of the greats' in my mind. Lastly, I would like to thank my advisor, Janet Tou, for taking a chance on me. Even though I was not a top candidate at the time, Dr. Tou has molded and trained me into a scientist and leader that I hope we are both proud of. I am so proud to say that I have trained under her throughout my doctoral degree. Throughout her constant moral support, knowledge, and friendship, I have gained the skills that will 
follow me wherever I go. I feel so fortunate for every single person that has helped me along the way. Thank you all. 


\section{TABLE OF CONTENTS}

$\begin{array}{lc} & \text { Page } \\ \text { ABSTRACT } & \text { ii } \\ \text { ACKNOWLEDGEMENTS } & \text { iv } \\ \text { TABLE OF CONTENTS } & \mathrm{v} \\ \text { LIST OF TABLES } & \text { vi } \\ \text { LIST OF FIGURES } & \text { vii } \\ \text { INTRODUCTION } & 1 \\ \text { 1.0. LITERATURE REVIEW } & 4 \\ \quad \text { 1.1 RENAL FUNCTION } & 4 \\ \quad 1.2 \quad \text { PKD COMPLICATIONS } & 32 \\ \quad \text { REFERENCES } & 39 \\ \text { 2.0. STUDY OBJECTIVES AND HYPOTHESES } & 56\end{array}$

3.0. CHAPTER 1.

$\begin{array}{llr}3.1 & \text { ABSTRACT } & 59\end{array}$

$\begin{array}{lll}3.2 & \text { INTRODUCTION }\end{array}$

3.3 MATERIALS AND METHODS 61

3.4 RESULTS 66

$\begin{array}{lll}3.5 & \text { DISCUSSION } & 68\end{array}$

3.6 REFERENCES 74

4.0. CHAPTER 2 85

$\begin{array}{lll}4.1 & \text { ABSTRACT } & 86\end{array}$

$\begin{array}{lll}4.2 & \text { INTRODUCTION } & 87\end{array}$ 
4.3 MATERIALS AND METHODS 89

4.4 RESULTS AND DISCUSSION 93

$\begin{array}{lll}4.5 & \text { REFERENCES } & 101\end{array}$

$\begin{array}{llr}\text { 5.0. CHAPTER } 3 & 115\end{array}$

$\begin{array}{lll}5.1 & \text { ABSTRACT } & 117\end{array}$

$\begin{array}{lll}5.2 & \text { INTRODUCTION } & 118\end{array}$

5.3 MATERIALS AND METHODS 119

$\begin{array}{lll}5.4 & \text { RESULTS } & 125\end{array}$

$\begin{array}{lll}5.5 & \text { DISCUSSION } & 126\end{array}$

5.6. REFERENCES 130

6.0. DISSERTATION SUMMARY AND CONCLUSIONS 141

$\begin{array}{lll}7.0 & \text { FUTURE STUDIES } & 143\end{array}$ 


\section{LIST OF TABLES}

1.0 LITERATURE REVIEW

TABLE 1.

TABLE 2.

3.0 CHAPTER 1

TABLE 1.

78

TABLE 2.

TABLE 3.

80

TABLE 4.

81

TABLE 5.

82

4.0 CHAPTER 2

TABLE 1. 106

TABLE 2.

107

TABLE 3. 108

TABLE 5. 109

TABLE 6. 110

TABLE 7.

5.0 CHAPTER 3

TABLE 1.

TABLE 2.

143

TABLE 3.

144

TABLE 4. 145

TABLE 5.

147

TABLE 6. 


\section{LIST OF FIGURES}

1.0 LITERATURE REVIEW

$\begin{array}{ll}\text { FIGURE } 1 & 30\end{array}$

$\begin{array}{ll}\text { FIGURE } 2 & 31\end{array}$

3.0 CHAPTER 1

FIGURE 1

$\begin{array}{ll}\text { FIGURE } 2 & 84\end{array}$

4.0 CHAPTER 2

$\begin{array}{ll}\text { FIGURE } 1 & 113\end{array}$

$\begin{array}{ll}\text { FIGURE } 2 & 114\end{array}$

5.0 CHAPTER 3

$\begin{array}{ll}\text { FIGURE } 1 & 140\end{array}$ 


\section{INTRODUCTION}

Polycystic kidney disease (PKD) is characterized by multiple benign cysts derived from the epithelial lining of the kidneys. Cysts can develop spontaneously as a consequence of aging, dialysis, medication, and hormones or can be the result of hereditary. ${ }^{1}$ In $2008,547,982$ patients in the United States were diagnosed with kidney disease and received treatment (i.e. dialysis or kidney transplant) for end stage renal disease (ESRD) at a cost of 39.46 billion dollars. $^{2}$ Of those patients, approximately $22 \%$ of all ESRD cases were due to PKD. ${ }^{2}$ The most prevalent inherited forms of PKD are autosomal dominant polycystic kidney disease (ADPKD) and autosomal recessive polycystic kidney disease (ARPKD). ADPKD manifests in early adulthood; whereas, the rarer ARPKD has infantile onset resulting in kidney failure before adulthood. ${ }^{3}$ In both forms of $\mathrm{PKD}$, the accumulation of renal cysts results in massive kidney enlargement, structural damage, and loss of renal function. ${ }^{4}$

PKD leading to ESRD, results in the need for long-term dialysis or kidney transplantation. ${ }^{5}$ PKD can also result in the development of various renal related complications. Compromised renal function could lead to increased mineral loss and in turn, decreased bone strength and health. PKD can also result in the development of various extra-renal comorbidities and complications. The most common extra-renal cyst manifestation of PKD is cysts in the liver. ${ }^{6}$ Given these various potential complications, PKD is a major health concern with detrimental outcomes.

Common strategies for the management of renal disease and bone health in childhood are to promote a healthy body weight and to maximize peak bone mass (PBM). Pharmacological therapies for PKD typically target cyst pathogenesis. However, reports of the efficacy of pharmacological agents have been inconsistent. ${ }^{7,8}$ Effective therapies should treat the disease, be 
low in side effects, and improve related disease complications such as bone loss and liver cysts in PKD. Diet intervention offers a potentially efficacious, cost-effective, and safe therapeutic option.

Studies have examined the role of different protein and/or lipid sources as a diet strategy for decreasing PKD progression and severity using the Hans:SPRD-cy rat, an animal model of ADPKD., ${ }^{910}$ Omega-3 polyunsaturated fatty acids (n-3 PUFAs) have been reported to have antiinflammatory actions mediated through alterations in membrane composition, gene expression, and eicosanoid production. ${ }^{11,12}$ Male Han:SPRD-cy rats fed diets supplemented with n-3 PUFAs significantly decreased renal inflammation and damage. ${ }^{13}$ Feeding soy protein isolate (SPI) has been shown to reduce cyst proliferation and to decrease cyst growth in male PKD animal models. ${ }^{14,15}$ Feeding male Han:SPRD-cy rats soy protein slowed PKD progression by decreasing inflammation indicated by decreased renal cyclooxygenase-2 (COX-2) enzyme activity and renal prostanoids. ${ }^{15}$ To our knowledge, no studies have evaluated SPI and/or n-3 fatty acids on female pck rats. This is of concern since females with PKD have a higher prevalence of severe polycystic liver disease (PLD) compared to males. ${ }^{6}$ Despite liver cysts being the most common extra-renal manifestation of PKD, no studies have examined the role of diet treatment on PLD progression. Cyst pathogenesis in the liver is similar to PKD. ${ }^{6}$ Therefore, diet components such as SPI and n-3 PUFAs that have showed to attenuate cysts in PKD may also attenuate liver cysts. Furthermore, SPI and n-3 PUFAs have been found in pre-clinical studies to improve bone health and to attenuate bone loss leading to osteoporosis. ${ }^{16,17}$ The pck rat developed as a spontaneous mutation in Sprague-Dawley rats. ${ }^{18}$ Growing female Sprague-Dawley rats fed SPI enhanced bone mineral content (BMC) and bone mineral density (BMD) compared to casein. ${ }^{19}$ Previously, we reported that female Sprague-Dawley rats fed fish oil rich in the long-chain n-3 PUFAs, 
eicosapentaenoic acid (EPA, 20:5n-3) and docosahexaeonic acid (DHA, 22:6n-3) increased femur and tibial BMD and BMC; whereas, flaxseed oil rich in the n-3 PUFA, alpha linolenic acid (ALA, 18:3n-3) improved long bone trabecular microarchitecture compared to rats fed corn oil. ${ }^{20}$ Female Han:SPRD-cy rats (age $21 \mathrm{~d}$ ) fed ALA-rich flaxseed oil had higher whole body BMC and BMD compared to animals fed corn oil low in n-3 PUFAs. ${ }^{21}$ To our knowledge no studies have investigated the role of feeding soy protein and/or n-3 PUFAs on bone health in pck rats.

Currently, no rodent model is genetically orthologous while expressing phenotypes typical of human ADPKD or ARPKD. The pck rat model has a phenotype that resembles a slow progressing form of human ARPKD and PLD and also has characteristics of human ADPKD. ${ }^{22}$ Although most dietary studies have used male rodent models, females with advanced PKD exhibit increased liver cyst progression and worsened PLD severity. ${ }^{6}$ Therefore, the objective of this dissertation is to examine the role of feeding soy protein and/or n-3 PUFA to female pck rats on PKD progression, bone health, and PLD severity. 


\subsection{Literature Review}

\subsection{Renal Function}

Renal physiology and function has been reviewed in detail in Gigliotti (2011) ${ }^{23}$ Briefly, the functions of the kidney include regulation of blood volume, waste content, $\mathrm{pH}$, electrolyte and mineral concentrations, and nutrient concentrations. By regulating these components of the blood, the kidneys are the primary organ responsible for maintaining a constant composition of all extracellular fluids. These functions are accomplished within specialized regions of the renal vasculature. The nephron is composed of vascular and tubular portions which are involved in filtering the blood. Healthy individuals have around 2 million nephrons; yet, only $~ 10 \%$ of this capacity is needed to support life. Despite this large reserve capacity, millions of Americans suffer from inadequate renal function each year. ${ }^{24}$ Of particular interest to this research is the role of the kidneys on mineral balance.

\section{$C a$ and $P$ reabsorption}

As described in Gigliotti $(2011)^{23}$, the reabsorption of Ca and P occurs predominately in the proximal tubule. Tubular $\mathrm{P}$ is reabsorbed in a sodium dependent co-transport mechanism, while Ca reabsorption primarily occurs via paracellular pathway. ${ }^{25}$ However, renal handling of $\mathrm{Ca}$ and $\mathrm{P}$ can also be influenced by hormonal signaling. The major hormones involved in $\mathrm{Ca}$ and P metabolism are parathyroid hormone, vitamin $\mathrm{D}$, and calcitonin. ${ }^{26}$ Generally, parathyroid hormone and vitamin D are involved in increasing serum Ca levels by influencing release of Ca and $\mathrm{P}$ from bone, increasing intestinal absorption of $\mathrm{Ca}$, and decreasing urinary excretion of $\mathrm{Ca}$. Increased urinary reabsorption of $\mathrm{Ca}$ is mediated by parathyroid hormone induced increase in $\mathrm{Ca}$ channels in the distal nephron. Due to the toxic effects of elevated serum P, parathyroid hormone also stimulates urinary excretion of $\mathrm{P}$ to counteract the increase in serum $\mathrm{P}$ induced by 
bone resorption. On the other hand, calcitonin is released from the thyroid gland in the presence of high serum $\mathrm{Ca}$. The release of calcitonin triggers a general hypocalcemic response, which primarily involves decreased Ca release from bone.

After losing a large portion of the solutes (i.e. organic nutrients, $\mathrm{Ca}$, P, etc.) in the proximal tubule, the remaining filtrate eventually descends from the cortex of the kidney (cortex includes the glomerulus and both the proximal and distal convoluted tubules) into the medullary tissue (medulla includes both the descending and ascending Loops of Henle and the collecting ducts). As the filtrate leaves the proximal tubule, it descends into the medulla via the descending limb of the Loop of Henle. The Loop of Henle has varying properties, which contribute to the development and maintenance of the medullary characteristics. The descending limb is water permeable. Therefore, water diffuses out of the tubular lumen in response to the loss of solutes within the proximal tubule. The filtrate then continues through the ascending limb, where sodium-chloride is actively pumped out of the lumen and into the interstitial space and associated capillaries. The increased interstitial salinity is the driving force for water reabsorption from the kidney tubules. This provides an ability to regulate water excretion, which is a key function of the kidneys. ${ }^{26}$

\section{Biomarkers of renal function}

Given the role of the kidney in maintaining blood composition, insufficient renal activity can influence multiple organ systems. Therefore, monitoring renal function is of importance in both clinical and research settings. ${ }^{23}$ Serum markers of renal function include Ca, P, uric acid, total protein, albumin, and blood urea nitrogen (BUN). BUN determines the filtrating ability of the kidney. Urea is a waste product derived from the metabolism of amino acids, and is removed from the circulation through renal filtration. Therefore, increases in BUN is a biomarker of renal 
deficiency. However, serum measures of total protein, albumin, $\mathrm{Ca}$, and $\mathrm{P}$ are not specific to renal function. For example, alterations in serum protein and albumin may result from liver abnormalities and not glomerular damage resulting in increased excretion of albumin. Similarly, changes in serum $\mathrm{Ca}$ and $\mathrm{P}$ may result in pathologies associated with bone and or mineral metabolism. PKD is currently a leading genetic cause (5-10\%) of end-stage renal disease (ESRD) in the United States. ${ }^{27}$

\section{Genetics and Pathogenesis of PKD}

The most common inherited renal disease, ADPKD is caused by mutations in either the PKD 1 ( $\sim 85 \%$ of cases) or PKD 2 ( $15 \%$ of cases) gene. ${ }^{8}$ PKD 2 gene mutation produces later onset of symptoms and slower disease progression than a defect in the PKD 1 gene. ${ }^{28}$ The PKD 1 and PKD 2 gene encode cilia-associated membrane glycoproteins, polycystin-1 and 2, respectively. ${ }^{29}$ The less prevalent, but more severe ARPKD afflicting neonates and children is caused by a mutation in the PKHD1 gene encoding the cilia-associated membrane glycoprotein, fibrocystin. ${ }^{30}$ Cilia act as mechanosensors and therefore, the disruption of cilia in the kidneys affects various signaling pathways. ${ }^{31}$ Currently, the main pathways targeted for development of therapeutics to treat PKD are related to cyclic adenosine monophosphate (cAMP), mammalian target of rapamycin (mTOR) or epidermal growth factor receptor (EGFR) signaling. ${ }^{7}$ However, PKD involves multiple signal pathways due to the complex pathogenesis of cyst development and enlargement. Shown in Figure 1, cyst pathogenesis includes aberrant epithelial proliferative rates, increased apoptosis, accumulation of fluid within the cysts, degradation of matrix components, and interstitial inflammation. ${ }^{32}$ Progressive cyst growth and the resulting fibrosis in surrounding tissue leads to obstruction of the nephron, impaired kidney function, and ultimately renal failure. ${ }^{33}$ 
Animal studies have advanced our knowledge of molecular mechanisms of PKD and potential therapeutic treatments. Genetic rodent models of PKD have been generated from spontaneous mutations, transgenic technology, and gene-specific targeting. Currently, none of the available rodent models fully meet the requirements of being both genetically orthologous and expressing phenotypes typical of human ADPKD or ARPKD. ${ }^{5}$ Table 1 shows characteristics of rodent models that have been useful in evaluating potential therapies for PKD.

A dietary recommendation for PKD patients has been low protein diets. The rationale is to prevent further renal injury and thereby, progression to ESRD. Furthermore, protein restriction may inhibit cystogenesis. Although protein restriction is a common dietary recommendation for PKD patients, its efficacy and safety is debated. The next section reviews the role of low protein diets on PKD.

\section{PKD and Protein Restriction}

The role of diet on PKD has been published as a review by Maditz et al. ${ }^{34}$ Although protein restriction is a common dietary recommendation for PKD patients, its efficacy and safety is debated. It is recommended that healthy individuals consume 0.8 to $1.5 \mathrm{~g}$ protein $/ \mathrm{kg}$ body weight daily. However, protein consumption exceeding $0.8 \mathrm{~g} / \mathrm{kg}$ body weight has been suggested to negatively affect PKD by causing higher renal perfusion and kidney hyperfiltration of the already compromised nephron. ${ }^{35}$ Higher levels of protein ( $\geq 0.8 \mathrm{~g} / \mathrm{kg}$ body weight) also stimulate renin activity, which increases circulating angiotensinogen and elevates blood pressure. ${ }^{36}$ According to Torres et al. ${ }^{37}$ the occurrence of renin in the epithelial lining of cyst walls raises the possibility that abnormal expression of the renin-angiotensin system may regulate epithelial hyperplasia in growing renal cysts. Only a few animal studies, small clinical trials, and the MDRD study have investigated the amount of dietary protein on PKD. Evaluating 
the value of low protein diets on PKD progression is important because protein restriction may be associated with risk of protein malnutrition, particularly for ARPKD characterized by early onset that includes rapid growth stages.

Tomobe et al. ${ }^{35}$ investigated the role of protein restriction on PKD progression using the pcy mouse model (Table 1). Young (age 70 days) male pcy mice were randomly assigned ( $\mathrm{n}=14 /$ group) to be fed either a normal ( $25 \mathrm{~g} / 100 \mathrm{~g}$ diet $)$ or a low $(6 \mathrm{~g} / 100 \mathrm{~g} \mathrm{diet})$ protein diet with the milk protein, casein as the source. The diets were adjusted to be isocaloric and were provided ad libitum throughout the 3.5 month study. Feeding male pcy mice a low protein diet reduced kidney weight by $50 \%$ and cyst area by $40 \%$ compared to rats fed a normal protein diet. Increased cyst burden interferes with kidney function and eventually leads to renal failure. ${ }^{32}$ Despite lower cyst area in pcy mice fed a low protein diet, there was no effect on renal function indicated by no significant differences in GFR, urine volume, and urinary protein and sodium concentrations (Table 2). Protein intake was sufficient indicated by similar body weights and higher survival rates in pcy mice fed a low (310 \pm 20 days ) compared a normal ( $251 \pm 16$ days) protein diet.

Using the Han:SPRD-cy another rodent model of PKD (Table 1), male rats (age 60 days) were randomly assigned ( $\mathrm{n}=10 / \mathrm{group})$ to be fed either a normal (20 g/100 g diet) or low protein (8 g/100 g diet) diet with casein as the protein source for 4 months. ${ }^{38}$ Renal volume corrected for body weight was significantly lower in rats fed a low $(6.2 \pm 1.64 \mathrm{ml} / \mathrm{kg})$ compared to a normal $(11.6 \pm 5.02 \mathrm{ml} / \mathrm{kg})$ protein diet. Total cyst volume was significantly reduced in rats fed a low $(0.47 \pm 0.16 \mathrm{ml})$ compared to a normal $(2.68 \pm 0.87 \mathrm{ml})$ protein diet. Renal function was also improved indicated by significantly lower urinary creatinine and urea concentration in rats fed a low compared to normal protein diet (Table 2). However, body weights were significantly 
decreased in male Han:SPRD-cy rats fed a low protein diet suggesting protein malnutrition. The diets were adjusted to be isocaloric, but rats were fed ad libitum and food intake was not reported. Therefore, reduced body weight may be due to reduced caloric rather than inadequate protein intake.

Bankovic-Calic et al. ${ }^{39}$ evaluated renal tissue from the Ogborn and Sareen study ${ }^{38}$ using proliferating cell nuclear antigen-positive cells (PCNA) to determine cell proliferation. Male Han:SPRD-cy rats fed a low protein diet had significantly fewer PCNA-positive cells (57.5 cells/mm epithelium) than rats fed a normal protein diet (71.6 cells $/ \mathrm{mm}$ epithelium). Rats fed a low protein diet also had fewer $(P=0.006)$ apoptotic cells $(31.2$ cells $/ \mathrm{mm}$ epithelium $)$ compared to rats fed a normal protein diet (35.6 cells/mm epithelium). Depicted in Figure 1, cyst pathogenesis is characterized by initial proliferation and apoptosis of tubular epithelial cells followed by inflammation and fibrosis as the disease progresses. ${ }^{40,32}$ All male Han:SPRD (age 60 days) showed histological evidence of renal inflammation and fibrosis, but there was less occurrence in animals fed a low protein diet. The study results indicated that low protein intake attenuated cyst growth and expansion.

Human studies investigating the effects of protein restriction on PKD have been limited in number. Studies conducted in the 1980s with a small number of ADPKD subjects reported that protein restriction delayed progression to ESRD indicated by slower increases in serum creatinine concentration. However, these studies also included other dietary changes such as keto acid supplementation ${ }^{41}$ and phosphorus restriction. ${ }^{42}$ In a larger study, Choukroun et al..$^{43}$ retrospectively analyzed 109 ADPKD dialysis patients ( $\mathrm{n}=57$ males, $n=52$ females, age $46.1 \pm$ 0.9 years $)$ for renal decline by measuring creatinine clearance $(\mathrm{CrCl})$. Measurement of $\mathrm{CrCl}$ from values of 30 to $50 \mathrm{ml} / \mathrm{min} / 1.73 \mathrm{~m}^{2}$ until ESRD resulted in an average follow-up time of 6.7 
\pm 0.3 years. The study results indicated that protein intake of 0.7 to $1.2 \mathrm{~g} / \mathrm{kg} / \mathrm{day}$ had no effect on progression to ESRD in patients with either advanced PKD or significantly impaired renal function. This was in agreement with the MDRD study conducted to determine whether lowering dietary protein slows progression to chronic renal disease. In the MDRD study, ADPKD participants $(n=200)$ were followed for 2.2 years. ${ }^{44}$ GFR was measured monthly during the three month baseline. Participants ( $n=141$, age 40 to 49 years) determined to have a GFR range of 22 to $55 \mathrm{ml} / \mathrm{min}$ per $1.73 \mathrm{~m}^{2}$ at baseline were randomly assigned to a normal $(1.3 \mathrm{~g} / \mathrm{kg} / \mathrm{d})$ or to a low $(0.58 \mathrm{~g} / \mathrm{kg} / \mathrm{d})$ protein diet. Participants ( $\mathrm{n}=59$, age 50 to 59 years) with more severe loss of renal function indicated by a GFR range of 13 to $24 \mathrm{ml} / \mathrm{min}$ per $1.73 \mathrm{~m}^{2}$ were randomly assigned to a low $(0.58 \mathrm{~g} / \mathrm{kg} / \mathrm{d})$ or a very low $(0.28 \mathrm{~g} / \mathrm{kg} / \mathrm{d})$ protein diet. Diet compliance was assessed by three-day diet record. The low protein diet had no effect on GFR in patients with moderate renal disease due to PKD, but there was a trend $(P=0.06)$ of the low protein diet improving GFR in older participants with more severely compromised kidney function. Secondary analyses of the MDRD Study have been undertaken to clarify the effect of protein restriction on GFR and onset of ESRD. Levey et al ${ }^{45}$ concluded that the balance of evidence was more consistent with the hypothesis of a beneficial effect of protein restriction than with the contrary hypothesis of no beneficial effect on chronic kidney disease. However, no recent randomized clinical trials have been conducted on the effects of low protein diets on PKD to specifically compare results from the MDRD study on loss of kidney function in ADPKD patients. The absence of a defined amount of protein that delays disease progression while meeting protein requirements has led to greater interest in investigating the source of protein on PKD.

\section{PKD and Different Types of Proteins}


Generally, plant proteins are of lower quality than animal proteins. ${ }^{46}$ Soy protein is a high quality plant protein indicated by rats fed soy protein $(20 \% \mathrm{wt})$ for 22 months having comparable food intake, weight gain, and major organ weights to rats fed the milk protein, casein (20\% wt). ${ }^{47}$ To determine the effect of different protein sources on PKD progression, young (age 28 days) male and female Han:SPRD-cy rats (n=9-10/group) were fed a purified diet with the protein source $(20 \% \mathrm{wt})$ as either casein or a soy for six weeks. ${ }^{48} \mathrm{PKD}$ progression was attenuated in male and female Han:SPRD-cy rats fed the soy protein diet indicated by lower $(P<$ 0.01) kidney weights, cyst area, and improved renal function measurements of serum creatinine, serum urea, and creatinine clearance (Table 2). The authors suggested that soy protein attenuated PKD progression by altering insulin growth factor-1 (IGF-1) which regulates growth and GFR. Additionally, IGF-1 has been reported to increase with disease progression. ${ }^{48}$ Male, but not female, Han:SPRD-cy rats fed soy protein had reduced serum IGF-1, kidney IGF-1 content compared to casein-fed rats. Based on the study results, soy protein attenuated PKD progression in both male and female Han:SPRD-cy rats. Male rats were more responsive to dietary soy protein due to delayed disease onset in females of this genetic rodent model of PKD. However, body weight was reduced in the male rats fed dietary soy protein. Whether this was due to inadequate protein was not addressed.

Cahill et al. ${ }^{49}$ exposed offspring to soy protein prenatally and during lactation. The animal model used was the Han:SPRD-cy rats, an animal model of ADPKD. Rat dams were fed a $20 \%$ (wt) casein or soy protein diet 2 week prior to mating and throughout pregnancy and lactation. Pups exposed to soy protein in utero and during lactation showed similar effects to rats fed soy protein at weaning of reduced $(P<0.05)$ epithelial cell proliferation, renal oxidized LDL content, and inflammation (Figure 1). However, offspring exposed to soy protein in utero 
and during pregnancy also had reduced renal cyst changes and improved renal function indicated by reduced serum urea, serum creatinine, creatinine clearance, and proteinuria (Table 2). Furthermore, continued consumption of soy protein after weaning enhanced anti-inflammatory effects. Soy protein was adequate to support growth in the rat pups as evidenced by similar body weights to casein at weaning and the end of the study. The observation of greater beneficial effects when soy protein was provided in utero and during lactation has important implication for ADPKD, but may be of particular significance to ARPKD since disease onset occurs in utero or shortly after birth.

Aside from soy protein, the effects of other plant proteins on PKD progression have also been investigated. Weanling male Han:SPRD-cy rats were randomly assigned ( $\mathrm{n}=12-14$ /group) to be fed diets containing $17 \%(\mathrm{wt})$ casein or plant protein sources consisting of soy, hemp, or pea protein for 8 weeks. ${ }^{50}$ Kidney weight and cyst volume were lower $(P<0.05)$ in rats fed soy and hemp protein compared to rats fed pea protein and casein. Renal fibrosis was observed in all protein groups, however occurrence was less $(P<0.05)$ in rats fed soy or hemp protein diets. Also, serum creatinine concentration was significantly lower in Han:SPRD-cy rats fed the soy and hemp protein than the pea protein and casein diets. Based on the results, different protein sources exerted different effects on kidney weight, cysts, fibrosis, and renal function with soy and hemp protein showing the highest potential for attenuating PKD progression and severity (Table 2). Additionally, body weight was higher in rats fed soy, pea, and hemp protein compared to casein.

Mechanistic studies of PKD have been conducted in animal models fed soy protein. Ogburn et al. ${ }^{51}$ reported that weanling male Han:SPRD-cy rats fed $20 \%$ (wt) soy protein for six weeks reduced renal volume $(P<0.001)$ and cyst volume $(P<0.0001)$ compared to casein-fed 
rats (Table 2). Histological evaluation indicated decreased epithelial cell proliferation, renal fibrosis volume, and inflammation indicated by lower $(P<0.0001)$ interstitial macrophage counts (Figure 1). The renal protective effect was attributed to changes in renal fatty acid composition. Higher renal n-6 PUFA, linoleic acid (LA, 18:2n-6) content was observed in rats fed soy protein compared to casein-fed rats. Higher renal LA content was suggested to be due to inhibition of $\Delta 6$ desaturase enzyme. Decreased $\Delta 6$ desaturase activity prevents conversion of the essential $n-6$ PUFA, LA to the long-chain n-6 PUFA, arachidonic acid (ARA, 20:4n-6). ARA is a substrate for the synthesis of the 2-series eicosanoids by cyclooxygenase (COX), which at elevated levels are considered to be pro-inflammatory (Figure 2). However, the proposed mechanism could not be confirmed in this study since $\Delta 6$ desaturase activity, tissue ARA content, and 2-series eicosanoids were not measured.

Fair et al. ${ }^{52}$ addressed this by measuring ARA-derived eicosanoids in weanling male Han:SPRD-cy rats fed $20 \%$ (wt) soy or casein diets. After 3 weeks, rats fed the soy protein diet had lower kidney weights $(1.27 \mathrm{~g} / 100 \mathrm{~g}$ bwt $)$ than casein-fed rats (1.73 g/100 g bwt). Also, cyst area ratio was significantly lower in Han:SPRD-cy rats fed soy protein diet after 3 weeks of feeding. Renal fibrosis was reduced by $22 \%$ after 1 week and $38 \%$ after 3 weeks, indicating the beneficial effects of longer-duration soy protein feeding (Table 2). Rats fed the soy protein diet had significantly higher renal LA content at week 1 and 3 and prostaglandin $\mathrm{E}_{2}\left(\mathrm{PGE}_{2}\right)$ which is suggested to be protective against disease progression in the early stages of PKD when inflammation is low.

Peng et al. ${ }^{53}$ measured the activity of the inducible COX-2 enzyme as well as the 2 -series eicosanoids in male weanling Han:SPRD-cy rats $(n=8-9 /$ diet group) fed a $20 \%$ wt soy protein isolate or casein diet. After 7 weeks, rats fed the soy protein isolate diet had significantly lower 
kidney COX-2 activity and 2-series eicosanoids compared to casein-fed rats (Figure 2). The results indicated that soy protein reduced inflammation by inhibiting COX-2 activity and this in turn, decreased the production of 2-series eicosanoids. Fatty acids more than protein have been studied as regulators of the eicosanoid synthesis. ${ }^{54}$ Due to its anti-inflammatory properties, $\mathrm{n}-3$ PUFAs has been investigated as a dietary therapeutic for various diseases including PKD. ${ }^{55}$ The next section reviews the potential role of different lipid sources on PKD progression and severity.

\section{PKD and Dietary Lipids}

Ogborn et al. ${ }^{56}$ randomly assigned weanling male and female Han:SPRD-cy rats $(\mathrm{n}=76$ 79) to be fed a standard purified diet with the lipid (7\% wt) source consisting of either flaxseed oil rich in ALA or corn oil rich in n-6 PUFA, LA for 12 weeks. Kidney weights were not significantly different between diet groups. However, male rats fed flaxseed oil had lower $(P<$ $0.05)$ renal cyst area and inflammation. Gender differences were indicated by greater renal benefits in female Han:SPRD-cy rats. In addition to lower renal cyst area and inflammation, female rats fed flaxseed oil had lower renal epithelial cell proliferation, oxidized LDL tissue area, and fibrosis. Pro-inflammatory responses contribute to disease development and progression. Animal studies have shown that the ARA-derived pro-inflammatory mediator, $\mathrm{PGE}_{2}$, is decreased by EPA or docosahexaenoic acid (DHA, 22:6n-3). ${ }^{54}$ Female and male Han:SPRD-cy rats fed flaxseed oil had increased renal tissue n-3 PUFA deposition, reduced n-6 PUFA content, and decreased $\mathrm{PGE}_{2}$ release. Females have been reported to have more efficient conversion of ALA to long-chain n-3 PUFAs than males, possibly due to estrogen. ${ }^{57}$ However, whether gender influenced renal long-chain n-3 PUFA composition and $\mathrm{PGE}_{2}$ production in Han:SPRD rats fed flaxseed oil was not assessed. 
To determine whether soy protein and n-3 PUFAs can benefit established PKD, male Han:SPRD-cy rats (age 2 months) were fed a combination of different lipid and protein sources for 4 months. ${ }^{58}$ The diets consisted of either soy protein isolate or casein $(20 \% \mathrm{wt})$ as the protein source and corn oil (7\% wt) as the lipid source. To determine the effect of different lipids, a flaxseed oil (7\% wt) and casein (20\% wt) diet was included. Flaxseed oil is the richest source of the n-3 PUFA, ALA; ${ }^{59}$ whereas, corn oil is rich in the n-6 PUFA, LA. ${ }^{60}$ As expected, feeding flaxseed oil resulted in higher $(P=0.003)$ renal tissue ALA content. Despite reported inefficient conversion of ALA to long-chain n-3 PUFAs, ${ }^{61}$ renal EPA and DHA content was significantly higher in rats fed the flaxseed oil/casein diet compared to the corn oil/casein and corn oil/soy protein isolate diets. Rats fed the flaxseed oil/casein diet also had lower $(P=0.01)$ n-6 PUFA, ARA (Figure 2), than rats fed corn oil/casein and corn oil/soy protein isolate diets due to competitive inhibition of n-6 PUFA synthesis to ARA by ALA.

Altered renal tissue fatty acid content reduced renal tubular epithelial cell proliferation indicated by lower number of PCNA-positive cells in rats fed flaxseed oil/casein diet $(23.3 \pm$ 1.32 cells/ field) than rats fed corn oil/casein (30.9 \pm 0.96 cells/field) and corn oil/soy protein (24.4 \pm 1.32 cells/ field) diets. Renal oxidative damage indicated by oxidized LDL tissue area was reduced $(P=0.01)$ in rats fed flaxseed oil/casein and corn oil/soy protein isolate diets compared to rats fed corn oil/casein diet. Rats fed corn oil/soy protein isolate diet had lower serum urea nitrogen than rats fed flaxseed oil/casein and corn oil/casein diets. The study results indicated that flaxseed oil rich in the n-3 PUFA, ALA, reduced cell proliferation and oxidative damage; whereas, soy protein isolate reduced oxidative damage and improved renal function (Figure 1, Table 2). A flaxseed oil/soy protein isolate group was not included to determine whether there were synergistic effects between n-3 PUFAs and soy protein. Regardless of diet, 
all animals had similar renal cyst volume and interstitial fibrosis (Table 2, Figure 1) indicating late diet intervention had limited benefits on PKD progression. The results provide important information regarding the disease stage when diet therapy should be implemented in order to be effective. Studies investigated the effects of flaxseed oil on PKD used diets consisting of $7 \%$ wt fat. Sankaran et al. ${ }^{62}$ compared feed a high $(20 \% \mathrm{wt})$ fat to a $7 \%$ wt fat diet. Feeding adult (age 70 d) male and female pcy mice, a high fat diet for 19 weeks increased kidney weight and serum urea nitrogen compared to mice fed a $7 \%$ wt. Feeding weanling male and female pcy mice a high fat diet for 8 weeks resulted in higher renal fibrosis volume. Similarly, feeding male weanling Han:SPRD-cy rats fed a high fat (20\%) diet for 6 weeks resulted in significantly higher renal fibrosis, but also higher renal weight and lower $\mathrm{CrCl}$ than rats fed a low fat (5\% wt) diet. ${ }^{63}$ Based on the results using the pcy mouse and Han:SPRD-cy rat model, a high fat diet worsens PKD progression (Table 2).

The detrimental effects of a high fat diet were modulated by the source of the dietary lipid. Male weanling Han:SPRD-cy rats fed fish oil (menhaden) attenuated the negative effects of the high fat diet and even lowered inflammation when fed as the lipid source in high fat diet. Feeding fish oil diet rich in n-3 PUFAs, EPA and DHA, lowered kidney weight and cyst volume compared to rats fed and cottonseed oil diet rich in n-6 PUFAs or soybean oil diet containing ALA. However, weanling Han:SPRD-cy rats fed the soybean oil diet had the least renal fibrosis. Fat type did not affect renal function indicated by no significant differences in serum creatinine or $\mathrm{CrCl}^{63}$ Similarly, weanling male and female pcy mice fed flaxseed oil rich in ALA mitigated renal fibrosis in mice fed high fat $(20 \% \mathrm{wt})$ diet. $^{62}$ In contrast, feeding algal oil rich in DHA, increased kidney weight, renal cyst volume, serum urea nitrogen, and showed failure to thrive indicated by reduced body weight (Table 2$)$. Weanling pcy mice fed $(10 \% \mathrm{wt})$ fish oil 
throughout the lifespan resulted in higher proteinuria $(P=0.04)$ and reduced $(P<0.05)$ survival compared to sunflower seed oil rich in n-6 PUFA, LA in male, but not female mice (Table 2). ${ }^{64}$ These results suggest the potential benefit of fat source rich in EPA and/or DHA may be limited to the early stages of PKD progression.

Sankaran et al. ${ }^{62,65}$ investigated potential mechanism of actions of different fat sources. The fat sources consisting of corn oil and cotton oil rich in the n-6 PUFA, LA, flaxseed oil rich in the n-3 PUFA, ALA, fish (menhaden) oil rich in long-chain n-3 PUFAs, EPA and DHA, and DHA-rich algal oil were fed for 8 weeks. CD1-pcy/pcy mice and Han:SPRD-cy rats fed EPA/DHA-rich fish oil and DHA-rich algal oil up-regulated COX-2 gene expression compared to LA-rich corn oil and cotton oil diets (Figure 2). However, feeding rats flaxseed oil diet rich in ALA had no significant effect on COX-2 gene expression. Results indicated that supplementing long-chain n-3 PUFAs up-regulated COX-2 gene expression in the kidneys. In models of chronic renal disease, renal injury increases COX-2 gene expression and activity; whereas, in models of renal cystic disease COX-2 expression is reduced, but activity is increased. ${ }^{66,67}$ Therefore, the authors suggested that increased renal COX-2 expression by diets containing EPA and DHA or DHA alone reflected a decrease in renal COX-2 activity. EPA, but not ALA, is a direct substrate for COX-2 and DHA can regulate COX-2 through the transcription factor, nuclear factor kappaB. ${ }^{68}$ Synthesis of the less potent 3-series eicosanoids through the COX pathway can reduce inflammatory responses that contribute to disease development and progression. ${ }^{54}$ However, the products of COX-2 enzymes were not determined in this study.

Worsened PKD progression in weanling pcy rats fed DHA-rich algal oil was suggested to be due to increase renal long-chain n-3 PUFA content at the expense of n-6 PUFAs that resulting in inadequate tissue n-6 PUFA content as well as the potential of higher oxidation. ${ }^{62}$ Similarly, 
feeding fish oil to pcy mice that contained DHA (11 mol\%) as well as EPA (22 mol\%) also worsened PKD progression. Yamaguchi et al ${ }^{69}$ investigated n-3 PUFA, EPA. Male $(\mathrm{n}=12)$ and female DBA/2FG-pcy mice $(\mathrm{n}=12)$ age 50-58 days were fed diets containing sunflower seed oil rich in n-6 PUFA, LA or MaxEPA, an EPA-enriched fish oil concentrate, for 60 days. Both male and female mice fed the MaxEPA diet had significantly lower mean kidney weights and tubular dilation of the renal cortex and medulla, but there was no effect on renal function indicated by no significant differences in blood urea and serum creatinine levels. Male, but not female, mice fed the MaxEPA diet had significantly decreased renal cyst area. Feeding male mice the MaxEPA diet increased renal n-3 PUFA and decreased n-6 PUFA content. The effect of diet on renal tissue fatty acid composition was not evaluated in female mice to determine whether this was a factor. Instead, the less pronounced renal effects of EPA feeding on female DBA/2FG-pcy mice were attributed to slower PKD progression compared to males.

Higashihara et al. ${ }^{70}$ determined the efficacy of n-3 PUFA supplementation on PKD in human subjects. In this prospective study, ADPKD patients were randomly divided into a treatment group ( $n=20$, age $47.5 \pm 12.5, n=14$ males and $n=6$ females) provided EPA capsules ( $2.4 \mathrm{~g} /$ day EPA ethyl ester) for 2 years and an untreated group ( $\mathrm{n}=20$, age $46.8 \pm 11.4, \mathrm{n}=15$ males and $n=6$ females) asked not to take any EPA-rich supplements. Results showed no significant differences between the dietary treatment groups for kidney volumes measured by computerized tomography or creatinine clearance and urinary albumin. The results contrasted animal studies reporting beneficial effects of n-3 PUFA supplementation on PKD. A major limitation of this study was the small sample size and therefore, conclusions regarding the efficacy of n-3 PUFA efficacy were problematic. In most animal studies n-3 PUFA supplementation occurred at weaning (Table 2); whereas, n-3 PUFA supplementation for 
ADPKD patients occurred in the more advanced disease stage. Additionally, individuals provided EPA capsules had higher erythrocyte $(P<0.001)$ EPA content, but DHA content was decreased $(P<0.01)$, suggesting inefficient conversion. Results obtained from rodent models should be carefully evaluated when extrapolating effects to humans since conversion of EPA and DHA is more efficient in mice and rats than in humans. ${ }^{71}$

Other fatty acids being investigated are the conjugated linoleic acids (CLAs). Most studies have use trans-10-cis-12 and the cis-9-trans-11 CLA isomers. Anti-inflammatory mechanisms attributed to CLAs include: 1) competition with LA for desaturase and elongase enzymes to reduce tissue ARA content, 2) inhibition of phospholipase $A_{2}$ enzyme that release tissue ARA, and 3) inhibition of COX-2 expression. ${ }^{72,73}$ In addition to inflammation, the CLA cis-9-trans-11 isomer has been associated with anti-proliferative effects of the cysts. ${ }^{74}$

Ogborn et al. ${ }^{75}$ fed weanling male Han:SPRD-cy rats a standard purified diet consisting of corn oil (7 \% wt) or corn oil ( $5.33 \% \mathrm{wt})$ supplemented with CLA $(1.67 \% \mathrm{wt})$ for 8 weeks. CLA supplementation had no significant effect on cyst formation or serum creatinine (Table 2), but reduced inflammation indicated by lower macrophage infiltration $(P<0.001)$, lower $(P=0.022)$ renal $\mathrm{PGE}_{2}$ content, and reduced renal interstitial fibrosis $(P=0.03)$ (Figure 1). Rats provided the CLA supplemented diet had significantly reduced renal tissue phospholipase $\mathrm{A}_{2}$ protein level, $\mathrm{COX}-2$ protein level and activity, and lower steady-state $\mathrm{TXB}_{2}, \mathrm{PGE}_{2}$, and 6-keto-PGF1 $\alpha$ (Figure 2) ${ }^{76}$ Based on the results, CLA supplementation attenuated the later stages of PKD by reducing the synthesis of ARA-derived pro-inflammatory eicosanoids.

To investigate gender differences, Ogborn et al. ${ }^{77}$ fed weanling male $(n=47)$ and female (n=54) Han:SPRD-cy rats a diet consisting of corn oil (7\% wt) or corn oil supplemented with 1 or $2 \%$ (wt) CLA for 12 weeks. Feeding both male and female rats diets supplemented with 
CLA increased $(P=0.001)$ renal CLA content. However, female rats showed a dose-dependent response in renal $(P=0.005)$ CLA cis-9-trans-11 content. Both male and female Han:SPRD-cy rats provided diets supplemented with CLA had lower $(P<0.001)$ renal epithelial cell proliferation. Female rats provided CLA also showed a dose-dependent decrease in oxidative damage, inflammation, and fibrosis. CLA acts as a ligand for the transcription factor peroxisome proliferator-activated receptor gamma (PPAR $\gamma$ ) which plays important roles in regulating cell proliferation, inflammation, and fibrosis. ${ }^{78}$ However, in this study was no significant effect of CLA supplementation on PPAR $\gamma$ activation in either gender. Also, CLA supplementation increased serum creatinine concentration in female rats suggesting a possible decline in renal function. Therefore, more studies are needed before CLA supplementation can be recommended as a dietary treatment for PKD.

Based on the results of the animal studies, different lipid sources exert different effects. CLAs and long-chain n-3 PUFAs altered COX-2 enzyme activity; whereas, ALA-rich flaxseed oil had no significant effect on COX-2 enzyme activity. However, weanling male Han:SPRD-cy rats fed standard purified diet supplemented with whole flaxseed (10\% wt) for eight weeks had reduced $(P<0.05)$ renal cyst volume, inflammation, fibrosis, and improved kidney function ${ }^{79}$ (Table 2, Figure 1). The results suggested that flaxseed has other dietary components with the potential to attenuate PKD progression and severity. Flaxseed oil and other plant oils are rich in the antioxidant, $\alpha$-tocopherol. ${ }^{80}$ Antioxidants can prevent tissue injury that promotes PKD progression and severity. Reduced endogenous antioxidant enzymes and increased oxidative stress has been reported in Han:SPRD-cy rat and C57BL/6J-cpk mice models of PKD. ${ }^{81,82}$ Therapeutic drugs with antioxidant properties have been reported to attenuate renal cystic diseases in rat and mouse models. ${ }^{83,84}$ In human studies, increased plasma lipid peroxidation and 
reduced endogenous antioxidant enzyme activity has been observed in individuals with inherited $\mathrm{ADPKD}^{85}$ as well as in individuals with spontaneous renal cysts. ${ }^{86}$ Men with ADPKD or spontaneous renal cysts have more rapid progression to ESRD than woman, indicating gender plays an important role in PKD progression and severity. ${ }^{87,43}$ Higher renal $\alpha$-tocopherol content in female Hans:SPRD-cy rats suggests that tissue differences in vitamin E may be responsible for slower PKD progression in females. ${ }^{88}$ Torres et al. ${ }^{88}$ provided weanling male $(n=6-7)$ and female $(n=4-10)$ Han:SPRD-cy rats a vitamin E deficient diet or diets supplemented with 65 IU or 10,000 IU $\alpha$-tocopherol for 8 weeks. Feeding diets supplemented with $\alpha$-tocopherol increased kidney $\alpha$-tocopherol content, but there were no significant effects on kidney weight, cyst index, inflammation, and kidney function markers, plasma creatinine and urea (Table 2, Figure 1). Due to the absence of significant beneficial effects, vitamin E supplementation is not being recommended as a treatment for PKD. Absence of antioxidant effects on PKD may be because cyst pathogenesis is regulated by multiple pathways. Phytochemicals and phytoestrogens have antioxidant as well as anti-proliferative, ant-inflammatory, and hormonal properties ${ }^{89}$ and therefore, may be effective therapeutic agents.

\section{PKD and Phytoestrogens and Phytochemicals}

Phytoestrogens and phytochemicals effect cellular signaling and therefore, can alter developmental and physiological events. ${ }^{90}$ Soy protein and soy products are the major sources of the phytoestrogen, isoflavones. ${ }^{90}$ Ogborn et al. ${ }^{91}$ fed weaning male Han:SPRD-cy rats diets consisting of $20 \%$ (wt) casein or soy protein diets with high $(3.62 \mathrm{mg} / \mathrm{g}$ protein) or low isoflavone $(0.11 \mathrm{mg} / \mathrm{g}$ protein $)$ content for 8 weeks. Rats fed the soy protein-based diets had similar effects on inflammation and renal function. However, rats fed the soy protein diet high in isoflavones showed less renal oxidative damaged; whereas, rats fed the soy protein diets low in 
isoflavones showed the greatest reduction in relative renal weight, cystic changes, and epithelial proliferation. Based on the results, the beneficial effects of soy containing isoflavones on PKD differed depending on the dose (Table 2, Figure 1).

To determine whether the renal effects of isoflavones were independent of soy protein, Tomobe et al.$^{82}$ fed young (age 60 days) male pcy mice a casein diet (25 g/100 g diet) with or without the isoflavone, genistein $(0.05 \mathrm{~g} / 100 \mathrm{~g}$ diet). Genistein supplementation for 60 days had no significant effect on kidney weight, water content, and cyst volume (Table 2). The study results suggested that dietary factors other than phytoestrogens were responsible for the beneficial effects of soy protein. Both studies investigating the effects of dietary phytoestrogens used males. However, gender differences should be considered since phytoestrogens are nonsteroidal plant-derived compounds with structural similarity to endogenous estrogens and therefore, have the ability to exert weak estrogenic or anti-estrogenic effects. ${ }^{92}$

Flaxseed is the richest source of secoisolariciresinol diglycoside (SDG) which is the precursor of mammalian lignans. ${ }^{93}$ Ogborn et al.${ }^{94}$ fed weanling male and female Han:SPRD-cy rats ( $\mathrm{n}=76-79)$ diets supplemented with SDG (20 mg/kg diet) or no SDG for 12 weeks. Male and female rats fed SDG diets had no significant effect on kidney weight, cysts, and fibrosis, but renal inflammation was reduced $(P<0.05)$ (Table 2, Figure 1). Female, but not male, Han:SPRDcy rats fed a diet supplemented with SDG reduced oxidative damage indicated by lower oxidized LDL renal tissue area (Figure 1). Estrogen has been reported to have antioxidant effects and to suppress inflammation. ${ }^{95}$ Based on the study results, dietary phytoestrogens effects differed depending on gender with more beneficial effects on PKD in female than male rats.

Phytoestrogens also act on several pathways involved in cytogenesis such as AMPactivated protein kinase, mitogen-activated protein kinase (MAPK), and peroxisome proliferator- 
activated receptor gamma (PPAR $\gamma){ }^{90}$ However, few studies have investigated the potential of phytoestrogens to attenuate PKD by inhibiting these pathways. Tumeric is a spice used as an ingredient in curry. The main biologically active phytochemical compound in turmeric is the yellow pigment, curcumin. Curcumin has been reported to show beneficial effect against inflammatory diseases and to be safe for human consumption. ${ }^{96}$ Gao et al.${ }^{97}$ used murine embryonic and Madin-Darby canine kidney cells as a cyst model to explore mechanisms of cyst inhibition. Cells treated with curcumin reduced cyst epithelial proliferation by inhibiting the Ras/MAPK signaling pathway. ${ }^{97}$ To determine the potential therapeutic effects of curcumin in vivo, a Pkd1-deletion mouse model of ADPKD ( $\mathrm{n}=5$, age 49 days, gender not provided) were fed a diet supplemented with $1 \%$ (wt) or no curcumin. Mice provided curcumin for 11 weeks showed beneficial effects on the early stages of PKD indicated by reduced cell proliferation index, cystic index, and kidney weight/body weight ratio (Table 2, Figure 1). Mice that continued to be fed curcumin for 15-17 weeks had postponed renal failure. ${ }^{98}$ Together these studies provided evidence that phytochemicals inhibited PKD progression and severity through multi-pathways. Compounds currently under investigation in clinical trials mainly act on single pathways although multiple pathways are involved in PKD. ${ }^{98}$ Consequently, this requires high doses which increasing the risk of side effects. By acting simultaneously on various PKDrelated pathways, diet can provide a successful and safer therapeutic option.

Various dietary components were reported to attenuate PKD progression and severity (data summarized in Table 2). Currently, low protein diets are recommended to PKD patients. However, data from animal and human studies are inconsistent and the benefits and safety of low protein diets for PKD remain controversial. Instead, the type of dietary protein may be of importance. In animal studies soy protein consumption attenuated the early stages cyst 
pathogenesis indicated by reduced epithelial cell proliferation and apoptosis as well as the later stages by reducing oxidative damage, inflammation, and fibrosis (Figure 1). Aside from dietary proteins, there are an increasing number of studies investigating the role of the amount of dietary lipids and fat type on PKD. Supplementation of n-3 PUFAs attenuated epithelial cell proliferation, oxidative damage, inflammation, and fibrosis. However, renal effects differed depending on whether the type of n-3 PUFA consumed was ALA, EPA or DHA. Dietary n-3 PUFAs has the potential to influence multiple steps in PKD pathogenesis, but studies have mainly focused on altering tissue fatty acid composition and eicosanoid metabolism. CLA, another class of fatty acids, also showed beneficial effects on PKD. However, potential safety concerns were raised based on the observation of reduced kidney function in female Han:SPRDcy rats. Flaxseed SDG, soy isoflavones, and curcumin are other dietary compounds that showed promise for attenuating cystogenesis. However, more research is needed to confirm the efficacy of these dietary compounds on PKD. 
Table 1. Characteristics of genetic animal models of polycystic kidney disease commonly used to study therapeutic inventions

\begin{tabular}{|c|c|c|c|c|}
\hline Model & Gene Mutation & Genotype & Human Phenotype Equivalent & Encoded Protein \\
\hline pcy mouse & NPHP3 & Autosomal Recessive & Autosomal Dominant & Nephrocystin \\
\hline cpk mouse & Cys $1^{\mathrm{cpk}}$ & Autosomal Recessive & Autosomal Recessive & Cystin \\
\hline \multirow[t]{3}{*}{ bpk mouse } & Bicc1 ${ }^{\text {bpk }}$ & Autosomal Recessive & Autosomal Recessive & mRNA-binding protein \\
\hline & & & & involved in posttranscriptional \\
\hline & & & & polyadenylation \\
\hline orpk mouse & Ift $88 \mathrm{Tg} 737^{\text {Rpw }}$ & Autosomal Recessive & Autosomal Recessive & Polaris \\
\hline Han:SPRD-cy & Pkdr1 & Autosomal Dominant & Autosomal Dominant & SamCystin \\
\hline pck rat & Pkhd1 & Autosomal Recessive & Autosomal Dominant/Recessive & Fibrocystin \\
\hline
\end{tabular}

Adaptation from Torres et al. (2007) ${ }^{5}$ and Guay-Woodford ${ }^{89}$ 
Table 2. The effect of different diet components on kidney weight, cysts, and function

\begin{tabular}{|c|c|c|}
\hline Authors & Dietary Study & Results \\
\hline \multicolumn{3}{|c|}{ Low Protein } \\
\hline \multirow[t]{3}{*}{ Tomobe et al. $(1994)^{35}$} & male pcy mice age $70 \mathrm{~d}$ & $\downarrow$ kidney weight \\
\hline & low protein $(6 \mathrm{~g} / 100 \mathrm{~g}$ diet $)$ for 3.5 months & $\downarrow$ kidney cyst area \\
\hline & & NS kidney function \\
\hline \multirow[t]{4}{*}{ Ogborn and Sareen. $(1995)^{38}$} & male Han:SPRD-cy rats age $60 \mathrm{~d}$ & $\downarrow$ relative kidney \\
\hline & low protein $(8 \mathrm{~g} / 100 \mathrm{~g}$ diet $)$ for 4 months & volume \\
\hline & & $\downarrow$ kidney cyst volume \\
\hline & & $\uparrow$ kidney function \\
\hline
\end{tabular}

\begin{tabular}{lll}
\hline Choukroun et al. $(1995)^{43}$ & ADPKD patients $(\mathrm{n}=109)$ age $46.1 \pm 0.9$ years & \\
& $0.7-1.2 \mathrm{~g} / \mathrm{kg} / \mathrm{d}$ protein for $6.7 \pm 0.3$ years & NS kidney function \\
\hline Klahr et al. $(1995)^{44}$ & ADPKD patients $(\mathrm{n}=41)$ age $40-49$ years & NS kidney function \\
& $0.58 \mathrm{~g} / \mathrm{kg} / \mathrm{d}$ protein for 2.2 years & \\
& ADPKD patients $(\mathrm{n}=59)$ age $50-59$ years & 个 trend $(P=0.06)$ \\
& $0.58 \mathrm{~g} / \mathrm{kg} / \mathrm{d}$ protein for 2.2 years & kidney function
\end{tabular}

\section{Types of Protein}

\begin{tabular}{|c|c|c|}
\hline $\begin{array}{l}\text { Aukema and Housini } \\
(2001)^{48}\end{array}$ & $\begin{array}{l}\text { male/female Han:SPRD-cy rats age } 28 \mathrm{~d} \\
20 \% \mathrm{wt} \text { soy protein for } 6 \text { weeks }\end{array}$ & $\begin{array}{l}\downarrow \text { kidney weight } \\
\downarrow \text { kidney cyst area } \\
\boldsymbol{\uparrow} \text { kidney function }\end{array}$ \\
\hline Cahill et al. $(2007)^{49}$ & $\begin{array}{l}\text { Han:SPRD-cy rats offspring in utero/lactation } \\
20 \% \text { wt soy protein }\end{array}$ & $\begin{array}{l}\downarrow \text { kidney cyst changes } \\
\uparrow \text { kidney function }\end{array}$ \\
\hline Aukema et al. $(2011)^{50}$ & $\begin{array}{l}\text { male Han:SPRD-cy rats age } 21 \mathrm{~d} \\
17 \% \text { wt soy protein and hemp protein }\end{array}$ & $\begin{array}{l}\downarrow \text { kidney weight } \\
\downarrow \text { kidney cyst volume } \\
\uparrow \text { kidney function }\end{array}$ \\
\hline Ogborn et al. $(2000)^{99}$ & $\begin{array}{l}\text { male Han:SPRD-cy rats age } 21 \mathrm{~d} \\
20 \% \text { wt soy protein for } 6 \text { weeks }\end{array}$ & $\begin{array}{l}\downarrow \text { kidney volume } \\
\downarrow_{\text {kidney cyst volume }}\end{array}$ \\
\hline Fair et al. $(2004)^{52}$ & $\begin{array}{l}\text { male Han:SPRD-cy rats age } 21 \mathrm{~d} \\
20 \% \text { wt soy protein for } 1 \text { or } 3 \text { weeks }\end{array}$ & $\begin{array}{l}\downarrow \text { relative kidney weight } \\
\downarrow \text { kidney cyst area ratio }\end{array}$ \\
\hline
\end{tabular}




\section{Dietary Lipids and Vitamin E}

\begin{tabular}{|c|c|c|}
\hline Ogborn et al. $(2006)^{94}$ & $\begin{array}{l}\text { male/female Han:SPRD-cy rats age } 21 \mathrm{~d} \\
7 \% \text { wt flaxseed oil for } 12 \text { weeks }\end{array}$ & $\begin{array}{l}\text { NS kidney weight } \\
\downarrow \text { kidney cyst area }\end{array}$ \\
\hline $\begin{array}{l}\text { Sankaran \& Bankovic } \\
(2007)^{62}\end{array}$ & $\begin{array}{l}\text { male Han:SPRD-cy rats age } 2 \text { months } \\
7 \% \text { wt flax seed oil for } 4 \text { months }\end{array}$ & NS kidney cyst volume \\
\hline Yamaguchi et al. $(1990)^{69}$ & $\begin{array}{l}\text { male/female DBA/2FG-pcy age } 50-58 \mathrm{~d} \\
\text { EPA supplement for } 60 \text { days }\end{array}$ & $\begin{array}{l}\downarrow \text { kidney weight } \\
\downarrow \text { renal tubular dilation } \\
\downarrow \text { kidney cyst area (males) } \\
\text { NS kidney function }\end{array}$ \\
\hline Higashihara et al. $(2008)^{70}$ & $\begin{array}{l}\text { male/female ADPKD patients }(\mathrm{n}=6-14) \\
\text { age } 47.5 \pm 12.5 \text { years } \\
2.4 \text { g/d EPA supplements for } 2 \text { years }\end{array}$ & $\begin{array}{l}\text { NS kidney volume } \\
\text { NS kidney function }\end{array}$ \\
\hline Ogborn et al. $(2003)^{75}$ & $\begin{array}{l}\text { male Han:SPRD-cy rats age } 21 \mathrm{~d} \\
1.67 \% \text { wt CLA for } 8 \text { weeks }\end{array}$ & $\begin{array}{l}\text { NS kidney cysts } \\
\text { NS kidney function }\end{array}$ \\
\hline Ogborn et al. $(2008)^{77}$ & $\begin{array}{l}\text { male/female Han:SPRD-cy rats age } 21 \mathrm{~d} \\
1 \text { or } 2 \% \text { wt CLA for } 12 \text { weeks }\end{array}$ & $\downarrow$ kidney function (females) \\
\hline Ogborn et al. (1999) $)^{79}$ & $\begin{array}{l}\text { male Han:SPRD-cy rats age } 21 \mathrm{~d} \\
10 \% \mathrm{wt} \text { flaxseed for } 8 \text { weeks }\end{array}$ & $\begin{array}{l}\downarrow \text { kidney cyst volume } \\
\uparrow \text { kidney function }\end{array}$ \\
\hline Torres et al. $(1998)^{100}$ & $\begin{array}{l}\text { male/female Han:SPRD-cy rats age } 21 \text { days } \\
65 \mathrm{IU} \text { or } 10,000 \mathrm{IU} \alpha \text {-tocopherol for } 8 \text { weeks }\end{array}$ & $\begin{array}{l}\text { NS kidney weight } \\
\text { NS kidney cyst index } \\
\text { NS kidney function }\end{array}$ \\
\hline
\end{tabular}

\section{Phytoestrogens/Phytochemicals}

\begin{tabular}{lll}
\hline Ogborn et al. (2010) & male Han:SPRD-cy rats age 21 d & $\boldsymbol{\downarrow}$ relative kidney \\
& soy protein + isoflavones (3.62 or 0.11 mg/g & weight \\
& protein) for 8 weeks & $\boldsymbol{\downarrow}$ kidney cyst changes \\
& & $\boldsymbol{\uparrow}$ kidney function \\
\hline Tomobe et al. (1998) & male pcy mice age 60 d & NS kidney weight \\
& genistein (0.05 mg/100 g diet) for 60 d & NS kidney cyst volume \\
\hline Ogborn et al. (2006) $)^{56}$ & male/female Han:SPRD-cy rats age 21 d & NS kidney weight \\
& SDG (20 mg/kg diet) for 12 weeks & NS kidney cysts \\
\hline
\end{tabular}




\begin{tabular}{llc}
\hline Leonard et al. $(2011)^{98}$ & Pkd1-deletion mice age $49 \mathrm{~d}$ & $\boldsymbol{\downarrow}$ relative kidney weight \\
& $1 \%$ wt curcumin for 11 or $15-17$ weeks & $\boldsymbol{\downarrow}_{\text {kidney cystic index }}$ \\
& $\boldsymbol{\uparrow}$ kidney function with \\
& longer feeding
\end{tabular}

Abbreviations NS, statistically non-significant; SDG, secoisolariciresinol diglycoside 
Figures 1. The role of dietary components on cyst pathogenesis in polycystic kidney disease. Abbreviations are (-) inhibition; CLA, conjugated linoleic acid; SDG, secoisolariciresinol diglycoside.

Figure 2. The role of dietary components on omega- 6 and omega-3 polyunsaturated fatty acids and eicosanoid production in polycystic kidney disease. Abbreviations are (-) inhibition; (+) simulation; n-6 PUFA, omega-6 polyunsaturated fatty acids; n-3 PUFA, omega-3 polyunsaturated fatty acids; LA, linoleic acid; ALA, alpha-linolenic acid; ARA, arachidonic acid; EPA, eicosapentaenoic acid; DHA, docosahexaenoic acid; COX-2, cyclooxygenase-2, $\mathrm{PGE}_{2}$, prostaglandin $\mathrm{E}_{2} ; \mathrm{TXB}_{2}$, thromboxane $\mathrm{B}_{2} ;$ 6-keto PGF1 $\alpha$, 6-keto prostaglandin $\mathrm{F} 1$ alpha; CLA, conjugated linoleic acid; SDG, secoisolariciresinol diglycoside. 
Figure 1.

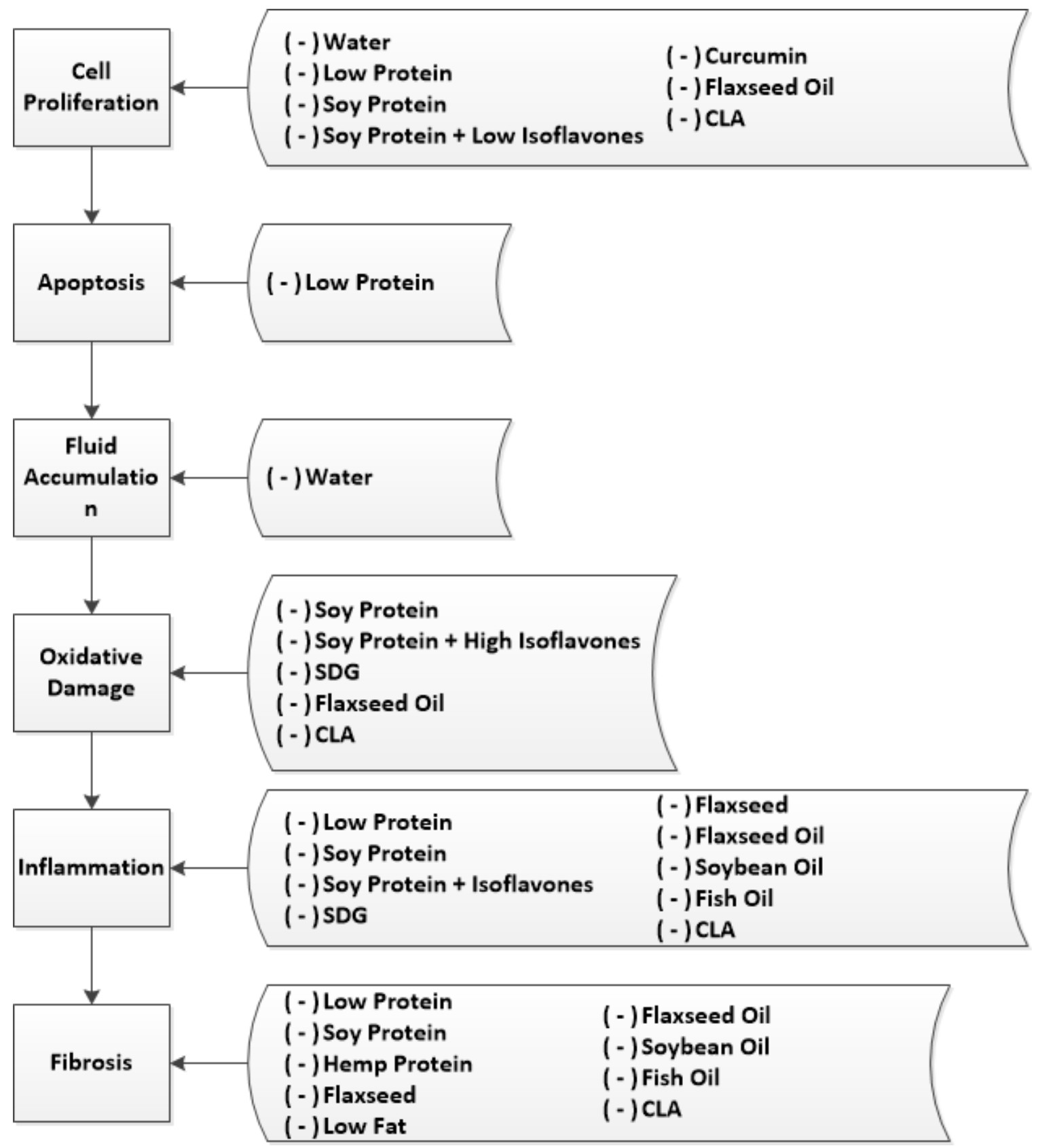


Figure 2.

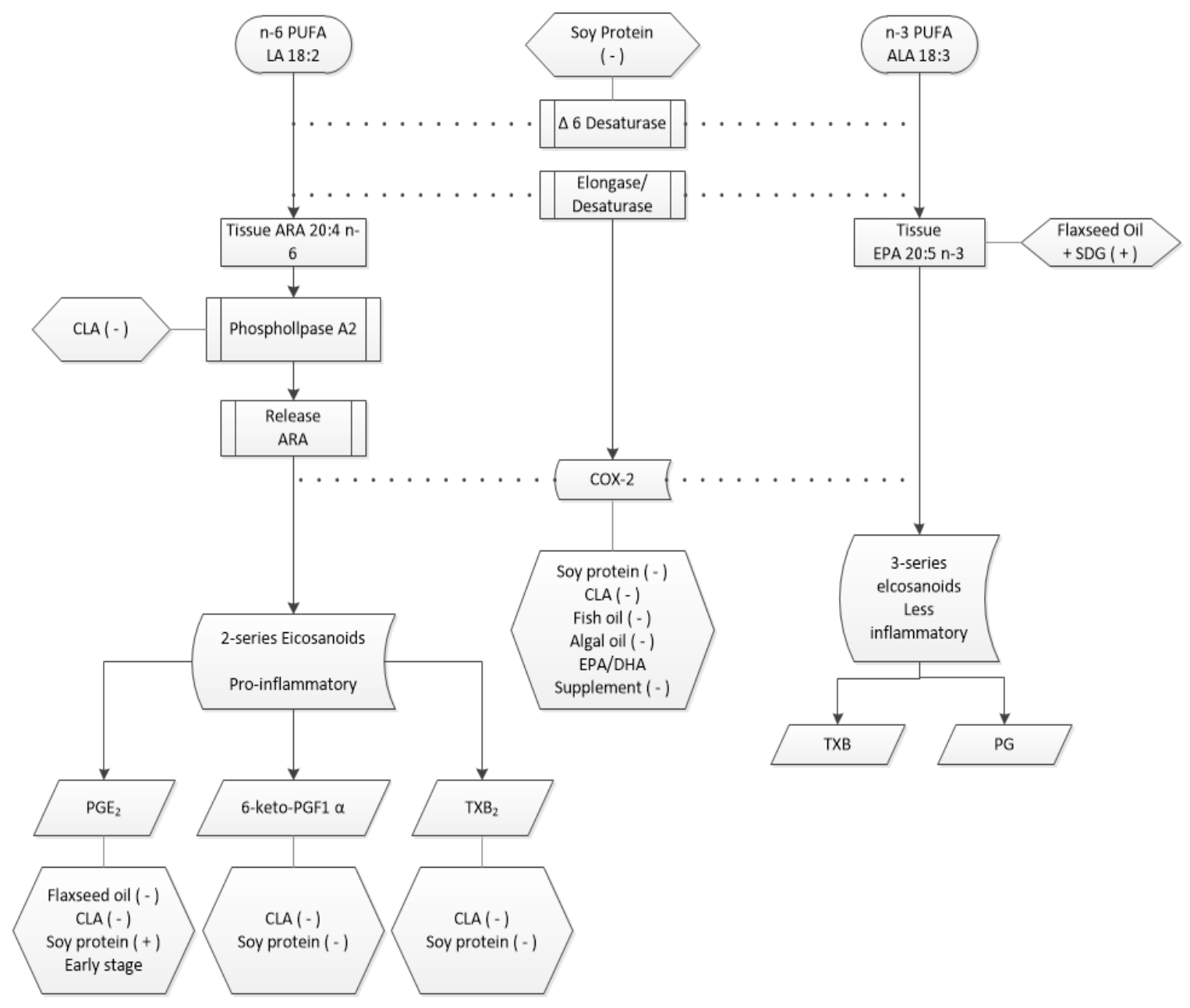




\subsection{PKD Complications}

\section{Bone Loss}

Effective therapies promote improvement at the disease site and related disease complications as well as reduce the risk of side-effects. As kidney function degrades, it is possible for minerals to be excreted in the urine. Excessive mineral losses may eventually compromise bone mineral content and decreased bone health. Epidemiological studies have demonstrated greater incidence of bone fractures in ESRD patients. ${ }^{102}$ PKD is a major cause of ESRD. In 2008, 547,982 patients in the United States were diagnosed with kidney disease and received treatment (i.e. dialysis or kidney transplant) for ESRD. ${ }^{2}$ Of those patients, approximately $22 \%$ of all ESRD cases were due to PKD. ${ }^{2}$ Also, several drugs used to treat PKD has reported side effects of bone loss. ${ }^{21}$

\section{Bone Morphometry and Function}

Bone biology and metabolism was extensively reviewed in Lukas 2010. ${ }^{103}$ Briefly, the skeletal system functions to support the body structurally, store minerals and lipids, produce blood cells, protect soft tissues, and act as levers to change direction and magnitude of the forces from skeletal muscles. Several segments make up the long bone. The diaphysis is the bone's shaft and the epiphyses are the proximal and distal ends of the bone. ${ }^{104}$ In a mature bone, the metaphyses are where the diaphysis joins the epiphyses. In a growing bone, the metaphyses include the epiphyseal plate. A tough sheath of dense irregular connective tissue called the periosteum covers the bone. Cartilage covers the bone where the bone forms a joint with another. The marrow cavity (i.e., medullary cavity) is the space within the diaphysis that contains bone marrow. The microarchitecture of the bone consists of epiphyses containing spongy or trabecular bone. Trabecular bone has a honeycombed structure and has a thin covering of cortical 
bone. ${ }^{104}$ In cortical bone, calcium phosphate [Ca3(PO4)2] accounts for almost two-thirds of the weight of the bone. ${ }^{104}$ Calcium phosphate interacts with calcium hydroxide, $[\mathrm{Ca}(\mathrm{OH}) 2]$ to form crystals of hydroxyapatite, [Ca10(PO4)6(OH)2]. The hard and brittle hydroxyapatite crystals are stored in the bone matrix and can withstand compression, but break when bent or twisted. ${ }^{104}$ In contrast, collagen fibers in the bone matrix are flexible and can tolerate twisting or bending, but not compression. ${ }^{104}$ The combination of the hydroxyapatite crystals and collagen fibers forms a strong bone that is somewhat flexible and highly resistant to fracture.

\section{Bone turnover markers}

There are three categories of bone turnover markers: enzymes/proteins that are secreted by cells involved in remodeling process, breakdown products generated in the resorption of old bone, and byproducts produced during the synthesis of new bone. ${ }^{105}$ Serum osteocalcin is commonly used as an indicator of bone formation (osteoblast activity). Osteocalcin is a bonespecific protein released into the blood during new matrix formation. ${ }^{106}$ Osteoblasts are rich in alkaline phosphatase, however the function of this enzyme is unknown. ${ }^{105}$ Osteoblast as well as osteoclast activity regulate bone mass. ${ }^{106}$ Bones weaken when osteoclasts remove bone faster than osteoblasts deposit bone. ${ }^{104}$ Urinary deoxypyridinoline (DPD) is the primary? clinical function marker that is used to determine system bone resorption. ${ }^{102}$ Increased levels of DPD in the urine indicate resorption is occurring within the bone.

\section{Bone Mineralization, Microarchitecture, and Strength}

Demineralization and the breakdown of collagen in the bone matrix results in bone loss. ${ }^{107}$ Cortical mineralization can be determined by using dual energy x-ray absorptiometry (DEXA) to measure bone mineral density (BMD), bone mineral content (BMC) and bone mineral area (BMA). BMD represents a measurement of the bone mass per $\mathrm{cm} 2, \mathrm{BMC}$ 
represents the mass of the bone, and BMA represents the area of bone occupied by minerals.

Decreased BMD and BMC increase bone fragility and susceptibility to fracture. ${ }^{108}$

Bone architecture can be determined using micro-computed tomography $(\mu \mathrm{CT})$.

Trabecular bone volume to total tissue volume ratio (BV/TV) is the trabecular fraction of bone in the sample, trabecular number $(\mathrm{TbN})$ is the number of trabeculae per mm of bone, trabecular thickness $(\mathrm{TbTh})$ represents the mean diameter of the trabeculae, trabecular separation $(\mathrm{TbSp})$ is the mean size of the intertrabecular spaces, connectivity density (CONN) is a quantified measurement of elasticity, and structure model index (SMI) characterizes the type of structure of the sample (rod-like, plate-like, or mixed structures). High values for BV/TV, TbN, TbTh and CONN correlate with a strong bone. High values for TbSp indicate a weak bone. A bone having more rod-like structures is weaker than bone having more plate-like structures. ${ }^{109}$ For an ideal plate structure, SMI is close to 0 and for an ideal rod structure the value is 3 . Low bone mineralization and microarchitecture decreased bone strength is defined as susceptibility to fracture. ${ }^{110}$

Bone fragility is defined by biomechanical parameters. These parameters include:

strength, brittleness, work to failure, and stiffness. ${ }^{110}$ A force- displacement curve generated by strength testing used to calculate bone biomechanical parameters.

\section{Dietary Treatment of PKD Related Bone Loss}

To our knowledge few studies have few studies have investigated the role of diet on bone in PKD. In the ADPKD rat model, Hans:SPRD-cy rats fed 5\% wt flaxseed oil rich in ALA for 8 weeks had no significant effect on whole body BMC and BMD. ${ }^{111}$ However, growing female Hans:SPRD rats, a model of ADPKD, fed 7\% wt flaxseed oil rich in n-3 PUFA, ALA, before the onset of disease and continuing for 12 weeks, lengthened the femur compared to rats fed corn oil 
low in ALA. ${ }^{21}$ Early diet management by optimizing bone health during the growth stage can potentially minimize bone loss due to renal dysfunction and ERSD at an early age in PKD patients. ${ }^{112,113}$ Dietary fats may affect bone by altering Ca balance. Kruger et al. $2005^{114}$ reported that young (age 5 weeks) male Sprague-Dawley rats fed 5\% tuna oil $\mathrm{g} / \mathrm{kg}$ diet had significantly higher $\mathrm{Ca}$ absorption and decreased urinary $\mathrm{Ca}$ compared to the rats fed evening primrose oil. The authors suggested that cell membrane saturation reduced $\mathrm{Ca}$ absorption and decreased cell membrane saturation due to n-3 PUFA consumption resulting in increased $\mathrm{Ca}$ absorption and decreased urinary Ca loss. Claassen et $\mathrm{al}^{115}$ fed growing (age 21 days) male Sprague-Dawley rats different ratios of $\gamma$-LA:EPA. Ratio of 3:1 of $\gamma$-LA:EPA decreased Ca excretion and led to rats with higher $(P<0.05)$ bone Ca content compared to the control ratio of 3:1 of LA:ALA. Feeding healthy growing female Sprague-Dawley rats SPI enhanced bone mineral content (BMC) and bone mineral density (BMD) compared to casein. ${ }^{19}$ It remains unknown if soy protein isolate can improve bone health in female pck rats.

Aside from renal related complication, an extra-renal complication of PKD is that cysts are not confined to the kidney and may form in various organs. The most common extra-renal cyst manifestation of PKD is cysts in the liver. ${ }^{6}$

\section{Liver Anatomy and Physiology}

Liver anatomy and physiology has been extensively described in Baynes and Dominiczak. ${ }^{116}$ Briefly, the human liver, comprised of four major lobes, is the largest solid organ in the body (secondary to skin) and is located in the upper right section of the abdominal cavity. The liver is known to perform a variety of functions, but a main function of the liver is nutrient and drug metabolism. The liver receives all products of digestion by venous blood via the hepatic portal vein from the intestine for metabolism. 


\section{Lipid digestion, absorption, transport}

Triglycerides comprise nearly $90 \%$ of all lipid intake in the diet. ${ }^{116}$ The other lipid components ingested in the diet consist of cholesterol, phospholipids, and free fatty acids. Following dietary intake of triglycerides and cholesterol, the lipids are hydrolyzed to allow for transport throughout the body. In the small intestine, triglycerides are broken down to free fatty acids, re-esterified, and packaged into chylomicrons for transport in the lymph to other peripheral tissues to be used for energy or stored?.

\section{Lipid Metabolism}

Lipid metabolism has been extensively reviewed by Baynes and Dominiczak. ${ }^{116}$ Briefly, triglycerides, cholesterol, and phospholipids are synthesized in the liver via de novo synthesis. After synthesis lipids may be transported from the liver by lipoproteins. Very low-density lipoproteins (VLDLs) are synthesized in the liver and are used to transport triglycerides from the liver to the adipose and skeletal muscle for storage and energy. Endogenous cholesterol is synthesized in the liver and transported in the plasma by other lipoproteins. Cholesterol is transported from the liver to other tissues as low-density lipoproteins (LDL). High-density lipoproteins (HDL) bring excess cholesterol from other tissues back to liver to be excreted as bile.

Nonalcoholic fatty liver disease (NAFLD) is a condition that has recently become more prevalent in the United States. NAFLD is the most common form of liver dysfunction and is a result of increased hepatic lipid accumulation. ${ }^{117}$ The main cause of NAFLD is increased accumulation of triglycerides stored in the liver, leading to increased lipid content within the hepatocytes. NAFLD can promote steatosis, liver inflammation, fibrosis, and eventually 
cirrhosis. Increased inflammation and fibrosis of the hepatic tissue are often associated with mortality. ${ }^{117}$

\section{Serum Biomarkers of Liver Function}

There are several measurements used to monitor the status of liver function and ensure proper regulation of lipid metabolism. ${ }^{116}$ Liver function markers are of importance in both in clinical and research settings. Serum markers of hepatic function include: cholesterol, gammaglutamyl transferase, alanine aminotransferase, and albumin. ${ }^{118}$ The most sensitive enzymatic clinical indicator of hepatobiliary disease is gamma-glutamyl transferase (GGT). Although GGT is present in both the kidneys and the liver, the serum enzyme GGT assay originates only from the liver. Although GGT levels are highest following a hepatic obstruction, any form of liver disease will cause GGT levels to become elevated, making it very reliable serum assay. Another clinical marker of liver function is alanine aminotransferase (ALT). Although this serum marker is not as sensitive as GGT, liver damage causes an increase in the serum ALT enzyme. Serum albumin is also a marker of liver function since albumin is produced in the liver. Decreased serum albumin levels are often indicative of acute or chronic liver damage. Serum cholesterol is generally used as a screening tool for cardiovascular risk, but can also indicate if the liver is properly excreting and transporting cholesterol to the tissues.

\section{Polycystic Liver Disease}

Polycystic liver disease (PLD) is characterized by the presence of fluid-filled sacs throughout the epithelium of the hepatic tissue. PLD is the most common complication associated with PKD. ${ }^{6}$ Furthermore, females with PKD experience more extensive liver cyst progression than males. Individuals with PKD that experience cysts in the liver may also eventually experience altered liver function. ${ }^{118}$ Although no studies have examined the role of 
diet in PLD, diet may offer a potential treatment to slow liver cyst progression. PLD has similar pathogenesis of PKD, therefore dietary treatment that has been shown to improved PKD progression and severity such as SPI and n-3 PUFAs may have beneficial effects on PLD. 


\section{References:}

1. Wilson PD. The genes and proteins associated with poly-cystic kidney diseases. Minerva Urol Nefrol. 2002;54(4):201-211.

2. Chang MY, Ong AC. Autosomal dominant polycystic kidney disease: Recent advances in pathogenesis and treatment. Nephron Physiol. 2008;108(1):p1-7. doi: 10.1159/000112495.

3. Davis ID, MacRae Dell K, Sweeney WE, Avner ED. Can progression of autosomal dominant or autosomal recessive polycystic kidney disease be prevented? Semin Nephrol. 2001;21(5):430440.

4. Torres VE, Harris PC. Polycystic kidney disease: Genes, proteins, animal models, disease mechanisms and therapeutic opportunities. J Intern Med. 2007;261(1):17-31. doi: 10.1111/j.1365-2796.2006.01743.x.

5. Torres VE, Harris PC. Polycystic kidney disease: Genes, proteins, animal models, disease mechanisms and therapeutic opportunities. J Intern Med. 2007;261(1):17-31. doi: 10.1111/j.1365-2796.2006.01743.x.

6. Gabow PA, Johnson AM, Kaehny WD, Manco-Johnson ML, Duley IT, Everson GT. Risk factors for the development of hepatic cysts in autosomal dominant polycystic kidney disease. Hepatology. 1990;11(6):1033-1037.

7. Aguiari G, Catizone L, Del Senno L. Multidrug therapy for polycystic kidney disease: A review and perspective. Am J Nephrol. 2013;37(2):175-182. doi: 10.1159/000346812; $10.1159 / 000346812$. 
8. Mochizuki T, Tsuchiya K, Nitta K. Autosomal dominant polycystic kidney disease: Recent advances in pathogenesis and potential therapies. Clin Exp Nephrol. 2012. doi: 10.1007/s10157012-0741-0.

9. Lager DJ, Qian Q, Bengal RJ, Ishibashi M, Torres VE. The pck rat: A new model that resembles human autosomal dominant polycystic kidney and liver disease. Kidney Int. 2001;59(1):126-136. doi: 10.1046/j.1523-1755.2001.00473.x.

10. Maditz KH, Gigliotti JC, Tou JC. Evidence for a role of proteins, lipids, and phytochemicals in the prevention of polycystic kidney disease progression and severity. Nutr Rev. 2013;71(12):802-814. doi: 10.1111/nure.12085; 10.1111/nure.12085.

11. Clandinin MT, Jumpsen J, Suh M. Relationship between fatty acid accretion, membrane composition, and biologic functions. J Pediatr. 1994;125(5 Pt 2):S25-32.

12. Kiecolt-Glaser JK, Belury MA, Porter K, Beversdorf DQ, Lemeshow S, Glaser R. Depressive symptoms, omega-6:Omega-3 fatty acids, and inflammation in older adults. Psychosom Med. 2007;69(3):217-224. doi: 10.1097/PSY.0b013e3180313a45.

13. Ogborn MR, Nitschmann E, Weiler H, Leswick D, Bankovic-Calic N. Flaxseed ameliorates interstitial nephritis in rat polycystic kidney disease. Kidney Int. 1999;55(2):417-423. doi: 10.1046/j.1523-1755.1999.00287.x.

14. Aukema HM, Housini I, Rawling JM. Dietary soy protein effects on inherited polycystic kidney disease are influenced by gender and protein level. J Am Soc Nephrol. 1999;10(2):300308. 
15. Peng CY, Sankaran D, Ogborn MR, Aukema HM. Dietary soy protein selectively reduces renal prostanoids and cyclooxygenases in polycystic kidney disease. Exp Biol Med (Maywood). 2009;234(7):737-743. doi: 10.3181/0811-RM-315; 10.3181/0811-RM-315.

16. Fernandes G, Lawrence R, Sun D. Protective role of n-3 lipids and soy protein in osteoporosis. Prostaglandins Leukot Essent Fatty Acids. 2003;68(6):361-372.

17. Watkins BA, Li Y, Lippman HE, Feng S. Modulatory effect of omega-3 polyunsaturated fatty acids on osteoblast function and bone metabolism. Prostaglandins Leukot Essent Fatty Acids. 2003;68(6):387-398.

18. Lager DJ, Qian Q, Bengal RJ, Ishibashi M, Torres VE. The pck rat: A new model that resembles human autosomal dominant polycystic kidney and liver disease. Kidney Int. 2001;59(1):126-136. doi: 10.1046/j.1523-1755.2001.00473.x.

19. Chen JR, Singhal R, Lazarenko OP, et al. Short term effects on bone quality associated with consumption of soy protein isolate and other dietary protein sources in rapidly growing female rats. Exp Biol Med (Maywood). 2008;233(11):1348-1358. doi: 10.3181/0802-RM-63; 10.3181/0802-RM-63.

20. Lukas R, Gigliotti JC, Smith BJ, Altman S, Tou JC. Consumption of different sources of omega-3 polyunsaturated fatty acids by growing female rats affects long bone mass and microarchitecture. Bone. 2011;49(3):455-462. doi: 10.1016/j.bone.2011.05.029; 10.1016/j.bone.2011.05.029. 
21. Weiler HA, Kovacs H, Nitschmann E, Bankovic-Calic N, Aukema H, Ogborn M. Feeding flaxseed oil but not secoisolariciresinol diglucoside results in higher bone mass in healthy rats and rats with kidney disease. Prostaglandins Leukot Essent Fatty Acids. 2007;76(5):269-275. doi: 10.1016/j.plefa.2007.02.001.

22. Torres VE, Harris PC. Polycystic kidney disease: Genes, proteins, animal models, disease mechanisms and therapeutic opportunities. J Intern Med. 2007;261(1):17-31. doi:

10.1111/j.1365-2796.2006.01743.x.

23. Gigliotti JC. Influencing kidney health and function in young female rats through dietary alterations. [Ph.D.]. West Virginia University; 2011.

24. Porth C, ed. Essentials of pathophysiology: Concepts of altered health states. . 3rd ed. Wolters Kluwer/Lippincott Williams \& Wilkins; 2010.

25. Gmaj, P. and Murer, H. Cellular mechanisms of inorganic phosphate transport in kidney. Physiol Rev. 1986;66:36.

26. Sherwood, L., Klandorf, H., and Yancey, P., ed. Animal physiology: From genes to organisms. 2nd ed. KY: Brookes/Cole; 2012.

27. Torres, V., Wang, X., Qian, Q., Somlo, S., Harris, P., Gattone, V. Effective treatment of an orthologous model of autosomal dominant polycystic kidney disease. Nature Medicine. 2004;10(4):363-364.

28. Wilson PD. Polycystic kidney disease. N Engl J Med. 2004;350(2):151-164. doi: 10.1056/NEJMra022161. 
29. Bertuccio CA, Caplan MJ. Polycystin-1C terminus cleavage and its relation with polycystin2, two proteins involved in polycystic kidney disease. Medicina (B Aires). 2013;73(2):155-162.

30. Hogan MC, Manganelli L, Woollard JR, et al. Characterization of PKD protein-positive exosome-like vesicles. J Am Soc Nephrol. 2009;20(2):278-288. doi: 10.1681/ASN.2008060564; 10.1681/ASN.2008060564.

31. Kotsis F, Boehlke C, Kuehn EW. The ciliary flow sensor and polycystic kidney disease. Nephrol Dial Transplant. 2013;28(3):518-526. doi: 10.1093/ndt/gfs524; 10.1093/ndt/gfs524.

32. Martinez JR, Grantham JJ. Polycystic kidney disease: Etiology, pathogenesis, and treatment. Dis Mon. 1995;41(11):693-765.

33. Grantham JJ, Mulamalla S, Swenson-Fields KI. Why kidneys fail in autosomal dominant polycystic kidney disease. Nat Rev Nephrol. 2011;7(10):556-566. doi: 10.1038/nrneph.2011.109; 10.1038/nrneph.2011.109.

34. Maditz KH, Gigliotti JC, Tou JC. Evidence for a role of proteins, lipids, and phytochemicals in the prevention of polycystic kidney disease progression and severity. Nutr Rev. 2013;71(12):802-814. doi: 10.1111/nure.12085; 10.1111/nure.12085.

35. Tomobe K, Philbrick D, Aukema HM, et al. Early dietary protein restriction slows disease progression and lengthens survival in mice with polycystic kidney disease. J Am Soc Nephrol. 1994;5(6):1355-1360.

36. Benabe JE, Wang S, Wilcox JN, Martinez-Maldonado M. Modulation of ANG II receptor and its mRNA in normal rat by low-protein feeding. Am J Physiol. 1993;265(5 Pt 2):F660-9. 
37. Torres VE, Donovan KA, Scicli G, et al. Synthesis of renin by tubulocystic epithelium in autosomal-dominant polycystic kidney disease. Kidney Int. 1992;42(2):364-373.

38. Ogborn MR, Sareen S. Amelioration of polycystic kidney disease by modification of dietary protein intake in the rat. J Am Soc Nephrol. 1995;6(6):1649-1654.

39. Bankovic-Calic N, Eddy A, Sareen S, Ogborn MR. Renal remodelling in dietary protein modified rat polycystic kidney disease. Pediatr Nephrol. 1999;13(7):567-570.

40. Grantham JJ, Mulamalla S, Swenson-Fields KI. Why kidneys fail in autosomal dominant polycystic kidney disease. Nat Rev Nephrol. 2011;7(10):556-566. doi: 10.1038/nrneph.2011.109; 10.1038/nrneph.2011.109.

41. Gretz N, Korb E, Strauch M. Low-protein diet supplemented by keto acids in chronic renal failure: A prospective controlled study. Kidney Int Suppl. 1983;16:S263-7.

42. Oldrizzi L, Rugiu C, Valvo E, et al. Progression of renal failure in patients with renal disease of diverse etiology on protein-restricted diet. Kidney Int. 1985;27(3):553-557.

43. Choukroun G, Itakura Y, Albouze G, et al. Factors influencing progression of renal failure in autosomal dominant polycystic kidney disease. J Am Soc Nephrol. 1995;6(6):1634-1642.

44. Klahr S, Breyer JA, Beck GJ, et al. Dietary protein restriction, blood pressure control, and the progression of polycystic kidney disease. modification of diet in renal disease study group. $J$ Am Soc Nephrol. 1995;5(12):2037-2047. 
45. Levey AS, Greene T, Beck GJ, et al. Dietary protein restriction and the progression of chronic renal disease: What have all of the results of the MDRD study shown? modification of diet in renal disease study group. J Am Soc Nephrol. 1999;10(11):2426-2439.

46. Massey LK. Dietary animal and plant protein and human bone health: A whole foods approach. J Nutr. 2003;133(3):862S-865S.

47. Anastasia JV, Braun BL, Smith KT. General and histopathological results of a two-year study of rats fed semi-purified diets containing casein and soya protein. Food Chem Toxicol. 1990;28(3):147-156.

48. Aukema HM, Housini I. Dietary soy protein effects on disease and IGF-I in male and female han:SPRD-cy rats. Kidney Int. 2001;59(1):52-61. doi: 10.1046/j.1523-1755.2001.00465.x.

49. Cahill LE, Peng CY, Bankovic-Calic N, Sankaran D, Ogborn MR, Aukema HM. Dietary soya protein during pregnancy and lactation in rats with hereditary kidney disease attenuates disease progression in offspring. Br J Nutr. 2007;97(1):77-84. doi:

10.1017/S0007114507250470.

50. Aukema HM, Gauthier J, Roy M, Jia Y, Li H, Aluko RE. Distinctive effects of plant protein sources on renal disease progression and associated cardiac hypertrophy in experimental kidney disease. Mol Nutr Food Res. 2011;55(7):1044-1051. doi: 10.1002/mnfr.201000558;

10.1002/mnfr.201000558. 
51. Ogborn MR, Nitschmann E, Weiler HA, Bankovic-Calic N. Modification of polycystic kidney disease and fatty acid status by soy protein diet. Kidney Int. 2000;57(1):159-166. doi: 10.1046/j.1523-1755.2000.00835.x.

52. Fair DE, Ogborn MR, Weiler HA, et al. Dietary soy protein attenuates renal disease progression after 1 and 3 weeks in han:SPRD-cy weanling rats. $J$ Nutr. 2004;134(6):1504-1507.

53. Peng CY, Sankaran D, Ogborn MR, Aukema HM. Dietary soy protein selectively reduces renal prostanoids and cyclooxygenases in polycystic kidney disease. Exp Biol Med (Maywood). 2009;234(7):737-743. doi: 10.3181/0811-RM-315.

54. Calder PC. N-3 fatty acids, inflammation and immunity: New mechanisms to explain old actions. Proc Nutr Soc. 2013:1-11. doi: 10.1017/S0029665113001031.

55. Fassett RG, Gobe GC, Peake JM, Coombes JS. Omega-3 polyunsaturated fatty acids in the treatment of kidney disease. Am J Kidney Dis. 2010;56(4):728-742. doi: 10.1053/j.ajkd.2010.03.009.

56. Ogborn MR, Nitschmann E, Bankovic-Calic N, Weiler HA, Aukema HM. Effects of flaxseed derivatives in experimental polycystic kidney disease vary with animal gender. Lipids. 2006;41(12):1141-1149.

57. Childs CE, Romeu-Nadal M, Burdge GC, Calder PC. Gender differences in the $\mathrm{n}-3$ fatty acid content of tissues. Proc Nutr Soc. 2008;67(1):19-27. doi: 10.1017/S0029665108005983; 10.1017/S0029665108005983. 
58. Sankaran D, Bankovic-Calic N, Cahill L, Yu-Chen Peng C, Ogborn MR, Aukema HM. Late dietary intervention limits benefits of soy protein or flax oil in experimental polycystic kidney disease. Nephron Exp Nephrol. 2007;106(4):e122-8. doi: 10.1159/000104836.

59. Cunnane SC, Hamadeh MJ, Liede AC, Thompson LU, Wolever TM, Jenkins DJ. Nutritional attributes of traditional flaxseed in healthy young adults. Am J Clin Nutr. 1995;61(1):62-68.

60. Tou JC, Altman SN, Gigliotti JC, Benedito VA, Cordonier EL. Different sources of omega-3 polyunsaturated fatty acids affects apparent digestibility, tissue deposition, and tissue oxidative stability in growing female rats. Lipids Health Dis. 2011;10:179-511X-10-179. doi:

10.1186/1476-511X-10-179; 10.1186/1476-511X-10-179.

61. Simopoulos AP. The importance of the omega-6/omega-3 fatty acid ratio in cardiovascular disease and other chronic diseases. Exp Biol Med (Maywood). 2008;233(6):674-688. doi: 10.3181/0711-MR-311; 10.3181/0711-MR-311.

62. Sankaran D, Lu J, Ogborn MR, Aukema HM. COX-2 expression in cystic kidneys is dependent on dietary n-3 fatty acid composition. J Nutr Biochem. 2007;18(12):806-812. doi: 10.1016/j.jnutbio.2006.12.017.

63. Lu J, Bankovic-Calic N, Ogborn M, Saboorian MH, Aukema HM. Detrimental effects of a high fat diet in early renal injury are ameliorated by fish oil in han:SPRD-cy rats. $J$ Nutr. 2003;133(1):180-186. 
64. Aukema HM, Yamaguchi T, Takahashi H, Philbrick DJ, Holub BJ. Effects of dietary fish oil on survival and renal fatty acid composition in murine polycystic kidney disease. Nutr Res. 1992;12(11):1383-1392. doi: http://dx.doi.org/10.1016/S0271-5317(05)80537-8.

65. Sankaran D, Lu J, Bankovic-Calic N, Ogborn MR, Aukema HM. Modulation of renal injury in pcy mice by dietary fat containing n-3 fatty acids depends on the level and type of fat. Lipids. 2004;39(3):207-214.

66. Horiba N, Kumano E, Watanabe T, Shinkura H, Sugimoto T, Inoue M. Subtotal nephrectomy stimulates cyclooxygenase 2 expression and prostacyclin synthesis in the rat remnant kidney. Nephron. 2002;91(1):134-141. doi: 57615.

67. Warford-Woolgar L, Peng CY, Shuhyta J, et al. Selectivity of cyclooxygenase isoform activity and prostanoid production in normal and diseased han:SPRD-cy rat kidneys. Am J Physiol Renal Physiol. 2006;290(4):F897-904. doi: 10.1152/ajprenal.00332.2005.

68. Lee WK, Yu SM, Cheong SW, Sonn JK, Kim SJ. Ectopic expression of cyclooxygenase-2induced dedifferentiation in articular chondrocytes. Exp Mol Med. 2008;40(6):721-727. doi: 10.3858/emm.2008.40.6.721.

69. Yamaguchi T, Valli VE, Philbrick D, Holub B, Yoshida K, Takahashi H. Effects of dietary supplementation with n-3 fatty acids on kidney morphology and the fatty acid composition of phospholipids and triglycerides from mice with polycystic kidney disease. Res Commun Chem Pathol Pharmacol. 1990;69(3):335-351. 
70. Higashihara E, Nutahara K, Horie S, et al. The effect of eicosapentaenoic acid on renal function and volume in patients with ADPKD. Nephrol Dial Transplant. 2008;23(9):2847-2852. doi: 10.1093/ndt/gfn144.

71. Anderson BM, Ma DW. Are all n-3 polyunsaturated fatty acids created equal? Lipids Health Dis. 2009;8:33-511X-8-33. doi: 10.1186/1476-511X-8-33; 10.1186/1476-511X-8-33.

72. Belury MA. Dietary conjugated linoleic acid in health: Physiological effects and mechanisms of action. Annu Rev Nutr. 2002;22:505-531. doi: 10.1146/annurev.nutr.22.021302.121842.

73. Bhattacharya A, Banu J, Rahman M, Causey J, Fernandes G. Biological effects of conjugated linoleic acids in health and disease. J Nutr Biochem. 2006;17(12):789-810. doi: 10.1016/j.jnutbio.2006.02.009.

74. Jensen RG, Lammi-Keefe C. The anticarcinogenic conjugated fatty acid c9, t11-c18:2, or rumenic acid, in human milk: Amounts and effects. Adv Exp Med Biol. 2001;501:153-156.

75. Ogborn MR, Nitschmann E, Bankovic-Calic N, Weiler HA, Fitzpatrick-Wong S, Aukema HM. Dietary conjugated linoleic acid reduces PGE2 release and interstitial injury in rat polycystic kidney disease. Kidney Int. 2003;64(4):1214-1221. doi: 10.1046/j.15231755.2003.00215.x.

76. Wakefield AP, Ogborn MR, Ibrahim N, Aukema HM. A dietary conjugated linoleic acid treatment that slows renal disease progression alters renal cyclooxygenase-2-derived prostanoids in the han: SPRD-cy rat. J Nutr Biochem. 2012;23(8):908-914. doi:

10.1016/j.jnutbio.2011.04.016; 10.1016/j.jnutbio.2011.04.016. 
77. Ogborn MR, Nitschmann E, Goldberg A, Bankovic-Calic N, Weiler HA, Aukema HM. Dietary conjugated linoleic acid renal benefits and possible toxicity vary with isomer, dose and gender in rat polycystic kidney disease. Lipids. 2008;43(9):783-791. doi: 10.1007/s11745-008$3211-4 ; 10.1007 / \mathrm{s} 11745-008-3211-4$.

78. Yu Y, Correll PH, Vanden Heuvel JP. Conjugated linoleic acid decreases production of proinflammatory products in macrophages: Evidence for a PPAR gamma-dependent mechanism. Biochim Biophys Acta. 2002;1581(3):89-99.

79. Ogborn MR, Nitschmann E, Weiler H, Leswick D, Bankovic-Calic N. Flaxseed ameliorates interstitial nephritis in rat polycystic kidney disease. Kidney Int. 1999;55(2):417-423. doi: 10.1046/j.1523-1755.1999.00287.x.

80. Murphy SP, Subar AF, Block G. Vitamin E intakes and sources in the united states. Am J Clin Nutr. 1990;52(2):361-367.

81. Maser RL, Vassmer D, Magenheimer BS, Calvet JP. Oxidant stress and reduced antioxidant enzyme protection in polycystic kidney disease. J Am Soc Nephrol. 2002;13(4):991-999.

82. Tomobe K, Philbrick DJ, Ogborn MR, Takahashi H, Holub BJ. Effect of dietary soy protein and genistein on disease progression in mice with polycystic kidney disease. Am J Kidney Dis. 1998;31(1):55-61.

83. Keith DS, Torres VE, Johnson CM, Holley KE. Effect of sodium chloride, enalapril, and losartan on the development of polycystic kidney disease in han:SPRD rats. Am J Kidney Dis. 1994;24(3):491-498. 
84. Nagao S, Yamaguchi T, Kasahara M, et al. Effect of probucol in a murine model of slowly progressive polycystic kidney disease. Am J Kidney Dis. 2000;35(2):221-226.

85. Merta M, Zima T, Stipek S, Crkovska J, Platenik J. Lipid peroxidation and activity of superoxide dismutase in ADPKD. Contrib Nephrol. 1995;115:109-112.

86. Yamamoto Y, Takekoshi Y, Itami N, et al. Enzyme-linked immunosorbent assay for extracellular glutathione peroxidase in serum of normal individuals and patients with renal failure on hemodialysis. Clin Chim Acta. 1995;236(1):93-99.

87. Stewart JH. End-stage renal failure appears earlier in men than in women with polycystic kidney disease. Am J Kidney Dis. 1994;24(2):181-183.

88. Torres VE, Bengal RJ, Nickander KK, Grande JP, Low PA. Renal concentration of alphatocopherol: Dependence on gender and lack of effect on polycystic kidney disease in han:SPRD rats. Am J Kidney Dis. 1998;31(4):687-693.

89. Martin JH, Crotty S, Nelson PN. Phytoestrogens: Perpetrators or protectors? Future Oncol. 2007;3(3):307-318. doi: 10.2217/14796694.3.3.307.

90. Guerrero-Bosagna CM, Skinner MK. Environmental epigenetics and phytoestrogen/phytochemical exposures. J Steroid Biochem Mol Biol. 2012. doi: 10.1016/j.jsbmb.2012.12.011; 10.1016/j.jsbmb.2012.12.011.

91. Ogborn MR, Nitschmann E, Bankovic-Calic N, Weiler HA, Aukema HM. Dietary soy protein benefit in experimental kidney disease is preserved after isoflavone depletion of diet. Exp 
Biol Med (Maywood). 2010;235(11):1315-1320. doi: 10.1258/ebm.2010.010059;

10.1258/ebm.2010.010059.

92. Murkies AL, Wilcox G, Davis SR. Clinical review 92: Phytoestrogens. J Clin Endocrinol Metab. 1998;83(2):297-303.

93. Zhang W, Wang X, Liu Y, et al. Dietary flaxseed lignan extract lowers plasma cholesterol and glucose concentrations in hypercholesterolaemic subjects. Br J Nutr. 2008;99(6):1301-1309. doi: $10.1017 /$ S0007114507871649.

94. Ogborn MR, Nitschmann E, Bankovic-Calic N, Weiler HA, Aukema HM. Effects of flaxseed derivatives in experimental polycystic kidney disease vary with animal gender. Lipids. 2006;41(12):1141-1149.

95. Silbiger SR, Neugarten J. The role of gender in the progression of renal disease. Adv Ren Replace Ther. 2003;10(1):3-14. doi: 10.1053/jarr.2003.50001.

96. Henrotin Y, Priem F, Mobasheri A. Curcumin: A new paradigm and therapeutic opportunity for the treatment of osteoarthritis: Curcumin for osteoarthritis management. Springerplus. 2013;2(1):56. doi: 10.1186/2193-1801-2-56.

97. Gao J, Zhou H, Lei T, et al. Curcumin inhibits renal cyst formation and enlargement in vitro by regulating intracellular signaling pathways. Eur J Pharmacol. 2011;654(1):92-99. doi: 10.1016/j.ejphar.2010.12.008; 10.1016/j.ejphar.2010.12.008.

98. Leonhard WN, van der Wal A, Novalic Z, et al. Curcumin inhibits cystogenesis by simultaneous interference of multiple signaling pathways: In vivo evidence from a Pkd1-deletion 
model. Am J Physiol Renal Physiol. 2011;300(5):F1193-202. doi: 10.1152/ajprenal.00419.2010; 10.1152/ajprenal.00419.2010.

99. Ogborn MR, Nitschmann E, Weiler HA, Bankovic-Calic N. Modification of polycystic kidney disease and fatty acid status by soy protein diet. Kidney Int. 2000;57(1):159-166. doi: 10.1046/j.1523-1755.2000.00835.x.

100. Torres VE, Bengal RJ, Nickander KK, Grande JP, Low PA. Renal concentration of alphatocopherol: Dependence on gender and lack of effect on polycystic kidney disease in han:SPRD rats. Am J Kidney Dis. 1998;31(4):687-693.

101. Tomobe K, Philbrick DJ, Ogborn MR, Takahashi H, Holub BJ. Effect of dietary soy protein and genistein on disease progression in mice with polycystic kidney disease. Am J Kidney Dis. 1998;31(1):55-61.

102. Kitatani, K., Nakatsuka, K., Naka, H., Miki, T., Morii, H., Nishizawa, Y. Clinical usefulness of measurements of urinary deoxypyridinoline (DPD) in patients with postmenopausal osteoporosis receiving intermittent cyclical etidronate: Advantage of free form of DPD over total DPD in predicting treatment efficacy. <br />. J Bone Miner Metab. $2003 ; 21(4): 217-224$.

103. Lukas RE. The effect of omega-3 polyunsaturated fatty acids derived from various sources on bone metabolism in growing female rats. [M.S.]. West Virginia University; 2010.

104. Martini FH. Fundamentals of anatomy and physiology. 7th ed. San Francisco, CA: Pearson Benjamin Cummings; 2006. 
105. Watts N. Clinical utility of biochemical markers of bone remodeling. Clinical Chemistry. 1999(45):1359-1368.

106. Poulsen, R., Moughan, P., Kruger, M. Long-chain polyunsaturated fatty acids and the regulation of bone metabolism. Exp Biol Med. 2007(232):1275-1288.

107. Claassen N, et al. Supplemented gamma-linolenic acid and eicosapentaenoic acid influence bone status in young male rats: Effects on free urinary collagen crosslinks, total urinary hydroxyproline, and bone calcium content. Bone. 1995b(16):385-392.

108. Cashman K. Diet, nutrition, and bone health. Journal of Nutrition. 2007(137):2507-2512.

109. Parkinson, I., Forbes, D., Sutton-Smith, P., Fazzalari, N. Model-independent 3D descriptors of vertebral cancellous bone architecture. Journal of Osteoporosis. 2009:1-6.

110. Turner C. Biomechanics of bone: Determinants of skeletal fragility and bone quality. Osteoporosis International. 2002;13:97-104.

111. Weiler H, Kovacs H, Nitschmann E, Fitzpatrick Wong S, Bankovic-Calic N, Ogborn M. Elevated bone turnover in rat polycystic kidney disease is not due to prostaglandin E2. Pediatr Nephrol. 2002;17(10):795-799. doi: 10.1007/s00467-002-0933-z.

112. Benun, J., Lewis, C. Polycystic kidney disease. Pediatrics in Review. 2009;30:78-79.

113. Dell, K., Avner, E. Polycystic kidney disease: Autosomal recessive. Seattle: University of Washington; 2012. 
114. Kruger, M., Schoum, L. Is docosahexaenoic acid more effective than eicosapentaenoic acid for increasing calcium bioavailability. Prostaglandins, Leukotrienes, and Essential Fatty Acids. 2005;73:327-334.

115. Claassen, N., Coetzer, H., Steinmann, C., Kruger, M. The effect of different n-6/n-3 essential fatty acid ratios on calcium balance in rats. Prostaglandins Leukotrienes and Essential Fatty Acids. 1995a(53):13-19.

116. Baynes, J., Dominiczak, M. Medical biochemistry. 2nd ed. England: Mosby; 1999.

117. Postic C, Girard J. Contribution of de novo fatty acid synthesis to hepatic steatosis and insulin resistance: Lessons from genetically engineered mice. J Clin Invest. 2008;118(3):829838. doi: 10.1172/JCI34275; 10.1172/JCI34275.

118. Chauveau, D., Fakhouri, F., Grunfeld, J.P. Liver involvement in autosomal-dominant polycystic kidney disease; dTherapeutic dilemma. JASN. 2000;11(9):1767-1775. 


\subsection{Study Objectives}

\section{Study 1}

Objective: To investigate the role of SPI and/or n-3 PUFAs on PKD progression and severity in female pck rats.

Hypothesis: The supplementation of SPI and n-3 PUFAs will reduce renal inflammation and fibrosis and therefore, delay PKD progression and reduce renal cyst severity in female pck rats.

\section{Study 2}

Objective: To determine the whether feeding growing female pck rats SPI and/or n-3 PUFAs can enhance bone morphometry, mineralization, microarchitecture, and strength. Hypothesis: Feeding SPI and n-3 PUFAs will enhance bone morphometry, mineralization, microarchitechture, strength, and overall bone health in female pck rats by increasing femur and tibial BMD and BMC.

\section{Study 3}

Objective: To determine the role of SPI and/or n-3 PUFAs on PLD progression and severity in female pck rats.

Hypothesis: SPI and n-3 PUFA supplementation will increase hepatic EPA and DHA tissue content and this in turn will reduce hepatic inflammation and PLD progression in female pck rats.

Overall Hypothesis: Feeding SPI and n-3 PUFAs will reduce PKD inflammation, progression, severity, and improve related PKD complications of bone loss and PLD. 
Omega-3 Polyunsaturated Fatty Acid and/or Soy Protein Isolate Supplementation Does Not Attenuate Disease Progression in a Female Rat Model of Autosomal Recessive Polycystic Kidney Disease

Kaitlin H. Maditz ${ }^{1}$, Chris Oldaker ${ }^{1}$, Nainika Nanda ${ }^{1}$, Vagner Benedito ${ }^{3}$, Ryan Livengood ${ }^{2}$, Janet C. Tou $^{* 1}$

${ }^{1}$ Division of Animal and Nutritional Sciences, ${ }^{2}$ Division of Plant and Soil Sciences, ${ }^{3}$ School of Medicine, West Virginia University, Morgantown, WV 26506,

*Corresponding Author:

Janet C. Tou, PhD

Tel: (304) 293-1919

Fax: (304) 293-2232

e-mail: janet.tou@mail.wvu.edu 


\section{Abbreviations}

AA; arachidonic acid

ADPKD; autosomal dominant polycystic kidney disease

ALA; alpha-linolenic acid

ARPKD; autosomal recessive polycystic kidney disease

BUN; blood urea nitrogen

CO; corn oil

COX-2; cyclooxygenase

EPA; eicosapentaenoic acid

DHA; docosahexaeonic acid

LA; linoleic acid

MapK; mitogen-activated protein kinase

mTOR; mammalian target of rapamycin

PKD; polycystic kidney disease

PPARY; peroxisome proliferator-activated receptor gamma

SB; soybean oil/salmon oil blend

SEM; standard error of the mean

SO; soybean oil

SPI; soy protein isolate 


\subsection{Abstract}

Polycystic kidney disease (PKD) is an incurable genetic disorder characterized by multiple benign cysts. As PKD progresses cyst growth increases kidney volume, decreases renal function, and may eventually lead to end stage renal disease. Feeding soy protein isolate reduced cyst proliferation and growth in a PKD rat model. Omega-3 polyunsaturated fatty acids (n-3 PUFAs) have anti-inflammatory actions. Therefore, diet therapy can offer a potentially efficacious, safe, and cost-effective strategy for treating PKD. The objective of this study was to investigate the role of soy protein and/or n-3 PUFAs on PKD progression and severity in the rat model of autosomal recessive PKD (ARPKD). We hypothesized that to anti-proliferative and anti-inflammatory actions associated with soy protein and n-3 PUFA supplementation will attenuate PKD progression in female PCK rats. Young (age $28 \mathrm{~d}$ ) female PCK rats were randomly assigned ( $n=12$ /group) to diets consisting of casein + corn oil (Casein $+C O)$, casein + soybean oil $($ Casein $+\mathrm{SO}), \mathrm{SPI}+$ soybean oil $(\mathrm{SPI}+\mathrm{SO})$ or SPI + 1:1 soybean/salmon oil (SPI + SB) for 12-weeks. Feeding different protein and lipid sources had no significant effect on relative kidney weight. Histological evaluation showed no significant differences in cortical or medullary cyst size, interstitial inflammation, and fibrosis among diet groups. However, rats fed SPI+ SB diet had cortical cyst obstruction and the highest $(P<0.01)$ serum blood urea nitrogen concentration. Rats fed SPI+SB diet had the highest $(P<0.001)$ renal DHA, but there were no significant differences in renal tissue inflammatory and proliferation gene expression among the diet groups. Based on the results, dietary soy protein and/or n-3 PUFAs did not attenuate disease progression or severity i the female PCK rat model of ARPKD.

Keywords: rat, polycystic kidney disease, n-3 PUFAs, soy protein, diet therapy 


\subsection{Introduction}

Polycystic kidney disease (PKD) is a genetic disorder characterized by multiple benign cysts derived from the epithelial lining of the nephron [1]. As PKD progresses cyst growth increases kidney volume, reduces renal function, and eventually leads to end stage renal disease [2]. In 2008, 547,982 patients in the United States were diagnosed with kidney disease and received treatment (i.e. dialysis or kidney transplant) for end stage renal disease at a cost of 39.46 billion dollars [3]. Of those patients, approximately $22 \%$ of all end stage renal disease cases were due to PKD [3].

The two main forms of PKD are autosomal dominant polycystic kidney disease (ADPKD) and autosomal recessive polycystic kidney disease (ARPKD). In ADPKD, renal disease onset occurs in early adulthood while ARPKD has infantile renal disease onset [4]. The poor prognosis associated with PKD has resulted in studies investigating various therapeutic strategies to attenuate disease progression. Diet therapy offers a potentially efficacious, safe, and cost-effective strategy for treating PKD. Studies have examined the role of different protein and lipid sources as a diet strategy for decreasing PKD progression and severity using the Hans:SPRD-cy rat, a non-orthologous animal model of ADPKD [5,6] Omega-3 polyunsaturated fatty acids (n-3 PUFAs) have been reported to have anti-inflammatory actions mediated through alterations in membrane composition, gene expression, and eicosanoid production [7,8] Male Han:SPRD-cy rats fed diets supplemented with n-3 PUFAs significantly decreased renal inflammation and damage [9].

Protein consumption exceeding $0.8 \mathrm{~g} / \mathrm{kg}$ body weight has been suggested to negatively affect PKD by causing higher renal perfusion and kidney hyperfiltration of the already compromised nephron [10]. However, protein restriction may be associated with risk of protein 
malnutrition, particularly for ARPKD characterized by early onset that includes rapid growth stages. The absence of a defined amount of protein that delays disease progression while meeting protein requirements has led to greater interest in investigating the source of protein on PKD [6]. Feeding soy protein isolate has been shown to reduce cyst proliferation and to decrease cyst growth in male PKD animal models [11,12]. Feeding male Han:SPRD-cy rats soy protein slowed PKD progression by decreasing inflammation indicated by decreased renal cyclooxygenase-2 (COX-2) enzyme activity and renal prostanoids [12].

Studies have mainly been conducted in male animal models although the rate of PKD progression and severity is affected by gender [13]. In research conducted by Aukema and Housini [14] feeding soy protein reduced kidney cysts and improved renal functional measurements in male, but not female Han:SPRD-cy rats. Currently, no rodent model is genetically orthologous while expressing phenotypes typical of human ADPKD or ARPKD. Therefore, Torres and Harris [15] suggested that several PKD rodent models be used to investigate experimental therapies. The PCK rat, an orthologous model of human ARPKD, has a phenotype that resembles a slow progressing form of ARPKD [16]. To our knowledge no studies have examined diet therapy using the PCK rat model. We hypothesized that the antiproliferative and anti-inflammatory actions associated with soy protein and n-3 PUFA supplementation will attenuate PKD progression in female PCK rats. Therefore, the objective of this study was to investigate the role of these bioactive ingredients on PKD progression by randomly assigning female PCK rats to diets containing soy protein and/or n-3 PUFAs. Due to the absence of human clinical trials including dietary intervention for PKD, human patients must relay on the evidence gained from animal models [6]. By examining various animal PKD 
models and their reaction to various dietary components, researchers can provide PKD patients with a better dietary treatment plan.

\subsection{Methods and materials}

\section{Animals and diets}

All animal procedures performed in this study were conducted in accordance with the National Research Council for the Care and Use of Laboratory Animals Guidelines [17] and were approved by the Animal Care and Use Committee at West Virginia University. Young (age 28 day) female PCK rats were purchased from Charles River Laboratories (Wilmington, MA). All rats were individually caged and maintained in a room kept at $21^{\circ} \mathrm{C}$ with a 12 hour light/dark cycle throughout the 12 week study period. Following a 7 day acclimation period, animals were randomly assigned ( $\mathrm{n}=12$ rats/group) to different experimental diets. The experimental diets were based on the American Institute of Nutrition-93G (AIN-93 G) diet. The AIN-93G is a standard diet consisting of purified ingredients and formulated to meet all the nutritional requirements for growing rats as defined by the National Research Council [18]. Diet ingredients and fatty acid composition are provided in Table 1. All diets were isocaloric and had similar ingredients except for the lipid and protein source. The protein sources consisted of 200 $\mathrm{g} / \mathrm{kg}$ diet as casein or soy protein isolate (SPI). Both protein sources consisted of $87 \%$ crude protein by proximate analysis. SPI was generously provided by DuPont Nutrition and Health (St. Louis, MO). The lipid sources consisted of $70 \mathrm{~g} / \mathrm{kg}$ diet as either corn oil which is low in $\mathrm{n}$ 3 PUFAs, soybean oil which contains the essential fatty acids linoleic acid (LA, 18:2n-6) and alpha-linolenic acid (ALA, 18:3n-3) or salmon oil which is rich in the long-chain n-3 PUFAs, eicosapentaenoic (EPA, 20:5n-3) and docosahexaenoic acid (DHA, 22:6n-3) as a 1:1 soybean oil + salmon oil blend. Salmon oil was purchased from Jedwards International Inc (Quincy, MA). 
Our four experimental diets consisted of: 1) casein + corn oil (Casein $+\mathrm{CO}), 2)$ casein + soybean oil $($ Casein $+\mathrm{SO}), 3)$ soy protein isolate + soybean oil $(\mathrm{SPI}+\mathrm{SO})$ or 4$)$ soy protein isolate $+1: 1$ soybean/salmon oil $(\mathrm{SPI}+\mathrm{SB})$.

To prevent variability in food intake, rats were restriction fed $15 \pm 2 \mathrm{~g}$ of powdered diet daily. This amount was based on previous studies showing young Sprague-Dawley female rats consuming $\sim 15 \mathrm{~g}$ powdered diet/d supported growth [19]. All diets were kept at $-20^{\circ} \mathrm{C}$ until fed. Food intake was measured daily and replaced with fresh diet daily. Rats were provided deonized distilled water $\left(\mathrm{ddH}_{2} \mathrm{O}\right)$ ad libitum. Body weights, water consumption, and urine outputs were recorded weekly throughout the study. At the end of the 12-week feeding study, rats were euthanized by $\mathrm{CO}_{2}$ inhalation. Blood was collected by aorta puncture and centrifuged at 1,500 $\mathrm{g}$ for $10 \mathrm{~min}$ at $4{ }^{\circ} \mathrm{C}$ to obtain serum. Right and left kidneys were excised, trimmed, decapsulated, and then weighed separately. The right kidneys were flash frozen in liquid nitrogen and stored at $-80{ }^{\circ} \mathrm{C}$ until used for fatty acid and molecular analysis. The left kidneys were cut distally and the left portion was immediately fixed in a $10 \%$ formalin solution for histological evaluation. Histological evaluation of kidney morphometry

The left kidneys ( $\mathrm{n}=11-12)$ were fixed, embedded, and stained with hematoxylin and eosin as described in Gigliotti et al. [20]. Renal cyst number and size $(0.3-1.0 \mathrm{~mm})$ and structural abnormalities such as cyst defacement and interstitial inflammation were analyzed. All slides were analyzed using a Nikon TE 2000-S light microscope (Nikon Instruments, NY) at 4X magnification by a pathologist blinded to the dietary treatments. Images were captured using a PC interfaced with Q-Capture imaging software (Quantitative Imaging Corporation, BC, Canada). Analysis of serum and kidney fatty acid composition 
Total lipids were extracted from serum and kidneys using a modified method of Bligh and Dyer [18]. Kidney sample were taken from a center sagittal section that included the cortex, medulla, and papilla. Briefly, frozen renal tissue ( 400 mg) with nonadecenoic (19:1) added as an internal standard was homogenized in Tris/EDTA buffer ( $\mathrm{pH}$ 7.4). Kidney tissue was homogenized in a chloroform: methanol:acetic acid (2:1:0.15 v/v/v) solution. After centrifugation at $900 \mathrm{~g}$ for $10 \mathrm{~min}$ at $10^{\circ} \mathrm{C}$, the bottom chloroform layer was collected. The collected chloroform was filtered through 1-phase separation filters and then dried under nitrogen gas.

The extracted lipid samples were transmethylated according to Fritsche and Johnston [22]. Dried samples were diluted in iso-octane to a concentration of $5 \mathrm{mg}$ fatty acid methyl esters/mL iso-octane. Samples were analyzed by gas chromatography (CP-3800, Varian, CA) as described in Gigliotti et al. [20]. Quantitative 37 Component fatty acid methyl esters Sigma Mix (Supelco, Bellefonte, PA) was used as a standard to identify fatty acids. Fatty acids were determined by retention time and quantified using peak area counts. All samples were performed in duplicate and reported as $\%$ total fatty acids.

\section{RNA isolation and gene expression analysis}

Right kidneys were frozen in liquid nitrogen and stored at $-80^{\circ} \mathrm{C}$ until processed for RNA isolation. Frozen tissue samples $(\sim 100 \mathrm{mg})$ were taken from a center sagittal section that include the cortex, medulla, and papilla. Total renal RNA was extracted following the Total RNA Isolation procedure of the mirVana miRNA Isolation Kit (Ambion, TX). Isolated RNA integrity was visualized on a 1.5\% agarose gel and isolated RNA concentration was quantified by spectrophotometry (Thermo Scientific, DE). After DNase treatment of the isolated RNA 
(Applied Biosystems, CA), total mRNA was amplified using the Superscript III First Strand Synthesis assay with oligo dT primers (Invitrogen, CA).

Primer efficiencies were determined on pooled RNA samples serially diluted in $\mathrm{ddH}_{2} \mathrm{O}$ up to $1: 10000$. PCR consisted of $2.5 \mu 1$ of SYBR ${ }^{\circledR}$ Green Master Mix (Applied Biosystems, CA), $1 \mu 1$ of cDNA, $1 \mu 1$ of respective forward and reverse primers, and $0.5 \mu 1$ of $d_{d d} \mathrm{H}_{2} \mathrm{O}$ for a total reaction volume of $5 \mu 1$. The thermal profile consisted of $50^{\circ} \mathrm{C}$ for 2 minutes, $95^{\circ} \mathrm{C}$ for 10 minutes, and then 40 cycles of $95^{\circ} \mathrm{C}$ for 15 seconds and $60^{\circ} \mathrm{C}$ for 1 minute. Primers were designed for rat cyclooxygenase -2 (COX-2), mammalian target of rapamycin (mTOR), mitogenactivated protein kinase (MapK), and peroxisome proliferator-activated receptor gamma (PPAR $\gamma$ ) and the housekeeping gene beta actin using the Primer3 program (Howard Hughes Medical Institute) and respective mRNA sequences obtained from NCBI. Forward and reverse primers for genes were: COX-2 (PTGS2) 5' CGGAGGAGAAGTGGGTTTTAG 3', and 5' TGAAAGAGGCAAAGGGACAC 3'; mTOR 5' GGCTTCAACAGCAAGGACAC 3' and 5' ACGGGTGAGGTAACAGGATG 3'; MapK 5'CGTTCAGATGTCGGTGTCC 3' and 5'CGGCTCAAAGGAGTCAAGAG 3'; PPAR $\gamma$ 5' TGGAGCCTAAGTTTGAGTTTGC 3' and 5'CAGCAGGTTGTCTTGGATGTC 3'. All primers were normalized to beta actin 5' TTGCTGACAGGATGCAGAAG 3' and 5' CAGTGAGGCCAGGATAGAGC 3'.

\section{Biomarkers of kidney function}

Serum measures of renal function were determined enzymatically using a commercially available Vet-16 rotor and quantified by a Hemagen Analyst automated spectrophotometer (Hemagen Diagnostics Inc., Columbia, MD). Statistical analyses 
A power analysis conducted prior to the experiment showed that with a minimum of 10 rats/group at an alpha $=0.05$ there is $80 \%$ power to detect a difference in renal weight among the dietary treatment groups. Results are expressed as means \pm standard error of the mean (SEM). One-way analysis of variance (ANOVA) was used to determine differences among treatment groups. Post-hoc multiple comparisons were performed using Tukey's test. Differences were considered significant at $P<0.05$. All statistical analyses were performed using SigmaStat 3.1 statistical software program (Systat Software Inc., San Jose, CA). Relative gene expression was calculated according to methods by Bari et al [23], with values obtained by calculating 40-DCt. DCt was calculated as the difference in threshold cycle $(\mathrm{Ct})$ of the gene of interest and the reference gene (ActB) while the number 40 was selected because it represents the highest $\mathrm{Ct}$ value. Following the 40-DCt calculation, gene expression was analyzed using a one way ANOVA.

\subsection{Results}

Body weight and kidney mass

There were no significant differences in food intake for rats fed Casein+CO $(15.0 \pm 0.4 \mathrm{~g})$, Casein+SO (15.0 $\pm 0.4 \mathrm{~g}), \mathrm{SPI}+\mathrm{SO}(15.1 \pm 0.4 \mathrm{~g})$ or SPI+SB diet $(15.3 \pm 1.4 \mathrm{~g})$. There were no significant differences in initial body weight, body weight gain, and final body weight among rats fed the different diets (Table 2). There were no significant differences in water consumption among rats fed the different diets. There were also no significant differences in relative kidney weights among growing female PCK rats fed the different diets (Table 2). A student's t-test determined there were no differences $(P<0.67)$ between right and left kidney weights in any of the dietary treatments.

Kidney histology 
At the end of the 12-week study, all female PCK rats had the same sizes of cortical and medullary cysts regardless of diet. Figure 1 is representative H\&E staining of renal cysts (1a), inflammation (1b), and fibrosis (1c). All rats also had interstitial inflammation, fibrotic changes, interstitial matrix deposition, and structural effacement due to cyst growth indicating disease progression (Table 3). Cortical cyst obstruction was observed in rats fed SPI + SB diet. There were no significant differences in any other histological measurements between rats fed the different diets.

\section{Renal tissue fatty acid composition}

There were no significant differences in tissue renal linoleic acid (LA, 18:2n-6) content among the diet treatment groups. Renal arachidonic acid (AA, 20:4n-6) content was significantly lower in rats fed the SPI $+\mathrm{SO}$ and $\mathrm{SPI}+\mathrm{SB}$ diet compared to rats fed Casein $+\mathrm{CO}$ and Casein + SO diet (Table 4).

Total n-3 PUFA intake was highest $(P<0.001)$ in rats fed SPI+SB diet $(2.49 \pm 0.06 \mathrm{~g})$. Rats fed Casein+SO (1.17+0.03 g) and SPI+SO (1.18+0.03 g) had significantly higher total $\mathrm{n}-3$ PUFA intake than rats fed Casein+CO $(0.89 \pm 0.02 \mathrm{~g})$ diet. Final serum ALA was highest $(P=0.01)$ in rats fed diets with SO as the oil source. Serum EPA and DHA was highest in rats fed the SPI+SB diet. Rats diets with SO had significantly higher serum EPA and DHA than rats fed Casein $+\mathrm{CO}$. Serum AA was reduced $(P=0.04)$ in rats fed SPI+SB compared to Casein $+\mathrm{CO}$ diet.

Rats fed either Casein or SPI with SO as the lipid source had higher $(P<0.001)$ renal tissue ALA content than rats fed SPI + SB diet. Rats fed Casein + CO diet had the lowest $(P<$ 0.001) renal ALA content. There were no differences in renal tissue EPA content among the diet treatment groups. Rats fed SPI + SB diet had the highest $(P<0.001)$ renal DHA content. Rats 
fed SO as the lipid source as Casein or SPI diet had similar renal DHA content. Rats fed Casein + CO diet had the lowest $(P<0.001)$ renal DHA content (Table 4).

Renal gene expression analysis

There were no significant differences in renal relative gene expression of $\operatorname{PAAR} \gamma, \mathrm{COX} 2$, MapK, and mTOR between rats fed the different diets (Figure 2A-D).

\section{Biomarkers of kidney function}

Rats fed the SPI + SB diet had the highest $(P=0.01)$ serum BUN concentration. Rats fed Casein + SO diet had the lowest $(P=0.01)$ serum BUN concentration. There were no significant differences in renal function measurements of serum uric acid, total protein, globulin, albumin, albumin/globulin, calcium or phosphorus among the diet treatment groups (Table 5).

\subsection{Discussion}

Multiple cyst formation in PKD increases renal size [24]. In our study, growing female PCK rats fed different lipid sources for 12 weeks resulted in no significant differences in relative kidney weights. Similarly, growing male and female Han:SPRD-cy rats fed 7\% wt corn oil or ALA rich flaxseed oil for 12 weeks resulted in no significant differences in relative kidney weights [9]. However, female DBA/2FG-pcy mice, a rodent model of adolescent nephronophthisis, fed EPA-enriched diets for 60 days significantly reduced mean kidney weights compared female mice fed n-6 PUFA rich sunflower seed oil [25]. This may be due to species and disease model differences among the studies.

In our study, growing female PCK rats fed different protein sources also produced no significant differences in relative kidney weights. However, growing female and male Han:SPRD-cy rats fed 20\% wt soy protein had significantly decreased kidney weights compared 
to casein-fed rats [14]. The inconsistent findings can be attributed to differences in the disease model used. It is important to evaluate dietary treatments using several models due to the absence of PKD rodent models that are orthologous to human PKD. The PCK rat model displays the Pkhd1 gene mutation orthologous to human ARPKD $[5,16]$ thus, making it an attractive model to examine the effectiveness of dietary treatment in ARPKD.

Multiple cyst formation in PKD enlarges renal size, which increases the risk of structural damage and loss of renal function [24]. At the end of our 12 week study, all growing female PCK rats showed histological evidence of renal cysts. There were no significant differences on the number or size of cortical or medullary cysts among the diet treatment groups. The results indicated that soy protein and/or n-3 PUFAs did not slow disease progression. Similarly, female and male DBA/2FG-pcy mice (age 50-58 d) fed n-3 PUFA as EPA-enriched fish oil concentrate for 60 days had similar renal cyst area compared to mice fed sunflower seed oil low in n-3 PUFAs [26]. However, growing male Han:SPRD-cy rats fed $20 \%$ wt soy protein reduced renal cyst size compared male rats fed casein for 8 and 12 weeks [14,27]. Dietary intervention may differed in the PCK female rat model, a model of ARPKD compared to the Han:SPRD-cy rat model, a model of ADPKD. Renal pathology in PCK rats is characterized by damage to the collecting ducts and distal nephron while in the Han:SPRD-cy rat renal pathology is characterized by damage to proximal tubules and all sections of the nephron $[15,28]$. Also, earlier dietary intervention may be required in ARPKD since disease onset occurs in utero or shortly after birth. Cahill et al. [29] exposed male Han:SPRD-cy rats offspring to soy protein prenatally and during lactation. Offspring exposed to soy protein in utero and during pregnancy had reduced renal cyst changes as well as improved renal function. The observation of greater beneficial effects when soy protein was provided in utero and during lactation has important 
implication for ADPKD, but may be of particular significance to ARPKD with infantile disease onset.

In some animal studies, soy protein intake attenuated the early stages of cyst pathogenesis indicated by reduced epithelial cell proliferation [6]. MapK and mTOR are key transcription factors regulating cell proliferation [30]. In our study, MapK and mTOR gene expression were not significantly down-regulated in female PCK rats fed soy protein at weaning compared to casein fed rats. Cyst pathogenesis is characterized by initial proliferation of tubular epithelial cells followed by inflammation and fibrosis as the disease progresses [31]. In our study, cortical cyst obstruction was observed in rats fed SPI + SB diet. Histological evaluation of the kidneys of rats fed SPI+SB diet showed no significant difference in inflammation or fibrosis compared to the other dietary treatment groups. Cyst obstruction may not have resulted in sufficient damage at 12 weeks to promote significantly greater inflammation or fibrosis.

Rats fed SPI + SB diet also resulted in the highest $(P=0.01)$ serum BUN concentrations. Detrimental effects were unexpected since higher tissue EPA or DHA content replaces tissue n-6 PUFA, AA content. AA can be converted by the enzyme COX-2 to eicosanoids with proinflammatory properties, therefore decreasing tissue AA content may reduce inflammation [32]. Rats fed SPI+SB diet had the highest $(P=0.03)$ serum EPA and DHA and reduced $(P=0.04)$ ARA. In renal tissue rat fed SPI+SB diet also had the highest $(P<0.001)$ renal DHA content and reduced ARA $(P<0.001)$, but there was no significant differences in renal EPA content compared to the other diet treatment groups. EPA may have be used for eicosanoid production due to renal damage resulting from greater cyst obstruction in rat fed SPI+SB diet. Altered phospholipase A2 and COX activity in disease kidneys has been reported for pcy mouse and Hans:SPRD-cy rats [33]. Rats fed SPI with lipid sources as soybean oil also had lower $(P<$ 
0.001) renal AA content than rats fed Casein + SO. Ogborn et al. [9] suggested that soy protein inhibits $\Delta 6$ desaturase enzyme, which plays a role in the conversion of the essential n-6 PUFA, LA (18:2n-6) to the long-chain n-6 PUFA, AA (20:4n-6).

Female PCK rats fed SPI+SB diet had the highest renal tissue DHA content and reduced tissue AA content resulted in higher cyst obstruction and reduced renal function. While dietary fish oil rich in DHA had protective effects in Han:SPRD-cy rats, Sankaran et al. [34] reported exacerbation of PKD progression in weanling pcy rats fed DHA-rich algal oil. The authors suggested this was due to increased renal long-chain n-3 PUFA content at the expense of n-6 PUFAs resulting in inadequate n-6 PUFA content in tissue, eicosanoid imbalance, and higher risk of tissue oxidation.

In our study there were no significant differences in COX-2 gene expression among any of the diet treatment groups. In contrast, Sankaran et al. [35] reported weanling CD1-pcy/pcy mice and Han:SPRD-cy rats fed 7\% and 20\% (wt) menhaden oil rich in EPA and DHA or DHArich algae oil, but not ALA rich flaxseed oil up-regulated COX-2 kidney gene expression levels compared to rats fed CO [34,35]. These studies used a higher n-3 PUFA doses of up to $20 \% \mathrm{wt}$ as pure fish oil or algae oil which likely resulted in higher EPA and DHA content compared to a 1:1 salmon oil and soybean oil blend. The n-3 PUFAs may also influence inflammation by other pathways than COX such as altering transcription factors regulating inflammation gene expression [36]. PPAR $\gamma$ is part of the ligand-dependent nuclear receptor family expressed in the kidneys where it plays a role in cellular proliferation, fibrosis, and inflammation that can be activated by fatty acids [37]. Yoshihara et al. [38] reported male and female PCK rats treated with PPAR $\gamma$ agonist decreased kidney weight and cysts. In our study, there were no significant differences in PPAR $\gamma$ expression, kidney weights and cysts among PCK rats fed different dietary 
treatments for 12 weeks. In the Yoshihara et al. [38] study rats were provided PPAR $\gamma$ agonist drugs for 16 weeks.

The advantage of using a dietary approach is that a simple modification such as water intake has the potential to improve renal health in PKD patients. Nagao et al. [39] reported slowed renal cyst growth in PCK rats that increased fluid intake sufficient to lower urine osmolality in comparison to animals who drank water ad libitum. In a pilot study of female ADPKD patients $(n=8)$ water prescription of 3-4 L reduced urine osmolality, however renal cytogenesis was not assessed [40]. In our animal study there were no significant differences in water intake; therefore, any effects on PKD progression and severity were attributable to the different dietary lipids and/or proteins.

Sarwar and others [41] found that different protein quality influenced rat growth. Since a common strategy in diet management of renal disease is to maintain a healthy body weight [42], it is important to determine whether different protein and lipid sources support adequate growth. In the present study, growing female PCK rats fed $20 \%$ wt (87\% purity) protein as either soy protein or casein and 7\% wt lipid from corn oil low in n-3 PUFAs, soybean oil moderate in n-3 PUFAs or a soybean oil:salmon oil blend rich in n-3 PUFAs for 12 weeks showed no significant differences in weight gain or final body weights. The results indicated that all experimental diets were similar for supporting body growth. Similarly, Aukema and Housini [14] reported that growing female Han:SPRD-cy rats, a non-orthologous rodent model of ADPKD, fed 20\% wt soy protein for 6 weeks had similar body weights to rats fed 20\% wt casein. Ogborn et al. [42] reported that growing female Han:SPRD-cy rats fed 7\% wt corn oil low in n-3 PUFAs for 12 weeks had similar body weights and growth compared to rats fed flaxseed oil rich in n-3 PUFAs. 
Some study limitations are diet restriction supported growth, but the possibility that higher intakes due to ad libitum consumption can influence PKD progression cannot be discounted. Cysts were detectable in all groups at 12 weeks, but detectable dietary effects may require a longer feeding since PKD disease progresses more slowly in female than male and the PCK rat model is a slow progressing form of ARPKD [15-16]. The hypothesis that soy protein and n-3 fatty acids will attenuate disease progression was rejected based on the results showing feeding SPI and/or n-3 PUFAs to female PCK rats had no significant effect on proliferation or inflammation. 


\section{Acknowledgement}

We thank Barbara Mickelson for her expertise in formulating and manufacturing the diet, and DuPont Nutrition and Health for generously donating the SPI to our laboratory. Also, we thank Jonathan Dehlin for his assistance in creating the figures for this manuscript. Funding for this project was provided by the United Soybean Board Soybean Health Incentive Grant, West Virginia University PSCoR 10008736.6-11-NT10055R, West Virginia University Agriculture and Forestry Experimental Station Hatch Grant WVAA00665, and West Virginia University summer undergraduate education program. 


\subsection{References}

[1] Wilson PD. The genes and proteins associated with poly-cystic kidney diseases. Minerva Urol Nefrol. 2002;54:201-11.

[2] Halvorson CR, Bremmer MS, Jacobs SC. Polycystic kidney disease: inheritance, pathophysiology, prognosis, and treatment. Int J Nephrol Renovasc Dis. 2010;3:69-83.

[3] Chang MY, Ong AC. Autosomal dominant polycystic kidney disease: recent advances in pathogenesis and treatment. Nephron Physiol. 2008;108:1-7.

[4] Cadnapaphornchai MA, McFann K, Strain JD, Masoumi A, Schrier RW. Prospective change in renal volume and function in children with ADPKD. Clin J Am Soc Nephrol. 2009;4:820-829.

[5] Lager DJ, Qian Q, Bengal RJ, Ishibashi M, Torres VE. The pck rat: a new model that resembles human autosomal dominant polycystic kidney and liver disease. Kidney Int. 2001;59:126-36.

[6] Maditz KH, Gigliotti JC, Tou JC. Evidence for a role of proteins, lipids, and phytochemicals in the prevention of polycystic kidney disease progression and severity. Nutr Rev. 2013;71:802814.

[7] Clandinin MT, Jumpsen J, Suh M. Relationship between fatty acid accretion, membrane composition, and biologic functions. J Pediatr. 1994;125:25-32.

[8] Kiecolt-Glaser JK, Belury MA, Porter K, Beversdorf DQ, Lemeshow S, Glaser R. Depressive symptoms, omega-6:omega-3 fatty acids, and inflammation in older adults. Psychosom Med. 2007;69:217-24.

[9] Ogborn MR, Nitschmann E, Weiler H, Leswick D, Bankovic-Calic N. Flaxseed ameliorates interstitial nephritis in rat polycystic kidney disease. Kidney Int. 1999;55:417-23.

[10] Tomobe K, Philbrick D, Aukema HM, et al. Early dietary protein restriction slows disease progression and lengthens survival in mice with polycystic kidney disease. J Am Soc Nephrol. 1994;5:1355-60.

[11] Aukema HM, Housini I, Rawling JM. Dietary soy protein effects on inherited polycystic kidney disease are influenced by gender and protein level. J Am Soc Nephrol. 1999;10:300-8.

[12] Peng CY, Sankaran D, Ogborn MR, Aukema HM. Dietary soy protein selectively reduces renal prostanoids and cyclooxygenases in polycystic kidney disease. Exp Biol Med. (Maywood) 2009;234:737-43. 
[13] Grzegorczyk K, Krajewska M, Weyde W, Jakuszko K, Gniewek A, Klinger M. Gender and kidney diseases: the clinical importance and mechanisms of modifying effects. Postepy Hig Med Dosw. 2011;65:849-57.

[14] Aukema HM, Housini I. Dietary soy protein effects on disease and IGF-I in male and female Han:SPRD-cy rats. Kidney Int. 2001;59:52-61.

[15] Torres VE, Harris PC. Polycystic kidney disease: genes, proteins, animal models, disease mechanisms and therapeutic opportunities. J Intern Med. 2007;261:17-31.

[16] Nagao, S, Kugita M, Yoshihara D, Yamaguchi T. Animal models for human polycystic kidney disease. Exp Anim. 2012;61:477-88.

[17] National Research Council. Guide for the care and use of laboratory animal. National Academy Press, Washington DC, 1996, pp. 21-55.

[18] National Research Council. Nutrient Requirements of Laboratory Animals. Fourth Revised Edition ed. Washington, DC: The National Academies Press; 1995, pp.11-79.

[19] Tou JC, Altman SN, Gigliotti JC, Benedito VA, Cordonier EL. Different sources of omega3 polyunsaturated fatty acids affects apparent digestibility, tissue deposition, and tissue oxidative stability in growing female rats. Lipids Health Dis. 2011;14;10-17.

[20] Gigliotti JC, Benedito VA, Livengood R, Oldaker C, Nanda N, Tou JC. Feeding different omega-3 polyunsaturated fatty acid sources influences renal fatty acid composition, inflammation, and occurrence of nephrocalcinosis in female Sprague-Dawley Rats. Food Nutr Sci. 2013;4:125-36.

[21] Bligh EG, Dyer WJ. A rapid method of total lipid extraction and purification. Can J Biochem Physiol. 1959;37:911-17.

[22] Fritsche KL, Johnston PV. Effect of dietary alpha-linolenic acid on growth, metastasis, fatty acid profile and prostaglandin production of two murine mammary adenocarcinomas. J Nutr 1990;120:1601-09.

[23] Bari R, Datt Pant B, Stitt M, Scheible WR. PHO2, microRNA399, and PHR1 define a phosphate-signaling pathway in plants. Plant Physiol 2006 Jul;141(3):988-999.

[24] Igarashi P, Somlo S. Genetics and pathogenesis of polycystic kidney disease. J Am Soc Nephrol. 2002;13:2384-98.

[26] Yamaguchi T, Valli VE, Philbrick D, Holub B, Yoshida K, Takahashi H. Effects of dietary supplementation with n-3 fatty acids on kidney morphology and the fatty acid composition of phospholipids and triglycerides from mice with polycystic kidney disease. Res Commun Chem Pathol Pharmacol. 1990;69:335-51. 
[27] Aukema HM, Gauthier J, Roy M, Jia Y, Li H, Aluko RE. Distinctive effects of plant protein sources on renal disease progression and associated cardiac hypertrophy in experimental kidney disease. Mol Nutr Food Res. 2011;55:1044-51.

[28] Kaspareit-Rittinghausen J, Deerberg F, Rapp KG, Wcislo A. Renal hypertension in rats with hereditary polycystic kidney disease. Z Versuchstierkd. 1990;33:201-4.

[29] Cahill LE, Peng CY, Bankovic-Calic N, Sankaran D, Ogborn MR, Aukema HM. Dietary soya protein during pregnancy and lactation in rats with hereditary kidney disease attenuates disease progression in offspring. Br J Nutr. 2007;97:77-84.

[30] Caron E, Ghosh S, Matsuoka Y, Ashton-Beaucage D, Therrien M, Lemieux S, et al. A comprehensive map of the mTOR signaling network. Mol Syst Biol. 2010;6:453.

[31] Martinez JR, Grantham JJ. Polycystic kidney disease: etiology, pathogenesis, and treatment. Dis Mon. 1995;41:693-765.

[32] Calder PC. N-3 Polyunsaturated Fatty Acids, Inflammation, and Inflammatory Diseases. Am J Clin Nutr. 2006;83 Suppl):1505S-19S.

[33] Aukema HM, Adolphe J, Mishra S, Jiang J, Cuozzo FP, Ogborn MR. Alterations in renal cystolic phospholipase $\mathrm{A}_{2}$ and cyclooxygenases in polycystic kidney disease. FASEB J. 2003;17:298-300.

[34] Sankaran D, Lu J, Bankovic-Calic N, Ogborn MR, Aukema HM. Modulation of renal injury in pcy mice by dietary fat containing n-3 fatty acids depends on the level and type of fat. Lipids 2004 Mar;39(3):207-214.

[36] Sankaran D, Lu J, Ogborn MR, Aukema HM. COX-2 expression in cystic kidneys is dependent on dietary n-3 fatty acid composition. J Nutr Biochem 2007 Dec;18(12):806-812.

[37] Nagao S, Yamaguchi T. PPAR-gamma agonists in polycystic kidney disease with frequent development of cardiovascular disorders. Curr Mol Pharmacol. 2012;5:292-300.

[38] Yoshihara D, Kurahashi H, Morita M, Kugita M, Yoshiyuki H, Aukema H, Yamaguchi T, Calvet JP, Wallace DP, Nagao S. PPAR-Y agonist ameliorates kidney and liver disease in an orthologous rat model of human autosomal recessive polycystic kidney disease. Am J Physiol Renal Physiol. 2011;300:F465-74.

[39] Nagao S, Nishii K, Katsuyama M, Kurahashi H, Marunouchi T, Takahashi H, Wallace DP. Increased water intake decreases progression of polycystic kidney disease in PCK rat. J Am Soc Nephrol. 2006;17:2220-7.

[40] Wang CJ, Creed C, Winklhofer FT, Grantham JJ. Water prescription in autosomal dominant polycystic kidney disease: a pilot study. Clin J Am Soc Nephrol. 2011;6:192-7. 
[40] Sarwar G, Blair R, Friedman M, Gumbmann MR, Hackler LR, Pellett PL, et al. Inter- and intra-laboratory variability in rat growth assays for estimating protein quality of foods. J Assoc Off Anal Chem. 1984;67:976-81.

[41] Torres VE, Grantham JJ, Chapman AB, Mrug M, Bae KT, King BF,Jr, et al. Potentially modifiable factors affecting the progression of autosomal dominant polycystic kidney disease. Clin J Am Soc Nephrol. 2011;6:640-47.

[42] Ogborn MR, Nitschmann E, Bankovic-Calic N, Weiler HA, Aukema HM. Effects of flaxseed derivatives in experimental polycystic kidney disease vary with animal gender. Lipids 2006;41:1141-49. 
Table 1. Ingredient composition of the diets fed to rats.

\begin{tabular}{|c|c|c|c|c|}
\hline 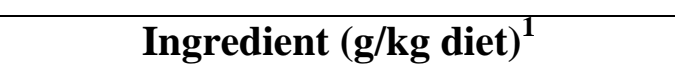 & Casein + CO & Casein + SO & SPI + SO & SPI + SB \\
\hline Casein & 200.0 & 200.0 & 0.0 & 0.0 \\
\hline Soy protein isolate & 0.0 & 0.0 & 200.0 & 200.0 \\
\hline L-Cystine & 3.0 & 3.0 & 1.3 & 1.3 \\
\hline Corn Starch & 397.5 & 397.5 & 397.5 & 397.5 \\
\hline Maltodextrin & 132.0 & 132.0 & 132.0 & 132.0 \\
\hline Sucrose & 100.0 & 100.0 & 100.0 & 100.0 \\
\hline Soybean Oil & 70.0 & 0.0 & 70.0 & 35.0 \\
\hline Corn Oil & 0.0 & 70.0 & 0.0 & 0.0 \\
\hline Salmon Oil & 0.0 & 0.0 & 0.0 & 35.0 \\
\hline Cellulose & 50.0 & 50.0 & 50.0 & 50.0 \\
\hline Mineral Mix ${ }^{2}$ & 35.0 & 35.0 & 35.0 & 35.0 \\
\hline Vitamin Mix ${ }^{2}$ & 10.0 & 10.0 & 10.0 & 10.0 \\
\hline Choline bitartrate & 2.5 & 2.5 & 2.5 & 2.5 \\
\hline TBHQ, antioxidant & 0.014 & 0.014 & 0.014 & 0.014 \\
\hline Calories & 377 & 377 & 377 & 377 \\
\hline \multicolumn{5}{|l|}{$\begin{array}{l}\text { Fatty acids (\%) } \\
n-3 \text { PUFAs }\end{array}$} \\
\hline Alpha-linolenic acid (ALA, 18:3n-3) & $0.59 \pm 0.18 \mathrm{c}$ & $7.69 \pm 0.02 \mathrm{a}$ & $7.68 \pm 0.04 \mathrm{a}$ & $4.85 \pm 0.01 \mathrm{~b}$ \\
\hline Eicosapentaenoic acid (EPA, 20:5n-3) & $\overline{N D}$ & $\overline{N D}$ & $\bar{N} \mathrm{D}$ & $7.4 \pm 0.03$ \\
\hline $\begin{array}{l}\text { Docosahexaenoic acid (DHA, 22:6n-3) } \\
n-6 \text { PUFAs }\end{array}$ & ND & ND & ND & $3.9 \pm 0.1$ \\
\hline Linoleic acid (LA, 18:2n-6) & $52.93 \pm 2.68 \mathrm{a}$ & $55.78 \pm 0.07 \mathrm{a}$ & $56.09 \pm 0.09 \mathrm{a}$ & $35.19 \pm 0.06 \mathrm{~b}$ \\
\hline Arachidonic acid (ARA, 20:4n-6) & $1.10 \pm 0.04 \mathrm{a}$ & $0.16 \pm 0.005 c$ & $0.21 \pm 0.01 \mathrm{c}$ & $0.41 \pm 0.007 \mathrm{~b}$ \\
\hline $\begin{array}{l}{ }^{1} \text { All ingredients are from Harlan Teklad } \\
\text { Louis, MO) and salmon oil from Jedwa } \\
\text { 2Based on the AIN-93G vitamin and mi } \\
\text { the same rows indicate significant diffe } \\
\text { Tukey's test. Abbreviations are CO, co } \\
\text { soybean oil:salmon oil blend; TBHQ, te }\end{array}$ & $\begin{array}{l}\text { except for SPI fi } \\
\text { ds International } \\
\text { eral mixes. Dif } \\
\text { nces at } P<0.05 \\
\text { oil; SO, soybe } \\
\text { tiary butylhydro }\end{array}$ & $\begin{array}{l}\text { m DuPont Nutr } \\
\text { Quincy, MA). } \\
\text { erent superscrip } \\
\text { y one-way ANC } \\
\text { n oil; SPI, soy p }\end{array}$ & $\begin{array}{l}\text { ition and Healt } \\
\text { letters a, b, c v } \\
\text { VA followed } \\
\text { rotein isolate; }\end{array}$ & $\begin{array}{l}\text { (St. } \\
\text { thin } \\
\text { B, } 1: 1\end{array}$ \\
\hline
\end{tabular}


Table 2. Body weight, body gain, water intake, and kidney weights in female PCK rats fed various protein and lipid sources.

\begin{tabular}{|c|c|c|c|c|c|}
\hline Measurements & Casein + CO & Casein + SO & SPI + SO & $\mathrm{SPI}+\mathrm{SB}$ & $P$-value \\
\hline Initial body weight (g) & $87 \pm 6$ & $86 \pm 6$ & $95 \pm 6$ & $93 \pm 7$ & 0.66 \\
\hline Body weight gain $(\mathrm{g})$ & $184 \pm 6$ & $184 \pm 5$ & $176 \pm 5$ & $186 \pm 13$ & 0.78 \\
\hline Final body weight (g) & $271 \pm 2$ & $270 \pm 3$ & $281 \pm 9$ & $269 \pm 4$ & 0.32 \\
\hline Water intake $(\mathrm{mL})$ & $14.4 \pm 9.4$ & $15.2 \pm 13.7$ & $16.3 \pm 11.5$ & $16.5 \pm 12.3$ & 0.79 \\
\hline $\begin{array}{l}\text { Relative left kidney weight } \\
\text { (g/100 g kidneys) }\end{array}$ & $4.4 \pm 0.1$ & $4.3 \pm 0.1$ & $4.6 \pm 0.2$ & $4.8 \pm 0.2$ & 0.09 \\
\hline $\begin{array}{l}\text { Relative right kidney weight } \\
\text { (g/100 g kidney) }\end{array}$ & $4.3 \pm 0.1$ & $4.3 \pm 0.1$ & $4.5 \pm 0.1$ & $4.6 \pm 0.2$ & 0.21 \\
\hline $\begin{array}{l}\text { Relative total kidney weights (g) } \\
\text { (g/100 g kidney) }\end{array}$ & $8.6 \pm 0.2$ & $8.5 \pm 0.2$ & $9.1 \pm 0.3$ & $9.3 \pm 0.4$ & 0.12 \\
\hline
\end{tabular}

Values are the mean \pm SEM of $n=11-12$ rats/group. Different means were compared by one-way ANOVA with significant differences at a $P$ value of $<0.05$. Abbreviations are CO, corn oil; SO, soybean oil; SPI, soy protein isolate; SB, 1:1 soybean oil:salmon oil blend. 
Table 3. Kidney histology of female PCK rats fed various protein and lipid sources.

\begin{tabular}{lccccc}
\hline \multicolumn{1}{c}{ Measurements } & Casein + CO & Casein + SO & SPI + SO & SPI + SB & P-value \\
\hline Number of medullary cysts $\geq 1.0 \mathrm{~mm}$ & $6.7 \pm 1.1$ & $5.8 \pm 1.5$ & $5.2 \pm 1.3$ & $6.3 \pm 1.0$ & 0.84 \\
Number of cortical cysts $\geq 0.3 \mathrm{~mm}$ & $2.6 \pm 0.7$ & $2.4 \pm 0.7$ & $2.3 \pm 1.0$ & $1.8 \pm 0.5$ & 0.91 \\
Structural effacement by cysts & $2.7 \pm 0.2$ & $2.3 \pm 0.3$ & $2.4 \pm 0.3$ & $2.6 \pm 0.2$ & 0.55 \\
Cortical cystic change & Present & Present & Present & Present \\
Cortical cyst obstruction & Not Present & Not Present & Not Present & Present \\
Medullary cystic change & Present & Present & Present & Present \\
Interstitial inflammation & $1.6 \pm 0.1$ & $1.5 \pm 0.2$ & $1.5 \pm 0.2$ & $1.4 \pm 0.2$ & $1.2 \pm 0.1$ \\
Tubulo-interstitial fibrotic changes & $1.3 \pm 0.2$ & $1.0 \pm 0.2$ & $1.0 \pm 0.2$ & $1.1 \pm 0.3$ \\
Tubulo-interstitial matrix & $0.9 \pm 0.3$ & $0.3 \pm 0.1$ & $1.0 \pm 0.2$ & 0.49 \\
deposition & & & & Not Present \\
Glomerular hypercellularity & Not Present & Not Present & Not Present & Not Present \\
Glomerular matrix deposition & Not Present & Not Present & Not Present & Not Present \\
Arteriolosclerosis & Not Present & Not Present & Not Present & Not Present \\
Interstitial calcification & Not Present & Not Present & Not Present & Not & \\
\hline
\end{tabular}

alues are the mean \pm SEM of $n=11-12$ rats/group. Different means were compared by one-way ANOVA with significant differences at a $P$ value of $<0.05$. Abbreviations are CO, corn oil; SO, soybean oil; SPI, soy protein isolate; SB, $1: 1$ soybean oil:salmon oil blend. 
Table 4. Kidney tissue and serum fatty acid composition in female PCK rats fed various protein and lipid sources.

\begin{tabular}{|c|c|c|c|c|c|}
\hline $\begin{array}{c}\text { Measurements } \\
\text { (\% total fatty acids) }\end{array}$ & Casein + CO & Casein + SO & SPI + SO & SPI + SB & $P$-value \\
\hline \multicolumn{6}{|l|}{ Kidney } \\
\hline \multicolumn{6}{|l|}{ n-6 PUFAs } \\
\hline Linoleic acid (18:2) & $7.95 \pm 0.39$ & $9.81 \pm 0.61$ & $10.05 \pm 0.84$ & $11.06 \pm 0.94$ & 0.05 \\
\hline Arachadonic acid (20:4) & $17.83 \pm 0.59 \mathrm{a}$ & $15.83 \pm 0.37 \mathrm{a}$ & $12.97 \pm 1.35 \mathrm{~b}$ & $10.49 \pm 0.82 b$ & $<0.001$ \\
\hline \multicolumn{6}{|l|}{ n-3 PUFAs } \\
\hline Alpha-linolenic acid (18:3) & $0.09 \pm 0.004 \mathrm{c}$ & $0.46 \pm 0.04 \mathrm{a}$ & $0.41 \pm 0.05 \mathrm{a}$ & $0.30 \pm 0.02 b$ & $<0.001$ \\
\hline Eicosapentaenoic acid (20:5) & $1.73 \pm 0.12$ & $2.06 \pm 0.09$ & $2.14 \pm 0.25$ & $2.33 \pm 0.31$ & 0.33 \\
\hline Docosahexaenoic acid (22:6) & $0.89 \pm 0.18 c$ & $1.99 \pm 0.04 \mathrm{~b}$ & $1.93 \pm 0.22 b$ & $4.25 \pm 0.17 \mathrm{a}$ & $<0.001$ \\
\hline \multicolumn{6}{|l|}{ Final Serum } \\
\hline Linoleic acid (18:2) & $24.27 \pm 2.48 \mathrm{a}$ & $12.56 \pm 0.69 b$ & $11.02 \pm 0.70 b$ & $7.61 \pm 0.25 b$ & $<0.05$ \\
\hline Arachadonic acid (20:4) & $0.43 \pm 0.07 \mathrm{a}$ & $0.39 \pm 0.07 \mathrm{ab}$ & $0.42 \pm 0.13 \mathrm{ab}$ & $0.14 \pm 0.02 b$ & 0.04 \\
\hline \multicolumn{6}{|l|}{ n-3 PUFAs } \\
\hline Alpha-linolenic acid (18:3) & $0.21 \pm 0.07 b$ & $0.67 \pm 0.05 \mathrm{a}$ & $0.76 \pm 0.3 \mathrm{a}$ & $0.35 \pm 0.01 b$ & $<0.001$ \\
\hline Eicosapentaenoic acid (20:5) & $0.47 \pm 0.04$ & $0.66 \pm 0.01$ & $0.76 \pm 0.05$ & $1.41 \pm 0.12$ & 0.33 \\
\hline Docosahexaenoic acid (22:6) & $0 \mathrm{c}$ & $1.00 \pm 0.31 b$ & $1.29 \pm 0.08 b$ & $4.13 \pm 0.53 \mathrm{a}$ & $<0.001$ \\
\hline
\end{tabular}

Values are the mean \pm SEM of $n=11-12$ rats/group. Different superscript letters $a, b, c$ within the same rows indicate significant differences at $P<0.05$ by one-way ANOVA followed by Tukey's test. Abbreviations are CO, corn oil; SO, soybean oil; SPI, soy protein isolate; $\mathrm{SB}, 1: 1$ soybean oil:salmon oil blend; $n-6$ PUFAs, omega-6 polyunsaturated fatty acids; n-3 PUFAs, omega-3 polyunsaturated fatty acids. 
Table 5. Serum measurements in female PCK rats fed various protein and lipid sources.

\begin{tabular}{|c|c|c|c|c|c|}
\hline Measurements & Casein + CO & Casein + SO & SPI + SO & SPI + SB & $P$-value \\
\hline $\begin{array}{l}\text { Serum Blood Urea Nitrogen } \\
(\mathrm{mg} / \mathrm{dL})\end{array}$ & $10.1 \pm 0.5 \mathrm{~b}$ & $9.3 \pm 0.8 \mathrm{c}$ & $11.6 \pm 0.5 b$ & $11.8 \pm 0.6 \mathrm{a}$ & 0.01 \\
\hline Serum Uric Acid (mg/dL) & $4.8 \pm 0.3$ & $5.3 \pm 0.5$ & $5.1 \pm 0.4$ & $4.7 \pm 0.2$ & 0.65 \\
\hline Serum Total protein $(\mathrm{g} / \mathrm{dL})$ & $6.2 \pm 0.4$ & $6.4 \pm 0.3$ & $6.5 \pm 0.4$ & $6.4 \pm 0.3$ & 0.92 \\
\hline Serum Globulin (g/dL) & $2.4 \pm 0.2$ & $2.6 \pm 0.2$ & $3.0 \pm 0.5$ & $2.9 \pm 0.3$ & 0.66 \\
\hline Serum Albumin (g/dL) & $3.8 \pm 0.1$ & $3.8 \pm 0.1$ & $3.6 \pm 0.2$ & $3.5 \pm 0.2$ & 0.55 \\
\hline $\begin{array}{l}\text { Serum Albumin/Globulin } \\
(\mathrm{g} / \mathrm{dL})\end{array}$ & $2.1 \pm 0.5$ & $1.5 \pm 0.1$ & $1.5 \pm 0.2$ & $1.5 \pm 0.2$ & 0.44 \\
\hline Serum Calcium (mg/dL) & $11.7 \pm 0.4$ & $11.7 \pm 0.1$ & $11.0 \pm 0.4$ & $11.0 \pm 0.3$ & 0.17 \\
\hline Serum Phosphorus (mg/dL) & $12.1 \pm 0.6$ & $13.1 \pm 0.7$ & $11.5+0.6$ & $12.0 \pm 0.5$ & 0.32 \\
\hline
\end{tabular}

Values are the mean \pm SEM of $n=11-12$ rats/group. Different superscript letters $a, b, c$ within the same rows indicate significant differences at $P<0.05$ by one-way ANOVA followed by Tukey's test. Abbreviations are CO, corn oil; SO, soybean oil; SPI, soy protein isolate; $\mathrm{SB}, 1: 1$ soybean oil:salmon oil blend. 
Figure 1 A-C. Histological evaluation by H\&E staining of kidneys from female PCK rats fed various dietary treatments.
A)
B)
C)

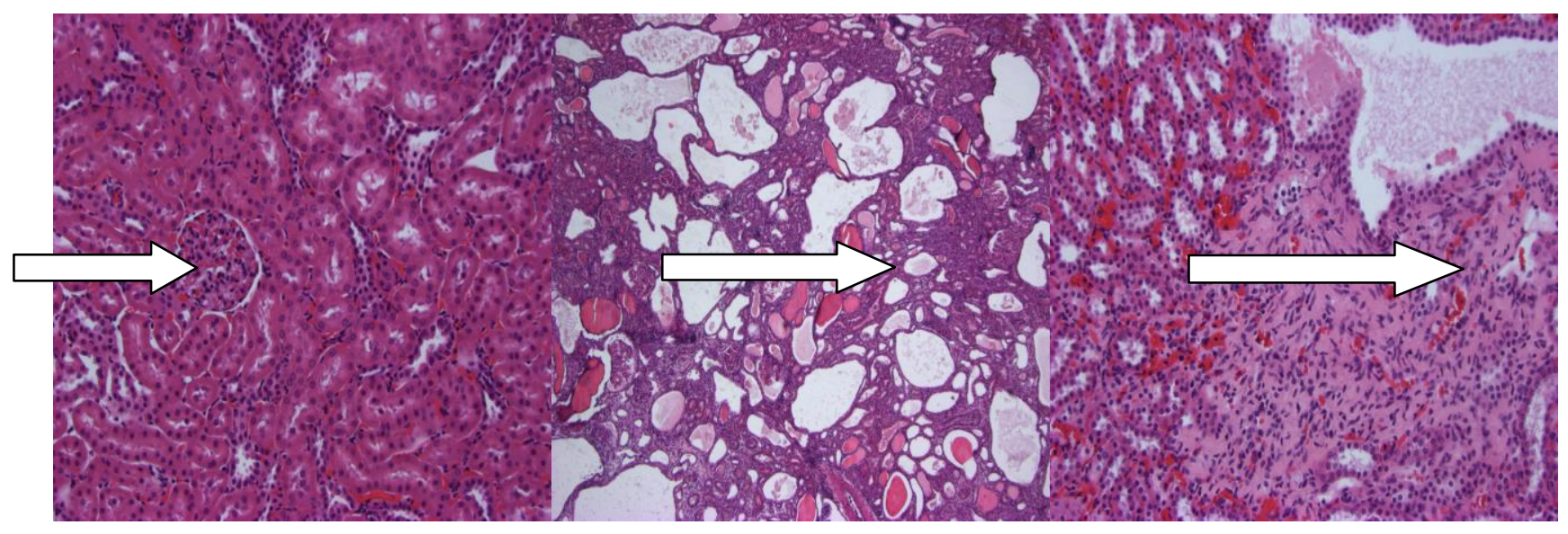

Slides depict (left to right) (A) inflammation, (B) cysts, and (C) fibrosis. 
Figure 2 A-D. Renal genetic expression levels of (A) PPAR-gamma, (B) COX-2, (C) MAPK, and (D) mTOR in relation to dietary treatments.

A)

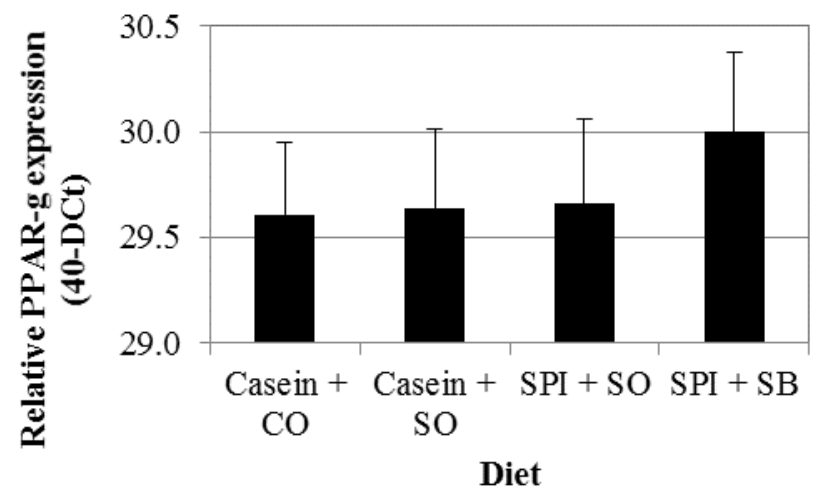

C)

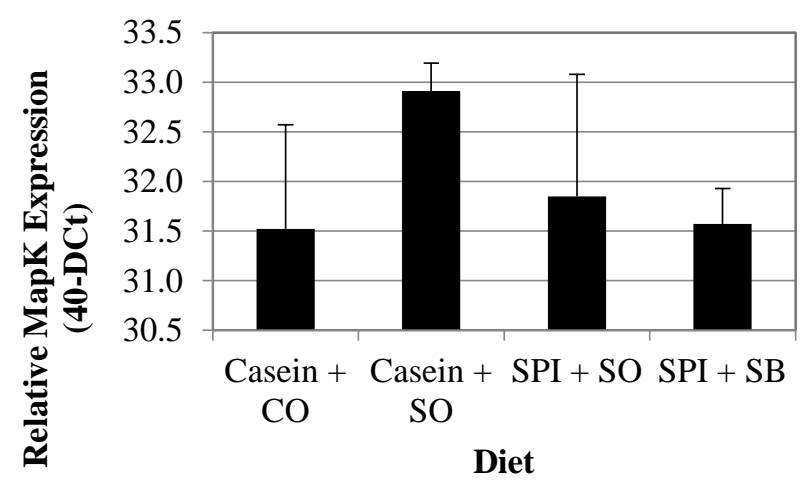

B)

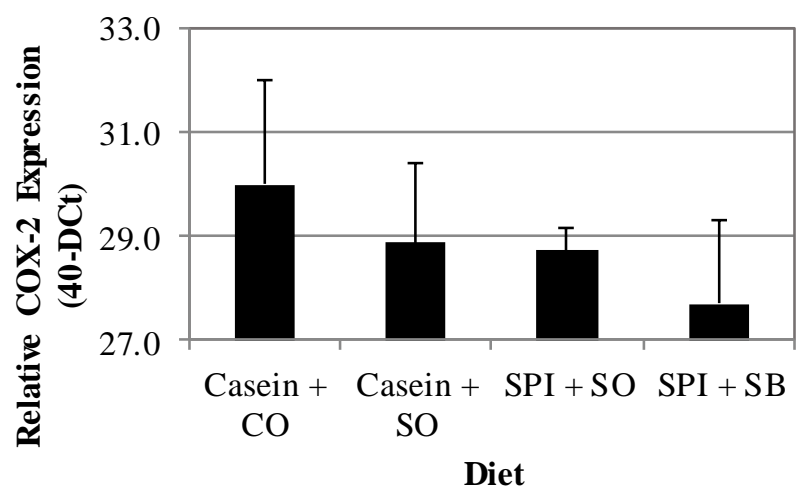

D)

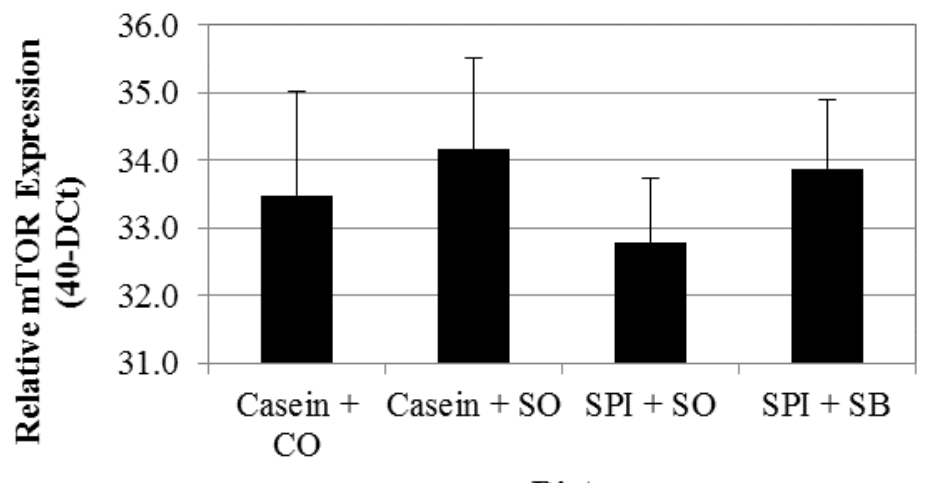

Diet 


\title{
Chapter 2:
}

Dietary Omega-3 Polyunsaturated Fatty Acid and/or Soy Protein Isolate Did Not Affect Mineral Balance and Bone in the PCK Rat Model of Polycystic Kidney Disease

\author{
Kaitlin H. Maditz ${ }^{1}$, Brenda J. Smith², Matthew Miller ${ }^{1}$, Chris Oldaker ${ }^{1}$, Janet C. Tou ${ }^{* 1}$ \\ ${ }^{1}$ Division of Animal and Nutritional Sciences, West Virginia University, Morgantown, WV \\ 26505. ${ }^{2}$ Department of Nutritional Sciences, Oklahoma State University, Stillwater, OK 74078.
}

Short Title: diet effects on bone in polycystic kidney disease

*Corresponding Author:

Janet C. Tou, PhD

Tel: (304) 293-1919

Fax: (304) 293-2232

e-mail: janet.tou@mail.wvu.edu 


\subsection{Abstract}

Polycystic kidney disease (PKD), a genetic disorder characterized by multiple cysts, leads to loss of kidney function and renal failure at an early age. Optimizing bone health during the growth stage may protect against bone loss associated with early renal dysfunction in PKD. Soy protein and omega-3 polyunsaturated fatty acids (n-3 PUFAs) are nutrients reported to ameliorate $\mathrm{PKD}$, to prevent bone loss in ovarectomized rats, and to enhance bone in nondiseased animals. The study objective was to determine the effects of feeding soy protein and/or n-3 PUFAs in PCK rats, a model of PKD on bone. Weanling female PCK rats (n=12/group) were randomly assigned to casein + corn oil $($ Casein $+\mathrm{CO})$, casein + soybean oil $($ Casein $+\mathrm{SO})$, soy protein isolate + soybean oil $(\mathrm{SPI}+\mathrm{SO})$ or soy protein isolate $+1: 1$ soybean oil:salmon oil blend $(\mathrm{SPI}+\mathrm{SB})$. At 12 weeks, rats fed the SPI+SO diet had lower $(P=0.001)$ femur length than casein-fed rats. Rats fed SPI+SB diet had higher $(P=0.01)$ calcium $(\mathrm{Ca})$ and phosphorus $(\mathrm{P})$ retention. However, there were no significant differences between diet groups in $\mathrm{Ca}$, $\mathrm{P}$ or bone mass. There were also no significant difference in bone microarchitecture according to microcomputed tomography or bone strength by three-point bending test between diet groups. Early diet management using SPI and/or n-3 PUFAs neither worsens nor enhances bone mineralization, microarchitecture or strength, but influenced other renal disease complications of longitudinal bone growth and mineral metabolism indicated by effects on femur length and by increased mineral retention.

Keywords: omega-3 fatty acids, protein, mineral balance, long bones, polycystic kidney disease 


\subsection{Introduction}

In children, kidney diseases are often accompanied by disordered mineral metabolism, decrease in maximum adult height achieved, and failure to achieve peak bone mass (PBM) [1-2]. Furthermore, epidemiological studies demonstrated greater incidence of bone fractures in end stage renal disease (ESRD) patients [3]. Worldwide, the third most common cause of ESRD is polycystic kidney disease (PKD) characterized by multiple cysts that lead to massive enlargement of the kidneys and loss of renal function [4]. In autosomal dominant polycystic kidney disease (ADPKD), the most prevalent inherited form of PKD, individuals are asymptomatic until the third or fifth decades of life [5]. In the rarer autosomal recessive polycystic kidney disease (ARPKD), disease onset occurs early in childhood with more than $50 \%$ of affected children progressing to ESRD in the first decade of life [6]. Common strategies for the management of renal disease and the resulting sketetal phenotype in childhood are to promote a healthy body weight and to maximize PBM.

Soy protein and omega-3 polyunsaturated fatty acids (n-3 PUFAs) are dietary components found in pre-clinical studies to ameliorate PKD progression and severity [7], to improve bone health, and to attenuate bone loss leading to osteoporosis [8-10]. Dietary protein restriction is advocated as a dietary regimen to attenuate renal disease and to delay the onset of ESRD, although evidence for its clinical effectiveness and feasibility is controversial [11]. Therefore, efforts to discern the best dietary approach as it relates to protein have focused on investigating the protein source rather than the amount consumed [12]. Feeding growing Hans:SPRD-cy rats, an animal model of ADPKD, soy protein isolate (SPI) has been shown to slow PKD progression and severity compared to rats fed the milk protein, casein [12-13]. Hans:SPRD-cy rats were derived from spontaneous mutations in Sprague-Dawley rats [14]. 
Feeding growing female Sprague-Dawley rats SPI enhanced bone mineral content (BMC) and bone mineral density (BMD) compared to casein [15]. The commercially available PCK rat derived from a Sprague-Dawley outbred strain is genetically orthologous to human ARPKD [14]. The PCK rat has been used for preclinical testing of treatment options for PKD [16]. To our knowledge no studies have investigated the effects of dietary SPI on PCK rats.

Previously, we reported that female Sprague-Dawley rats (age 28 d) fed fish oil rich in the long-chain n-3 PUFAs, eicosapentaenoic acid (EPA, 20:5n-3) and docosahexaeonic acid (DHA, 22:6 n-3) increased femur and tibial BMD and BMC; whereas, flaxseed oil rich in the n-3 PUFA, alpha linolenic acid (ALA, 18:3n-3) improved long bone trabecular microarchitecture compared to rats fed corn oil [17]. Female Han:SPRD-cy rats (age $21 \mathrm{~d}$ ) fed ALA-rich flaxseed oil had higher whole body BMC and BMD compared to animals fed corn oil low in n-3 PUFAs [18]. These studies demonstrated favorable effects of n-3 PUFA intake on bone in young growing non-diseased and ADPKD rats. To our knowledge no studies have investigated whether dietary n-3 PUFAs can enhance bone health in PCK rats.

There has been a lack of research regarding the potential bone effects of PKD, particularly in ARPKD, because the priority in PKD therapy strategies has been to slow progression to hypertension, renal failure, and early age at morbidity. Studies are needed because many drugs used in the treatment of osteoporosis are not approved for use in patients with moderate to advanced kidney diseases [3]. Also, drug therapies in development to treat PKD such as peroxisome-proliferator-activated receptor-gamma agonists have reported side effects that include bone loss [19]. Early diet management by optimizing bone health during the growth stage can potentially minimize bone loss due to renal dysfunction and ERSD at an early age in PKD patients [5-6]. Therefore, the objective of this study was to determine the whether 
feeding growing female PCK rats SPI and/or n-3 PUFAs can enhance bone morphometry, mineralization, microarchitecture, and strength.

\subsection{Materials and Methods}

Animals and Diets

All animal procedures were conducted in accordance with the Institute of Laboratory Animal for the Care and Use of Laboratory Animals Guidelines [20], and were approved by the Animal Care and Use Committee at West Virginia University. Growing (age 28 d) female PCK rats were purchased from Charles River Laboratories (Wilmington, MA). All rats were kept in a $21^{\circ} \mathrm{C}$ room with a 12 hour light/dark cycle throughout the 12 week study period. Following a 7 day acclimation period, animals were randomly assigned ( $\mathrm{n}=12$ rats/group) to experimental diets. A power analysis was conducted prior to the experiment showed that with 10 rats/group at an alpha $=0.05$ there is $80 \%$ power to detect a difference in BMD and microarchitecture between the diet groups. An additional 1-2\% rats was included due to possibility of morbidity or mortality due to disease in PCK rats.

The experimental diets were based on the American Institute of Nutrition-93G (AIN-93 G) diet. The AIN-93G is a standard diet consisting of purified ingredients and formulated to meet all the nutritional requirements for growing rats as defined by the National Research Council [21]. The AIN-93G diet is formulated with casein as the protein source ( $200 \mathrm{~g} / \mathrm{kg}$ diet $)$ and soybean oil (SO) as the lipid source (70 g/kg diet). SO contains both essential fatty acids, the n-6 PUFA, linoleic acid (LA, 18:2n-6) and the n-3 PUFA, ALA. The experimental diets consisted of casein or SPI as the protein source. SPI was generously provided by DuPont Nutrition and Health (St. Louis, MO). The lipid sources in the experimental diets consisted of CO because it is high in n-6 PUFA and low in n-3 PUFAs which is typical of Western diets [22], 
soybean oil or a 1:1 ratio of soybean oil:salmon oil to provide a source of the n-3 PUFA, ALA as well as long-chain n-3 PUFAs, DHA and particularly EPA. Salmon oil was purchased from JEdwards International Inc (Quincy, MA). The experimental diets consisted of: 1) casein + corn oil $($ Casein $+\mathrm{CO}), 2)$ casein + soybean oil $($ Casein $+\mathrm{SO}), 3)$ soy protein isolate + soybean oil $(\mathrm{SPI}+\mathrm{SO})$ or 4) soy protein isolate $+1: 1$ soybean/salmon oil $(\mathrm{SPI}+\mathrm{SB})$. All experimental diets were manufactured by Harlan Teklad (Madison, WI). Ingredients and fatty acid analysis are provided in Table 1.

To prevent variation in total caloric and nutrient intake, all diets were adjusted to be isocaloric and rats were provided $15 \pm 2 \mathrm{~g}$ of powdered diet daily. This is based on previous studies showing growing female rats consume $\sim 15 \mathrm{~g}$ powdered diet/d [23]. All diets were kept at $-20^{\circ} \mathrm{C}$ until fed. Fresh diet was provided daily. Rats were provided deonized distilled water $\left(\mathrm{ddH}_{2} \mathrm{O}\right)$ to prevent mineral intake from sources other than the diet. Body weights were measured weekly throughout the 12 weeks study.

\section{Mineral Balance}

Rats were individually housed in metabolic cages during the final week of the 12 weeks feeding study to collect urine and feces. Final $7 \mathrm{~d}$ urine samples were collected and centrifuged at $1,500 \mathrm{~g}$ for $10 \mathrm{~min}$ at $4{ }^{\circ} \mathrm{C}$, filtered through Whatman no. 1 paper, and diluted 1:10 in $\mathrm{ddH}_{2} \mathrm{O}$. Urinary calcium $(\mathrm{Ca})$ and phosphorus $(\mathrm{P})$ concentrations were determined using inductively coupled plasma spectrometry (ICP, model P400, Perkin Elmer, Shelton, CN). Urinary values were corrected for urinary creatinine. Creatinine was measured using a colorimetric assay kit (Cayman Chemical, Ann Arbor, MI) and absorbance read at $500 \mathrm{~nm}$ using a Spectramax Plus microplate reader (Molecular Devices, Sunnyvale, CA). Urinary creatinine values were higher $(P<0.05)$ for rats fed the Casein+CO diet $(58.6 \pm 9.6 \mathrm{mg} / \mathrm{dl})$ and Casein+SO $(40.2 \pm 5.4 \mathrm{mg} / \mathrm{dl})$ 
compared to rats fed the SPI+SO diet $(20.7 \pm 3.4 \mathrm{mg} / \mathrm{dl})$ and SPI+SB diet $(26.9 \pm 5.4 \mathrm{mg} / \mathrm{dl})$. All urinary measurements were adjusted for creatinine.

Diet and fecal samples were freeze-dried for $48 \mathrm{~h}$, ashed in a muffle furnace at $550^{\circ} \mathrm{C}$ for $24 \mathrm{~h}$, and then acidified in $70 \%$ nitric acid. The acidified samples were neutralized in $\mathrm{ddH}_{2} \mathrm{O}$, filtered through Whatman no. 1 paper, diluted 1:50 in $\mathrm{ddH}_{2} \mathrm{O}$, and fecal $\mathrm{Ca}$ and $\mathrm{P}$ content determined by ICP.

Bone Morphometry

Following euthanization by $\mathrm{CO}_{2}$ asphyxiation, the right and left femurs and tibiae were collected ( $\mathrm{n}=12$ rats/group). Bones were defleshed and morphometry measurements of medial lateral width, anterior posterior width, and length were determined using a vernier caliper (Bel-Art Products, Pequannock, NJ). Length was measured from the medial condyle to greater trochanter. Bones were dried at $110^{\circ} \mathrm{C}$ for $48 \mathrm{~h}$ then weighed using an analytical balance (Mettler Toledo, Columbus, $\mathrm{OH})$. Morphometry measurements were averaged for bone pairs (i.e. right and left) after no bilateral differences were determined using paired t-test with significance level set at $P<0.05$.

\section{Bone Turnover Markers}

Serum samples were stored at $-80^{\circ} \mathrm{C}$ until assayed. Serum osteocalcin, a marker of osteoblast activity was determined using a commercially available rat specific osteocalcin enzyme immunoassay (EIA) (Biomedical Technologies, Stoughton, MA). Urinary deoxypyridinoline (DPD) crosslinks, a marker of osteoclast activity, was determined by commercially available EIA kit (Quidel Corporation, CA). Serum osteocalcin was measured at $450 \mathrm{~nm}$ and urinary DPD was read at $405 \mathrm{~nm}$ using a Spectramax Plus microplate reader (Molecular Devices, Sunnyvale, CA).

Bone Densitometry, Ash, Ca, and P 
Dual energy X-ray absorptiometry (DXA) scans (Hologic QDR 4500-A Elite) were performed on the left bones. Tibial and femoral specimens were placed in Millipore water. Bone mineral area (BMA), BMC, BMD were evaluated from all scans using the Regional High Resolution software package designed for studying isolated bone specimens (Hologic Waltham, MA).

Following DXA, bones were ashed in a muffle furnace (model CP18210, Thermolyne, Dubuque, IA) at $600^{\circ} \mathrm{C}$ for $24 \mathrm{~h}$ then weighed. Bone ash was dissolved in $2 \mathrm{~mL}$ of $70 \%$ nitric acid. Acidified samples were filtered through Whatman no. 1 paper and diluted (1:500 v/v) to volume with $\mathrm{ddH}_{2} \mathrm{O}$. Bone $\mathrm{Ca}$ and $\mathrm{P}$ content of the samples were measured using inductively coupled plasma optical emission spectrometry (model P400, Perkin Elmer, Shelton, CT).

Trabecular and Cortical Bone Microarchitectural Analyses

Trabecular and cortical bone architecture was determined in the left bones using microcomputed tomography ( $\mu \mathrm{CT}$ ) (MicroCT40, SCANCO Medical, Switzerland). Cortical bone architecture was evaluated on a $512 \mu \mathrm{m}$ region of the femur and tibia mid-diaphysis. Cortical indices included the medullary area and cortical thickness, area, and porosity. The trabecular bone within the distal femur metaphysis and proximal tibial metaphysis were scanned and 200 images $(\sim 16 \mu \mathrm{m} / \mathrm{slice}$ or $3.2 \mathrm{~mm})$ were analyzed with semi-automatically drawn contours beginning $400 \mu \mathrm{m}$ from the growth plate including only secondary spongiosa within the volume of interest. The volume of interest was assessed for structural parameters included trabecular bone volume per unit of total volume (BV/TV), trabecular number $(\mathrm{TbN})$, trabecular thickness $(\mathrm{TbTH})$, trabecular connectivity, trabecular separation (TbSp), and structure model index (SMI). All scans were performed utilizing a 1024 x 1024 matrix resulting in an isotropic voxel 
resolution of $22 \mu \mathrm{m}^{3}$. An integration time of 70 milliseconds per projection was used with a rotational step of $0.36^{\circ}$ resulting in total acquisition time of approximately $\sim 150 \mathrm{~min} / \mathrm{sample}$.

\section{Bone Biomechanical Strength}

Bone strength indices were assessed using a TA.XT2i Texture Analyzer (Texture Technologies, Scarsdale, NY) outfitted with a three-point bending apparatus. Femora and tibiae were placed on supports and force applied on the medial surface of the bones by lowering a centrally placed blade $(1 \mathrm{~mm}$ width $)$ at a constant crosshead speed $(0.1 \mathrm{~mm} / \mathrm{sec})$ until the bone was broken. The load cell was $250 \mathrm{~kg}$. The load-deflection data were collected by a PC interfaced with the TA.XT2i. Sample test distance was set at $10 \mathrm{~mm}$ with a signal collection rate of 100 points per sec.

\section{Statistical Analysis}

Results are expressed as means \pm standard error of the mean (SEM). One way analysis of variance (ANOVA) was used to determine differences between treatment groups. Post-hoc multiple comparisons were performed using Tukey's test (parametric) or Wilcoxon rank test (non-parametric). Differences were considered significant at $P<0.05$. All statistical analyses were performed using SigmaStat 3.1 statistical software program (Systat Software Inc., San Jose, CA).

\subsection{Results and Discussion}

Growing female PCK rats fed different protein sources as casein or SPI for 12 weeks had similar body weights (Figure 1). Previously, long-term (22 months) soy protein consumption has been reported to produce no difference in body weight gain in Sprague-Dawley rats compared to a casein-based diet [24]. In addition to different dietary proteins, growing female PCK rats were fed different amounts and types of n-3 PUFAs in our study. PCK rats fed 
soybean oil or 1:1 soybean:salmon oil blend for 12 weeks showed similar body weights (Figure 1). Others have reported similar body weight gain in growing rats fed soybean oil, flaxseed oil or fish oil [17] [25].

Growth disturbances occur early in children with chronic kidney disease [26] and early management is required to prevent growth failure and shorter stature [2]. In the current study, growing female PCK rats fed SPI with the lipid source as either pure soybean oil or a blend of soybean oil and fish oil had no significant differences in femur length (Table 2). Similarly, Sirosis et al. [25] reported femur length was not significantly different for growing female Sprague-Dawley rats fed 7\% wt fish oil compared to soybean oil. However, growing female Hans:SPRD rats, a model of ADPKD, fed 7\% wt flaxseed oil rich in n-3 PUFA, ALA, before the onset of disease and continuing for 12 weeks, lengthened the femur compared to rats fed corn oil low in ALA [18]. Since ALA content is higher in flaxseed oil compared to soybean oil [27], lengthen femur may have been due to feeding a higher ALA dose. In our study, femur length was shorter $(P=0.001)$ in PCK rats fed SPI+SO compared to rats fed Casein $+\mathrm{CO}$ and Casein + SO (Table 2). SPI contains isoflavone phytoestrogens [7]. Estrogen receptor beta (ER $\beta)$ has been shown to be a physiological inhibitor of bone growth in young adult (age four month old) female mice [28]. It has been reported that phytoestrogens have binding specificity for ER $\beta$ [29]. Tou et al. [30] reported that young adult (age $50 \mathrm{~d}$ ) female Sprague-Dawley rats fed a phytoestrogen diet decreased $(P<0.05)$ femur length compared to rats fed Casein+SO diet. Therefore, we speculate that decreased femur length in PCK rats fed SPI+SO in this study was due to the phytoestrogens in the SPI diet. However, growing female rats fed SPI+SB diet showed no significant differences in femur length compared to casein-fed rats (Table 2). The type of lipid associated with the protein may exert different bone effects. SPI+SB diet had the 
highest n-3:n-6 PUFA ratio as well as EPA and DHA content (Table 1) which has been associated with bone growth. Mechanisms whereby n-3 PUFAs have been suggested to promote bone growth include reducing prostaglandin $E_{2}$ production by decreasing the $n-6 / n-3$ PUFA ratio to promote bone formation rate and to inhibit bone resorption, enhancing bone specific alkaline phosphatase activity to increase osteoblastic function, and by increasing circulating insulin-like growth factor binding protein to promote growth factors [10][31-32].

In addition to decreased height, children with kidney diseases often have disordered mineral metabolism [1]. The lower sulfur amino acid content of soybean protein compared to animal proteins has been suggested to decrease Ca excretion [33]. Growing female PCK rats showed no significant differences in Ca excretion; however, urinary $\mathrm{P}$ excretion was lower $(P<0.001)$ in rats fed the SPI+SB diet despite higher $\mathrm{P}$ intake compared to rats fed casein (Table 3). Dietary P content was higher in SPI+SO $(7.3 \pm 0.3 \mathrm{mg})$ and $\mathrm{SPI}+\mathrm{SB}(7.2 \pm 0.3 \mathrm{mg})$ compared to Casein $+\mathrm{CO}(6.5 \pm 0.2 \mathrm{mg})$ and Casein $+\mathrm{SO}(6.1 \pm 0.5 \mathrm{mg})$ diets. Similarly, dietary Ca content was higher in SPI+SO $(10.0 \pm 0.7 \mathrm{mg})$ and SPI+SB $(9.7 \pm 0.4 \mathrm{mg})$ compared to Casein+CO $(8.2 \pm 0.2 \mathrm{mg})$ and Casein+SO $(8.8 \pm 0.1 \mathrm{mg})$ diets. In turn, higher $\mathrm{Ca}$ and $\mathrm{P}$ resulted in higher $\mathrm{Ca}$ and $\mathrm{P}$ intake, but there were no significant differences in $\mathrm{Ca}$ and $\mathrm{P}$ apparent absorption (Table 3). PCK rats fed the SPI+SB diet had the highest Ca and P retention. The SPI+SB diet had the highest EPA and DHA content (Table 1). EPA and DHA alters cell membrane fluidity and this may alter intestinal cell membrane fatty acid composition [34]. Along with higher $\mathrm{Ca}$ and $\mathrm{P}$ intake, this may have contributed to higher $\mathrm{Ca}$ and $\mathrm{P}$ retention in rats fed the SPI+SB diet.

Despite greater $\mathrm{Ca}$ and $\mathrm{P}$ retention in rats fed the SPI+SB diet, there were no significant differences in long bone Ca or P between the dietary groups (Table 4). Additionally, there were no significant differences in femoral and tibial bone mineral area (BMA), BMC, and BMD 
(Table 4). In contrast, Lukas et al. [17] reported that growing female Sprague-Dawley rats fed salmon oil for 12 weeks experienced an increase in femur and tibia BMC and BMD. This discrepancy in response may be due to the use of a higher oil dose $(12 \% \mathrm{wt})$ and the use of pure salmon oil compared to the lower dose (7\% wt) and soybean oil:salmon oil blend provided to growing female PCK rats in this study. Others have shown in the ADPKD rat model, Hans:SPRD-cy rats fed 5\% wt flaxseed oil rich in ALA [35] for 8 weeks had no significant effect on whole body BMC and BMD. On the other hand, feeding growing female Hans:SPRD-cy rats fed 7\% wt flaxseed oil for 12 weeks enhanced whole body BMD and BMC [18]. Flaxseed oil contains higher ALA (57\%) [23] than soybean oil (7.69\%) or soybean:salmon oil blend (4.85\%) used in the present study (Table 1). Therefore, higher doses of n-3 PUFA may be necessary in order to enhance bone mass in growing female PCK rats.

Metabolic abnormalities accompanying renal diseases differentially affect cortical and trabecular bone that cannot be detected by DXA [36]. Using $\mu \mathrm{CT}$ technology, we found no significant differences in trabecular microarchitecture measurements of BV/TV, trabecular number, thickness, spacing, connectivity or SMI in growing female PCK rats fed different diets (Table 5). In contrast, growing female Sprague-Dawley rats fed oil sources rich in ALA enhanced femur and tibia microarchitecture due to increased bone formation indicated by higher serum osteocalcin concentration and no significant differences in bone resorption markers [17]. In growing female PCK rats, there were no significant differences in serum osteocalcin (Figure 2A) or the bone resorption marker, urinary DPD (Figure 2B). In the Lukas et al. [17] study, higher doses (12\% wt) of pure flaxseed oil or fish oil was provided to Sprague-Dawley rats compared to the $7 \%$ wt dose oil blend provided to PCK rats in this study. High fat diets were not fed to PCK rats due to reports of worsen polycystic kidney disease progression and severity [37- 
38]. However, the detrimental renal effects of feeding high fat diets were shown to be modulated by the dietary lipid source. Feeding fish oil rich in EPA and DHA reduced renal cysts, whereas ALA rich soybean oil and flaxseed oil reduced renal fibrosis in Hans:SPRD-cy rats, a model of ADPKD, and in pcy mice, a model of recessive inheritance of PKD [37-38]. Future studies may consider high fat diets provided as n-3 PUFAs for early management of bone health and to attenuate renal damage, but hypertension and cardiovascular defects are severe complications of PKD that also need to be considered when recommending a high fat diet [39-41].

In kidney disease, chronic elevated parathyroid hormone preferentially causes cortical bone loss [36] [42]. In the present study, there were no significant differences in cortical thickness, area, porosity and medullary area in growing female PCK rats fed the different experimental diets for 12 weeks (Table 6). A previous study with growing Sprague-Dawley rats showed that feeding oils rich in ALA, EPA, and/or DHA had no effect on cortical bone microarchitecture [17]. The main structural determinants of bone mechanical strength include width and porosity in the cortical bone; shape, width, connectivity, and anisotropy in the trabecular bone [43]. As expected in the absence of significant differences in bone mass and trabecular and cortical microarchitecture there were no significant differences in bone strength measurements between growing female PCK rats fed the different experimental diets (Table 7). In studies reporting enhanced bone mass and microarchitecture with n-3 PUFA consumption, the protein source was casein. Fernandes et al. [8] reported that fish oil reduced bone loss in ovariectomized mice particularly in the casein group, but it was unclear whether a synergistic effect of soy protein and fish oil on bone existed. In our study, a casein and soybean oil:salmon oil group was not included to assess for synergistic effects between different types of proteins and n-3 PUFAs. 
In summary, to our knowledge this was the first study to investigate diet as a therapeutic strategy to promote bone health in PCK rats, an animal model of ARPKD. We focused on dietary n-3 PUFA and SPI since current general dietary guidelines to promote a healthier population include increasing consumption of plant proteins and n-3 PUFAs [44]. Growing female $\mathrm{PCK}$ rats fed the $\mathrm{SPI}+\mathrm{SB}$ diet increased $\mathrm{Ca}$ and $\mathrm{P}$ retention, however bone mineralization was not significantly enhanced at 12 weeks feeding. A longer feeding duration and/or the use of pharmalogical doses may be required in order to enhance bone mineralization. All diets equally supported body weight gain and produced no greater or worse long bone mass, microarchitecture, and strength, but may influence other renal disease complications of longitudinal bone growth and mineral metabolism indicated by effects on femur length and increased mineral retention. 


\begin{abstract}
Abbreviations
ADPKD, autosomal recessive polycystic kidney disease; AIN-93G, American Institute of Nutrition-93G; ALA, alpha-linolenic acid; ANOVA, analysis of variance; ARPKD, autosomal recessive polycystic kidney disease; BMA, bone mineral area; BMC, bone mineral content; $\mathrm{BMD}$, bone mineral density; $\mathrm{BV} / \mathrm{TV}$, bone volume per unit of total volume; $\mathrm{Ca}$, calcium; $\mathrm{CO}_{2}$, carbon dioxide; $\mathrm{ddH}_{2} \mathrm{O}$, deionized distilled water; DPD, deoxypyridinoline; DHA, docosahexaeonic acid; DXA, dual energy X-ray absorptiometry; EIA, enzyme immunoassay; EPA, eicosapentaenoic acid; ER $\beta$, estrogen receptor beta; ESRD, end stage renal disease; ICP, inductively coupled plasma spectrometry; LA, linoleic acid; n-3 PUFA, omega-3 polyunsaturated fatty acids; n-6 PUFA, omega- 6 polyunsaturated fatty acids; $\mu$ CT, microcomputed tomography; PBM, peak bone mass; PKD, polycystic kidney disease; P, phosphorus; SB, soybean oil:salmon oil blend; SEM, standard error of the mean; SPI, soy protein isolate; SMI, structure model index; SO, soybean oil; TbN; trabecular number, $\mathrm{TbTH}$, trabecular thickness, TbSP, trabecular separation.
\end{abstract}




\section{Acknowledgements}

We thank Dr. Lewis MacDonald for use of the ICP, Joan Wright for performing the ICP analysis, Dr. Barbara Mickelson for her expertise in formulating and manufacturing the diet, and DuPont Nutrition and Health for generously donating the SPI to our laboratory. Funding for this project was provided by the United Soybean Board Soybean Health Incentive Grant, West Virginia University PSCoR 10008736.6-11-NT10055R, West Virginia University Agriculture and Forestry Experimental Station Hatch Grant WVAA00665, and West Virginia University summer undergraduate education program. 


\subsection{References}

1. Wesseling-Perry K, Salusky IB. Chronic kidney disease: mineral and bone disorder in children. Semin Nephrol 2013;33:169-79.

2. Bacchetta J, Harambat J, Cochat P, Salusky IB, Wesseling-Perry. The consequences of chronic kidney disease on bone metabolism and growth in children. Nephrol Dial Transplant 2012;27:3063-71.

3. Stompor T, Zabłocki M, Łesiów M. Osteoporosis in mineral and bone disorders of chronic kidney disease. Pol Arch Med Wewn 2013;123:314-20.

4. Torres VE, Harris PC. Mechanisms of disease: autosomal dominant and recessive polycystic kidney diseases. Nature Clin Practice Nephrol 2006;2:40-55.

5. Benun J, Lewis C. Polycystic kidney disease. Pediatrics in Review 2009;30:e78-9

6. Dell KMR, Avner ED. Polycystic Kidney Disease: Autosomal Recessive. In: Pagon RA, Adam MP, Bird TD, Dolan CR, Fong CT, Stephens K, editors. GeneReviews ${ }^{\mathrm{TM}}$ [Internet]. Seattle (WA): University of Washington, Seattle 2012;1993-2013.

7. Maditz K, Gigliotti JC, Tou JC. Evidence for a Role of Proteins, Lipids, and Phytochemicals in the Prevention of Polycystic Kidney Disease Progression and Severity. Nutrition Reviews (in press).

8. Fernandes G, Lawrence R, Sun D. Protective role of n-3 lipids and soy protein in osteoporosis. Prostaglandins Leukot Essent Fatty Acids 2003;68:361-72.

9. Salari P, Rexale A, Larijani B, Abdollahl M. A systematic review of the impact of n-3 fatty acids in bone health and osteoporosis. Med Sci Monit 2008;14:RA37-44.

10. Watkins BA, Li Y, Lippman HE, Feng S. Modulatory effect of omega-3 polyunsaturated fatty acids on osteoblast function and bone metabolism. Prostaglandins Leukot Essential Fatty Acids 2003;68:387-98.

11. Lentine K, Wrone, EM. New insights into protein intake and progression of renal disease. Curr Opin Nephrol Hypertens 2004;13:333-36.

12. Aukema HM, Gauthier J, Roy M, Jia Y, Li H, Aluko RE. Distinctive effects of plant protein sources on renal disease progression and associated cardiac hypertrophy in experimental kidney disease. Mol Nutr Food Res 2011;55:1044-51.

13. Fair DE, Ogborn MR, Weiler HA, Bankovic-Calic N, Nitschmann EP, Fitzpatrick-Wong SC, Aukema HM. Dietary soy protein attenuates renal disease progression after 1 and 3 weeks in Han:SPRD-cy weanling rats. J Nutr 2004;134:1504-07. 
14. Nagao S, Kugita M, Yoshihara D, Yamaguchi T. Animal models for human polycystic kidney disease. Exp Anim 2012;61:477-88.

15. Chen JR, Singhal R, Lazarenko OP, Liu X, Hogue WR, Badger TM, Ronis MJ. Short term effects on bone quality associated with consumption of soy protein isolate and other dietary protein sources in rapidly growing female rats. Exp Biol Med (Maywood) 2008;233:134858.

16. Blazer-Yost BL, Haydon J, Eggleston-Gulyas T, Chen JH, Wang X, Gattone V, Torres VE. Pioglitazone attenuates cystic burden in the PCK rodent model of polycystic kidney disease. PPAR Res 2010;2010:1-8.

17. Lukas R, Gigliotti JC, Smith BJ, Altman S, Tou JC. Consumption of different sources of omega-3 polyunsaturated fatty acids by growing female rats affects long bone mass and microarchitecture. Bone 2011;49:455-62.

18. Weiler HA, Kovacs H, Nitschmann E, Bankovic-Calic N, Aukema H, Ogborn M. Feeding flaxseed oil but not secoisolariciresinol diglucoside results in higher bone mass in healthy rats and rats with kidney disease. Prostaglandins Leukot Essent Fatty Acids 2007;76:269-75.

19. Shah P, Mudaliar S. Pioglitazone: side effect and safety profile. Expert Opin Drug Saf 2010;9:347-54.

20. NRC, National Research Council. Guide for the Care and Use of Laboratory Animals. Washington, DC: National Academy Press 1996.

21. NRC, National Research Council. Nutrient requirements of laboratory animals. Washington, DC: National Academy Press 4th rev. 1995.

22. Cordain L, Eaton SB, Sebastian A, Mann N, Lindeberg S, Watkins BA, O'Keefe JH, BrandMiller J. Origins and evolution of the Western diet: health implications for the $21^{\text {st }}$ century. Am. J. Clin. Nutr 2005;81:341-54.

23. Tou JC, Altman SN, Gigliotti JC, Benedito VA, Cordonier EL. Different sources of omega-3 polyunsaturated fatty acids affects apparent digestibility, tissue deposition, and tissue oxidative stability in growing female rats. Lipids Health Dis 2011;10:179-85.

24. Anastasia JV, Braun BL, Smith KT. General and histopathological results of a two-year study of rats fed semi-purified diets containing casein and soya protein. Food Chem Toxicol 1990;28:147-56.

25. Sirois I, Cheung AM, Ward WE. Biomechanical bone strength and bone mass in young male and female rats fed a fish oil diet. Prostaglandins Leukot Essent Fatty Acids 2003;68:415-21.

26. Norman LJ, Coleman JE, Macdonald IA, Tomsett AM, Watson, AR. Nutrition and growth in relation to severity of renal disease in children. Pediatr Nephrol 2000;15:259-265. 
27. Cunnane, SC. Nutritional attributes of traditional flaxseed in healthy young adults. Am J Clin Nutr 1995;61:62-8.

28. Chagin AS, Limber MK, Andersson N, Moverare S, Gustaftson JA, Savendahl L, Ohlsson C. Estrogen receptor- $\beta$ inhibits skeletal growth and has the capacity to mediate growth plate fusion in female mice. J Bone Min Res 2004;19:72-7.

29. Kuiper GG, Lemmen JG, Carlsson B, Corton JC, Safe SH, Van der Saag PT, van der Burg, Gustafsson JA. Interaction of estrogenic chemicals and phytoestrogens with estrogen receptor beta. Endocrinology 1998;39:4252-63.

30. Tou JC, Arnaud SB, Grindeland R, Wade C. The effect of purified compared with nonpurified diet on bone changes induced by hindlimb suspension of female rats. Exp Biol Med (Maywood) 2005;230:31-8.

31. Watkins BA, Li Y, Allen KG, Hoffmann WE, Seifert MF. Dietary ratio of (n-6)/(n-3) polyunsaturated fatty acids alters the fatty acid composition of bone compartments and biomarkers of bone formation in rats. J Nutr 2000;130:2274-84.

32. Watkins BA, Li Y, Lippman HE, Seifert MF. Omega-3 polyunsaturated fatty acids and skeletal health. Exp Biol Med (Maywood) 2001;226:485-97.

33. Messina M, Messina V. Soyfoods, soybean isoflavones, and bone health: a brief overview. J Ren Nutr 2002;10:63-8.

34. Haag M, Kruger MC. Upregulation of duodenal calcium absorption by polyunsaturated fatty acids: events at the basolateral membrane. Med Hypotheses 2001;56:637-40.

35. Weiler H, Kovacs H, Nitschmann E, Wong SF, Bankovic-Calic N, Ogborn M. Elevated bone turnover in rat polycystic kidney disease is not due to prostaglandin $\mathrm{E}_{2}$. Pediatr Nephrol 2002;17:795-99.

36. Nickolas TL, Leonard MB, Shane E. Chronic kidney disease and bone fracture: a growing concern. Kidney Int 2008;74:721-31.

37. Sankaran D, Lu J, Bankovic-Calic N, Ogborn MR, Aukema HM. Modulation of renal injury in pcy mice by dietary fat containing $\mathrm{n}-3$ fatty acids depends on the level and type of fat. Lipids 2004;39:207-14.

38. Lu J, Bankovic-Calic N, Ogborn M, Saboorian MH, Aukema HM. Detrimental effects of a high fat diet in early renal injury are ameliorated by fish oil in Han:SPRD-cy rats. J Nutr 2003;133:180-86.

39. Ecder T. Cardiovascular complications in autosomal dominant polycystic kidney disease. Curr Hypertens Rev 2003;9:2-11. 
40. Cadnapaphornchai MA. Hypertension in Children with Autosomal Dominant Polycystic Kidney Disease (ADPKD). Curr Hypertens Rev 2013;9:21-6.

41. Goto M, Hoxha N, Osman R, Dell KM. The renin-angiotensin system and hypertension in autosomal recessive polycystic kidney disease. Pediatr Nephrol 2010;25:2449-57.

42. Carney EF. Bone: Cortical bone loss in patients with chronic kidney disease. Nat Rev Nephrol 2013; 9:248-56.

43. Carbonare D, Giannini S. Bone microarchitecture as an important determinant of bone strength. J Endocrinol Invest 2004;27:99-105.

44. Guenther PM, Casavale KO, Reedy J, Kirkpatrick SI, Hiza HA, Kuczynski KJ, Kahle LL, Krebs-Smith SM. Update of the healthy eating index: HEI-2010. J Acad Nutr Diet 2013;113:569-80.

45. Reeves PG, Nielsen FH, Fahey GC Jr. AIN-93 purified diets for laboratory rodents: final report of the American Institute of Nutrition ad hoc writing committee on the reformulation of the AIN-76A rodent diet. J Nutr 1993;123:1939-51. 
Figure 1. The effect of feeding growing PCK female rats soy protein isolate and/or omega-3 polyunsaturated fatty acids on body weight during the 12 week feeding study. Values are the mean \pm SEM of $n=12$ rats/diet group. Abbreviations are casein + corn oil $($ Casein $+C O)$, casein + soybean oil $($ Casein $+\mathrm{SO})$, soy protein isolate + soybean oil $(\mathrm{SPI}+\mathrm{SO})$ or soy protein isolate $+1: 1$ soybean/salmon oil $(\mathrm{SPI}+\mathrm{SB})$.

Figure 2. The effect of feeding growing PCK female rats on soy protein isolate and/or omega-3 polyunsaturated fatty acids on body weight for 12 weeks on A) serum osteocalcin concentrations and B) urinary deoxypyridinoline. Bars represent the mean \pm SEM of $n=10$ rats/diet group. Abbreviations are casein + corn oil $($ Casein $+\mathrm{CO})$, casein + soybean oil $($ Casein $+\mathrm{SO})$, soy protein isolate + soybean oil $(\mathrm{SPI}+\mathrm{SO})$ or soy protein isolate $+1: 1$ soybean/salmon oil $(\mathrm{SPI}+\mathrm{SB})$. 
Table 1. Experimental Diet Composition.

\begin{tabular}{|c|c|c|c|c|}
\hline 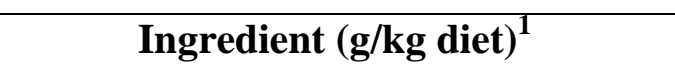 & Casein + CO & Casein + SO & SPI + SO & SPI + SB \\
\hline Casein & 200.0 & 200.0 & 0.0 & 0.0 \\
\hline Soy protein isolate & 0.0 & 0.0 & 200.0 & 200.0 \\
\hline L-Cystine & 3.0 & 3.0 & 1.3 & 1.3 \\
\hline Corn Starch & 397.5 & 397.5 & 397.5 & 397.5 \\
\hline Maltodextrin & 132.0 & 132.0 & 132.0 & 132.0 \\
\hline Sucrose & 100.0 & 100.0 & 100.0 & 100.0 \\
\hline Soybean Oil & 70.0 & 0.0 & 70.0 & 35.0 \\
\hline Corn Oil & 0.0 & 70.0 & 0.0 & 0.0 \\
\hline Salmon Oil & 0.0 & 0.0 & 0.0 & 35.0 \\
\hline Cellulose & 50.0 & 50.0 & 50.0 & 50.0 \\
\hline Mineral Mix ${ }^{2}$ & 35.0 & 35.0 & 35.0 & 35.0 \\
\hline Vitamin $\mathrm{Mix}^{2}$ & 10.0 & 10.0 & 10.0 & 10.0 \\
\hline Choline bitartrate & 2.5 & 2.5 & 2.5 & 2.5 \\
\hline TBHQ, antioxidant & 0.014 & 0.014 & 0.014 & 0.014 \\
\hline Calories & 377 & 377 & 377 & 377 \\
\hline \multicolumn{5}{|l|}{ Fatty acids (\%) } \\
\hline Alpha-linolenic acid (ALA, 18:3n-3) & $0.59 \pm 0.18 \mathrm{c}$ & $7.69 \pm 0.02 \mathrm{a}$ & $7.68 \pm 0.04 \mathrm{a}$ & $4.85 \pm 0.01 \mathrm{~b}$ \\
\hline Eicosapentaenoic acid (EPA, 20:5n-3) & ND & ND & ND & $7.4 \pm 0.03$ \\
\hline $\begin{array}{l}\text { Docosahexaenoic acid (DHA, 22:6n-3) } \\
n-6 \text { PUFAs }\end{array}$ & ND & ND & ND & $3.9 \pm 0.1$ \\
\hline Linoleic acid (LA, 18:2n-6) & $52.93 \pm 2.68 \mathrm{a}$ & $55.78 \pm 0.07 \mathrm{a}$ & $56.09 \pm 0.09 a$ & $35.19 \pm 0.06 \mathrm{~b}$ \\
\hline Arachidonic acid (ARA, 20:4n-6) & $1.10 \pm 0.04 \mathrm{a}$ & $0.16 \pm 0.005 c$ & $0.21 \pm 0.01 \mathrm{c}$ & $0.41 \pm 0.007 \mathrm{~b}$ \\
\hline$n-3 / n-6$ & 0.01 & $\overline{0.14}$ & 0.14 & $\overline{0.44}$ \\
\hline
\end{tabular}

${ }^{1}$ All ingredients are from Harlan Teklad except for SPI from DuPont Nutrition and Health (St. Louis, MO) and salmon oil from JEdwards International (Quincy, MA).

${ }^{2}$ Based on the AIN-93G vitamin and mineral mixes [45]. Different superscript letters a, b, c within the same rows indicate significant differences at $P<0.05$ by one-way ANOVA followed by Tukey's test. Abbreviations are CO, corn oil; SO, soybean oil; SPI, soy protein isolate; SB, soybean oil:salmon oil blend; TBHQ, tertiary butylhydroquinone; ND, not detectable. 
Table 2. Bone Morphometry in Growing Female PCK Rats Fed Different Diets.

\begin{tabular}{lccccc}
\hline Measurement* & Casein + CO & Casein + SO & SPI + SO & SPI + SB & P-value \\
& & & & & \\
Femur & & & & & \\
Length (cm) & $31.01 \pm 0.13 \mathrm{~b}$ & $31.23 \pm 0.15 \mathrm{~b}$ & $30.17 \pm 0.28 \mathrm{ab}$ & $30.74 \pm 0.14 \mathrm{a}$ & 0.001 \\
Medial Lateral width (mm) & $3.77 \pm 0.02$ & $3.75 \pm 0.03$ & $3.78 \pm 0.02$ & $3.79 \pm 0.03$ & 0.78 \\
Anterior posterior width (mm) & $2.78 \pm 0.03$ & $2.77 \pm 0.03$ & $2.75 \pm 0.03$ & $2.84 \pm 0.03$ & 0.22 \\
Dry weight (g) & $0.69 \pm 0.04$ & $0.70 \pm 0.04$ & $0.68 \pm 0.46$ & $0.68 \pm 0.04$ & 0.98 \\
Tibia & & & & & \\
Length (cm) & $36.24 \pm 0.15$ & $36.45 \pm 0.07$ & $36.20 \pm 0.07$ & $36.17 \pm 0.11$ & 0.25 \\
Medial Lateral width (mm) & $2.24 \pm 0.02$ & $2.29 \pm 0.02$ & $2.24 \pm 0.02$ & $2.29 \pm 0.02$ & 0.18 \\
Anterior posterior width (mm) & $2.68 \pm 0.02$ & $2.67 \pm 0.02$ & $2.67 \pm 0.02$ & $2.66 \pm 0.02$ & 0.88 \\
Dry weight (g) & $0.47 \pm 0.02$ & $0.48 \pm 0.02$ & $0.46 \pm 0.02$ & $0.47 \pm 0.02$ & 0.95 \\
\hline
\end{tabular}

*Values are the means \pm SEM of $n=12$ rats/group. Different superscript letters $a, b$ within the same rows indicate significant differences at $P<0.05$ by one-way ANOVA followed by Tukey's test. Abbreviations are CO, corn oil; SO,

soybean oil; SPI, soy protein isolate; SB, soybean oil:salmon oil blend. 
Table 3. Calcium and Phosphorus Balance in Growing Female PCK Rats Fed Different Diets.

\begin{tabular}{|c|c|c|c|c|c|}
\hline Measurement* & Casein + CO & Casein + SO & SPI + SO & SPI + SB & $P$-value \\
\hline \multicolumn{6}{|l|}{ Calcium } \\
\hline Ca Intake $(\mathrm{g} / \mathrm{d})$ & $131.8 \pm 2.4 b$ & $123.4 \pm 2.2 b$ & $145.3 \pm 2.1 \mathrm{a}$ & $150.0 \pm 2.4 a$ & $<0.001$ \\
\hline Fecal Ca Excretion (mg/d) & $29.9 \pm 2.3$ & $25.8 \pm 2.9$ & $34.0 \pm 3.0$ & $29.0 \pm 2.7$ & 0.23 \\
\hline $\begin{array}{l}\text { Urinary Ca Excretion/Creatinine } \\
(\mathrm{mg} / \mathrm{dl})\end{array}$ & $2.5 \pm 0.5$ & $2.6 \pm 0.9$ & $1.1 \pm 0.1$ & $2.2 \pm 0.5$ & 0.18 \\
\hline Ca Apparent Absorption $(\%)^{1}$ & $77.2 \pm 1.7$ & $79.0 \pm 2.4$ & $76.5 \pm 2.1$ & $80.6 \pm 1.8$ & 0.46 \\
\hline Ca Retention $(\mathrm{mg} / \mathrm{d})^{2}$ & $1.6 \pm 0.3 b$ & $2.2 \pm 0.3 b$ & $4.5 \pm 0.7 \mathrm{a}$ & $4.6 \pm 1.0 \mathrm{a}$ & 0.004 \\
\hline \multicolumn{6}{|l|}{ Phosphorus } \\
\hline P Intake $(g)$ & $92.0 \pm 1.0 \mathrm{~b}$ & $96.5 \pm 2.1 b$ & $109.9 \pm 2.0 \mathrm{a}$ & $108.7 \pm 2.3 \mathrm{a}$ & $<0.001$ \\
\hline Fecal P Excretion $(\mathrm{mg} / \mathrm{d})^{3}$ & $26.1 \pm 2.6$ & $22.3 \pm 3.1$ & $34.0 \pm 3.0$ & $26.3 \pm 2.7$ & 0.05 \\
\hline $\begin{array}{l}\text { Urinary P Excretion/Creatinine } \\
(\mathrm{mg} / \mathrm{dl})^{4}\end{array}$ & $10.6 \pm 1.0 \mathrm{a}$ & $10.8 \pm 2.1 \mathrm{a}$ & $7.3 \pm 1.0 \mathrm{ab}$ & $3.5 \pm 0.9 b$ & $<0.001$ \\
\hline P Apparent Absorption (\%) & $71.6 \pm 2.9$ & $77.0 \pm 3.2$ & $69.0 \pm 2.8$ & $75.7 \pm 2.5$ & 0.18 \\
\hline P Retention $(\mathrm{mg} / \mathrm{d})$ & $0.09 \pm 0.008 b$ & $0.12 \pm 0.007 b$ & $0.14 \pm 0.01 \mathrm{ab}$ & $0.15 \pm 0.02 \mathrm{a}$ & 0.01 \\
\hline
\end{tabular}

*Values are expressed as the mean \pm SEM of $n=10$ rats/group. Different letters $a, b$ within the same column indicate significant differences at $P<0.05$ by one-way ANOVA followed by Tukey's test. Abbreviations are SO, soybean oil; SPI, soy protein isolate; $\mathrm{SB}$, soybean oil:salmon oil blend; $\mathrm{Ca}$, calcium, $\mathrm{P}$, phosphorus.

${ }^{1}$ Calcium apparent absorption was calculated as [(Ca intake - fecal Ca excretion)/Ca intake] x 100 .

${ }^{2}$ Calcium retention was determined by calculating [Ca intake - (fecal Ca excretion + urinary Ca excretion)].

${ }^{3}$ Phosphorus apparent absorption was calculated as [(P intake - fecal $\mathrm{P}$ excretion $) / \mathrm{P}$ intake] x 100 .

${ }^{4}$ Phosphours retention was determined by calculating [P intake - (fecal P excretion + urinary P excretion)]. 
Table 4. Bone Mineralization in Growing Female PCK Rats Fed Different Diets.

\begin{tabular}{|c|c|c|c|c|c|}
\hline Measurement* & Casein + CO & Casein + SO & SPI + SO & SPI + SB & $P$-value \\
\hline \multicolumn{6}{|l|}{ Femur } \\
\hline $\mathrm{Ca}$ (mg/mg bone) & $9.07 \pm 0.17$ & $9.30 \pm 0.10$ & $9.43 \pm 0.07$ & $9.40 \pm 0.150$ & 0.23 \\
\hline $\mathrm{P}$ (mg/mg bone) & $4.90 \pm 0.09$ & $5.01 \pm 0.05$ & $5.05 \pm 0.04$ & $5.05 \pm 0.07$ & 0.39 \\
\hline Ash (mg/mg bone) & $0.061 \pm 0.001$ & $0.058 \pm 0.001$ & $0.060 \pm 0.001$ & $0.061 \pm 0.001$ & 0.66 \\
\hline BMA $\left(\mathrm{cm}^{2}\right)$ & $1.30 \pm 0.01$ & $1.29 \pm 0.02$ & $1.28 \pm 0.01$ & $1.30 \pm 0.01$ & 0.27 \\
\hline $\mathrm{BMC}(\mathrm{g})$ & $0.23 \pm 0.0001$ & $0.23 \pm 0.0002$ & $0.22 \pm 0.0001$ & $0.23 \pm 0.0001$ & 0.67 \\
\hline $\operatorname{BMD}\left(\mathrm{mg} / \mathrm{cm}^{2}\right)$ & $0.18 \pm 0.0001$ & $0.18 \pm 0.0002$ & $0.17 \pm 0.0001$ & $0.18 \pm 0.0002$ & 0.35 \\
\hline \multicolumn{6}{|l|}{ Tibia } \\
\hline $\mathrm{Ca}$ (mg/mg bone) & $9.30 \pm 0.11$ & $9.07 \pm 1.20$ & $9.68 \pm 0.25$ & $9.55 \pm 0.19$ & 0.14 \\
\hline P (mg/mg bone) & $4.83 \pm 0.06$ & $4.68 \pm 0.09$ & $4.99 \pm 0.13$ & $4.95 \pm 0.10$ & 0.12 \\
\hline Ash (mg/mg bone) & $0.060 \pm 0.001$ & $0.059 \pm 0.001$ & $0.059 \pm 0.002$ & $0.061 \pm 0.0012$ & 0.59 \\
\hline $\mathrm{BMA}\left(\mathrm{cm}^{2}\right)$ & $1.54 \pm 0.04$ & $1.50 \pm 0.06$ & $1.56 \pm 0.06$ & $1.49 \pm 0.04$ & 0.56 \\
\hline $\mathrm{BMC}(\mathrm{g})$ & $0.33 \pm 0.01$ & $0.32 \pm 0.01$ & $0.33 \pm 0.01$ & $0.31 \pm 0.02$ & 0.48 \\
\hline $\mathrm{BMD}\left(\mathrm{mg} / \mathrm{cm}^{2}\right)$ & $0.21 \pm 0.002$ & $0.21 \pm 0.003$ & $0.21 \pm 0.001$ & $0.21 \pm 0.002$ & 0.68 \\
\hline
\end{tabular}

*Values are the means \pm SEM of $n=12$ rats/group. Abbreviations are CO, corn oil; SO, soybean oil; SPI, soy protein isolate; SB, soybean oil:salmon oil blend; BMA, bone mineral area; BMC, bone mineral content; BMD, bone mineral density; Ca, calcium; P, phosphorus. 
Table 5. Trabecular Bone Microarchitecture in Growing Female PCK Rats Fed Different Diets.

\begin{tabular}{llllll}
\hline Measurement & Casein + CO & Casein + SO & SPI + SO & SPI + SB & P-value \\
\hline Femur & & & & & \\
BV/TV $(\%)$ & $14.30 \pm 0.54$ & $14.00 \pm 0.58$ & $12.95 \pm 0.96$ & $13.64 \pm 0.86$ & 0.61 \\
TbN $($ per mm) & $2.87 \pm 0.11$ & $2.74 \pm 0.11$ & $2.77 \pm 0.20$ & $2.86 \pm 0.10$ & 0.87 \\
TbTh $(\mathrm{mm})$ & $0.07 \pm 0.0009$ & $0.07 \pm 0.001$ & $0.06 \pm 0.001$ & $0.07 \pm 0.002$ & 0.18 \\
TbSp $(\mathrm{mm})$ & $0.36 \pm 0.01$ & $0.38 \pm 0.01$ & $0.40 \pm 0.04$ & $0.36 \pm 0.01$ & 0.65 \\
Conn $\left(1 / \mathrm{mm}^{3}\right)$ & $80.77 \pm 2.99$ & $76.47 \pm 2.83$ & $77.06 \pm 5.26$ & $77.83 \pm 3.59$ & 0.86 \\
SMI & $2.28 \pm 0.03$ & $2.30 \pm 0.05$ & $2.12 \pm 0.06$ & $2.36 \pm 0.07$ & 0.31 \\
Tibia & & & & & \\
BV/TV $(\%)$ & $9.43 \pm 0.62$ & $9.67 \pm 0.63$ & $9.13 \pm 0.84$ & $9.24 \pm 0.83$ & 0.96 \\
TbN $($ per mm) & $2.51 \pm 0.13$ & $2.44 \pm 0.17$ & $2.39 \pm 0.19$ & $2.61 \pm 0.16$ & 0.82 \\
TbTh $(\mathrm{mm})$ & $0.06 \pm 0.001$ & $0.06 \pm 0.0009$ & $0.06 \pm 0.001$ & $0.06 \pm 0.001$ & 0.33 \\
TbSp $(\mathrm{mm})$ & $0.42 \pm 0.02$ & $0.44 \pm 0.30$ & $0.46 \pm 0.05$ & $0.41 \pm 0.03$ & 0.63 \\
Conn $\left(1 / \mathrm{mm}^{3}\right)$ & $43.00 \pm 4.56$ & $43.58 \pm 4.59$ & $43.53 \pm 6.11$ & $43.26 \pm 6.34$ & 1.00 \\
SMI & $2.85 \pm 0.05$ & $2.80 \pm 0.04$ & $2.88 \pm 0.07$ & $2.88 \pm 0.07$ & 0.72 \\
\hline
\end{tabular}

*Values are expressed as the mean \pm SEM of $n=12$ bones/group. Abbreviations are CO, corn oil; SO, soybean oil; SPI, soy protein isolate; SB, soybean oil:salmon oil blend, BV/TV, trabecular bone volume per unit of total volume; TbN, trabecular number; TbTh, trabecular thickness; TbSp, trabecular space; Conn, connectivity; SMI, structure model index. 
Table 6. Cortical Bone Microarchitecture in Growing Female PCK Rats Provided Different Diets.

\begin{tabular}{llllll}
\hline Measurement & Casein + CO & Casein + SO & SPI + SO & SPI + SB & P value \\
\hline Femur & & & & & \\
Medullary Area $\left(\mathrm{mm}^{2}\right)$ & $0.26 \pm 0.006$ & $0.25 \pm 0.007$ & $0.25 \pm 0.006$ & $0.26 \pm 0.007$ & 0.94 \\
Cortical Thickness (mm) & $0.55 \pm 0.008$ & $0.55 \pm 0.004$ & $0.56 \pm 0.004$ & $0.55 \pm 0.004$ & 0.47 \\
Cortical Area $\left(\mathrm{mm}^{2}\right)$ & $4.49 \pm 0.03$ & $4.40 \pm 0.05$ & $4.56 \pm 0.03$ & $4.52 \pm 0.05$ & 0.06 \\
Porosity $(\%)$ & $5.42 \pm 0.12$ & $5.45 \pm 0.15$ & $5.28 \pm 0.14$ & $5.39 \pm 0.12$ & 0.78 \\
Tibia & & & & \\
Medullary Area $\left(\mathrm{mm}^{2}\right)$ & $0.20 \pm 0.004$ & $0.19 \pm 0.003$ & $0.18 \pm 0.004$ & $0.19 \pm 0.005$ & 0.46 \\
Cortical Thickness (mm) & $0.52 \pm 0.004$ & $0.53 \pm 0.003$ & $0.53 \pm 0.01$ & $0.53 \pm 0.006$ & 0.59 \\
Cortical Area $\left(\mathrm{mm}^{2}\right)$ & $2.90 \pm 0.03$ & $2.94 \pm 0.03$ & $2.88 \pm 0.05$ & $2.98 \pm 0.04$ & 0.29 \\
Porosity $(\%)$ & $6.32 \pm 0.02$ & $6.06 \pm 0.09$ & $6.11 \pm 0.13$ & $6.04 \pm 0.16$ & 0.37 \\
\hline
\end{tabular}

*Values are expressed as the mean \pm SEM of $n=12$ bones/group. Abbreviations are are CO, corn oil; SO, soybean oil; SPI, soy protein isolate; $\mathrm{SB}$, soybean oil:salmon oil. 
Table 7. Bone Strength Measurements in Growing Female PCK Rats Fed Different Diets.

\begin{tabular}{|c|c|c|c|c|c|}
\hline Measurement & Casein + CO & Casein + SO & SPI + SO & $\mathrm{SPI}+\mathrm{SB}$ & $P$-value \\
\hline \multicolumn{6}{|l|}{ Femur } \\
\hline Peak Force $(\mathrm{N})$ & $42.48 \pm 2.67$ & $37.19 \pm 2.62$ & $40.41 \pm 2.57$ & $44.47 \pm 3.05$ & 0.26 \\
\hline Ultimate Stiffness (N/S) & $4.29 \pm 0.36$ & $4.29 \pm 0.23$ & $3.78 \pm 0.33$ & $4.21 \pm 0.29$ & 0.63 \\
\hline $\begin{array}{l}\text { Ultimate Bending Stress } \\
\left(\mathrm{N} / \mathrm{mm}^{2}\right)\end{array}$ & $47.29 \pm 2.35$ & $41.77 \pm 3.16$ & $45.74 \pm 3.03$ & $48.60 \pm 3.51$ & 0.4 \\
\hline $\begin{array}{l}\text { Young's Modulus } \\
\left(\mathrm{N} / \mathrm{mm}^{2}\right)\end{array}$ & $11.49 \pm 1.04$ & $11.39 \pm 0.53$ & $10.20 \pm 0.98$ & $10.97 \pm 0.97$ & 0.75 \\
\hline \multicolumn{6}{|l|}{ Tibia } \\
\hline Peak Force $(\mathrm{N})$ & $22.30 \pm 1.72$ & $19.23 \pm 1.29$ & $19.98 \pm 1.72$ & $20.73 \pm 1.34$ & 0.57 \\
\hline Ultimate Stiffness (N/S) & $1.68 \pm 0.13$ & $1.75 \pm 0.13$ & $1.58 \pm 0.11$ & $1.56 \pm 0.08$ & 0.61 \\
\hline $\begin{array}{l}\text { Ultimate Bending Stress } \\
\left(\mathrm{N} / \mathrm{mm}^{2}\right)\end{array}$ & $61.71 \pm 4.01$ & $51.52 \pm 3.42$ & $56.37 \pm 5.58$ & $57.41 \pm 5.26$ & 0.5 \\
\hline $\begin{array}{l}\text { Young's Modulus } \\
\left(\mathrm{N} / \mathrm{mm}^{2}\right)\end{array}$ & $19.33 \pm 1.70$ & $19.02 \pm 1.64$ & $17.81 \pm 1.23$ & $17.32 \pm 4.90$ & 0.76 \\
\hline
\end{tabular}


Figure 1.

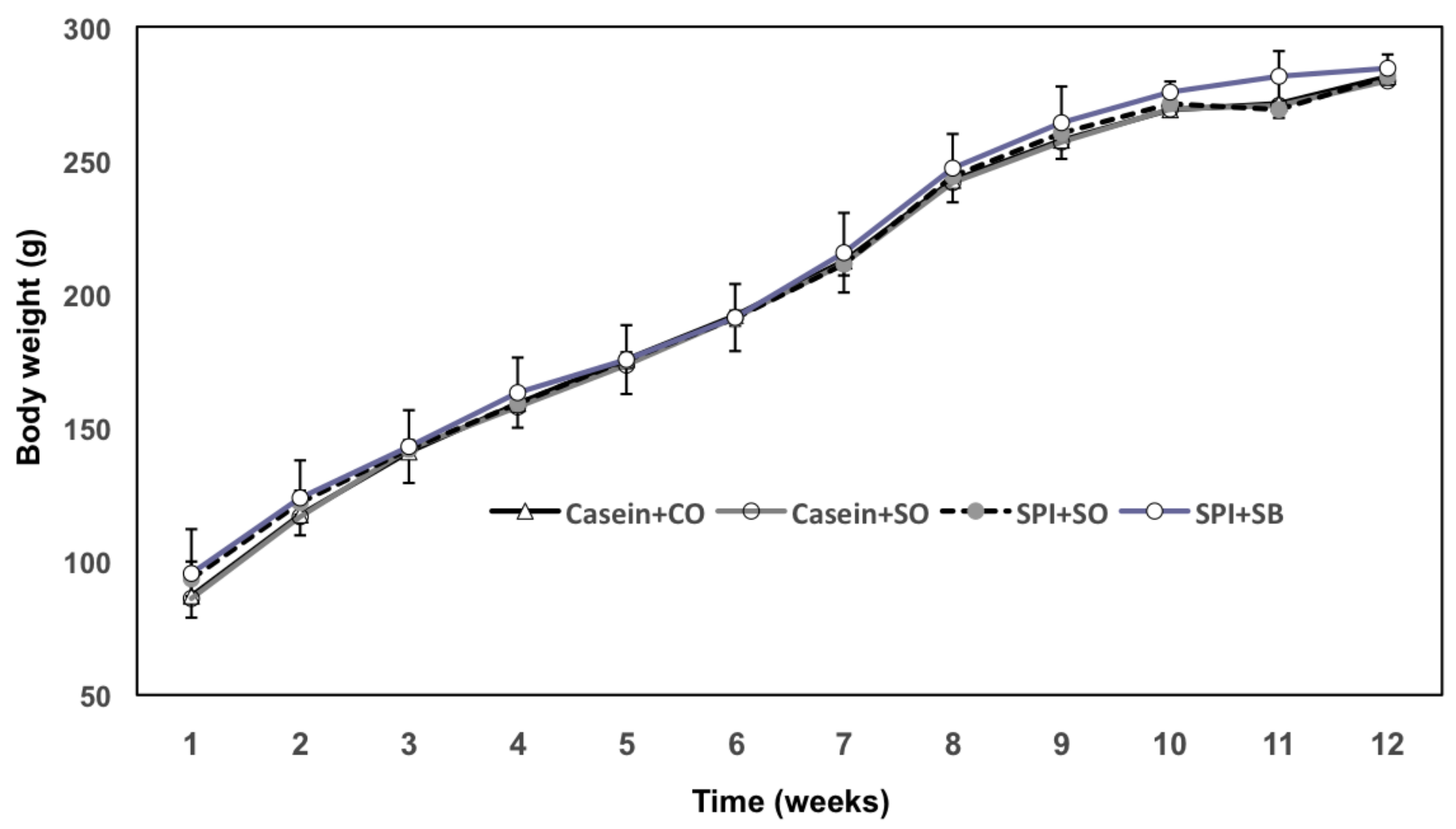


Figure 2.

A)

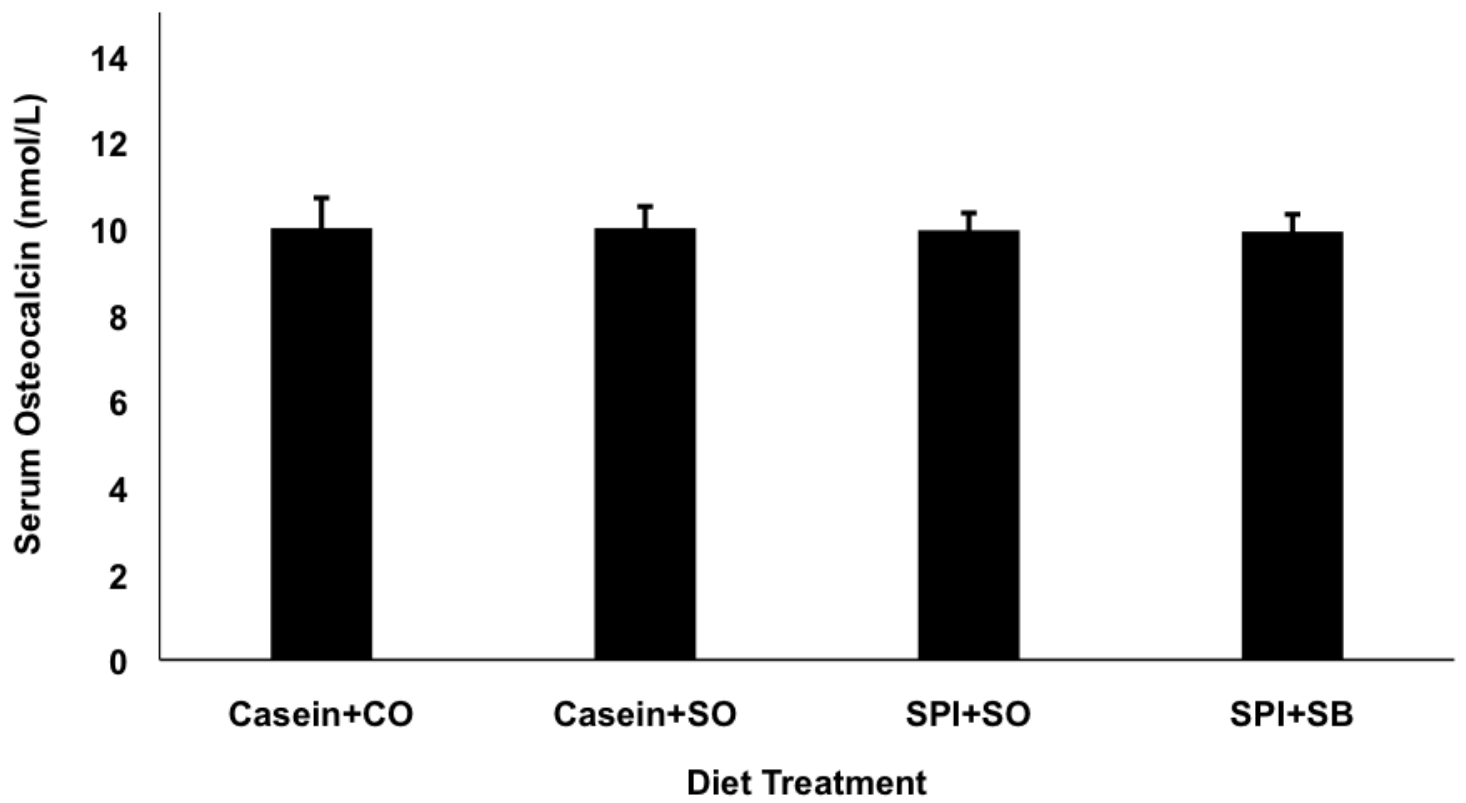

B)

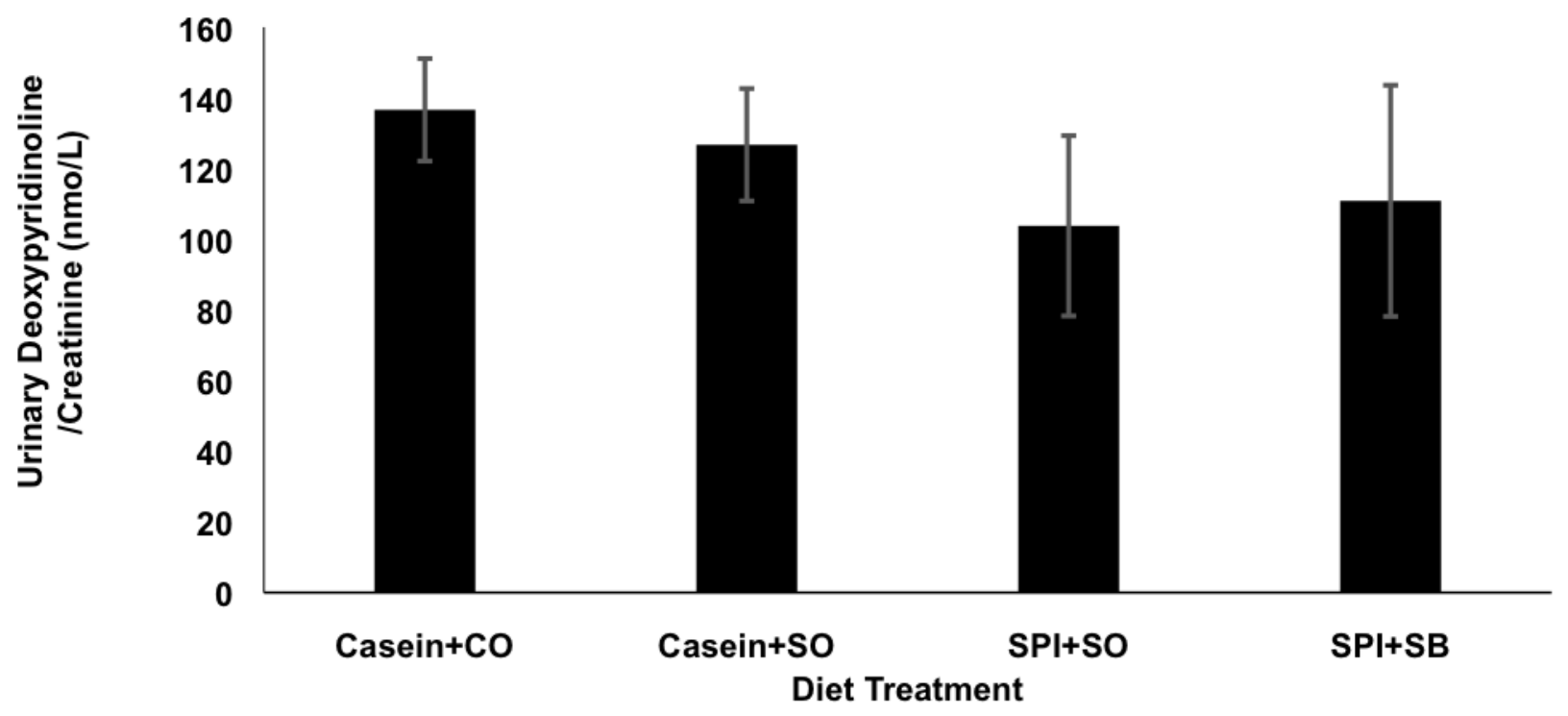




\section{Chapter 3:}

The Effect of Omega-3 Polyunsaturated Fatty Acid and/or Soy Protein Isolate Supplementation on Attenuating the Progression of Polycystic Liver Disease as a Complication of Polycystic Kidney Disease in Female pck Rats

Kaitlin H. Maditz ${ }^{1}$, Chris Oldaker ${ }^{1}$, Nainika Nanda ${ }^{1}$, Vagner A. Benedito ${ }^{3}$, Ryan Livengood ${ }^{2}$, Janet C. Tou ${ }^{* 1}$

${ }^{1}$ Division of Animal and Nutritional Sciences, ${ }^{2}$ Division of Plant and Soil Sciences, ${ }^{3}$ School of Medicine, West Virginia University, Morgantown, WV 26506,

Short Title: diet and polycystic liver disease

*Corresponding Author:

Janet C. Tou, PhD

Tel: (304) 293-1919

Fax: (304) 293-2232

e-mail: janet.tou@mail.wvu.edu

Journal to be Determined 


\author{
Abbreviations \\ ActB; beta actin \\ ADPKD; autosomal dominant polycystic kidney disease \\ ARPKD; autosomal recessive polycystic kidney disease \\ BUN; blood urea nitrogen \\ $\mathrm{CO}$; corn oil \\ COX-2; cyclooxygenase \\ ESRD; end stage renal disease \\ MapK; mitogen-activated protein kinase \\ mTOR; mammalian target of rapamycin \\ n-3 PUFA; omega-3 polyunsaturated fatty acid \\ PLD; polycystic liver disease \\ PPAR; peroxisome proliferator-activated receptor gamma \\ SB; soybean oil/salmon oil blend \\ SEM; standard error of the mean \\ SO; soybean oil \\ SPI; soy protein isolate
}




\subsection{Abstract}

Polycystic Liver Disease (PLD) is characterized by multiple cyst formation leading to increased liver size, structural damage, and loss of function. Feeding soy protein isolate has been shown to decrease cystic growth and proliferation, dietary omega-3 polyunsaturated fatty acids (n-3 PUFAs) have been reported to have anti-inflammatory actions. Therefore, the objective of this study was to investigate whether soy protein isolate (SPI) and/or n-3 PUFA supplementation attenuates PLD progression. Young (age $28 \mathrm{~d}$ ) female pck rats were fed diets (n=12/group) consisting of casein + corn oil $($ Casein $+\mathrm{CO})$, casein + soybean oil $($ Casein + SO), SPI + soybean oil $(\mathrm{SPI}+\mathrm{SO})$, or SPI + 1:1 soybean/salmon oil blend $(\mathrm{SPI}+\mathrm{SB})$. Liver weights were not significantly different among the diet treatment groups. Histological evaluation of the liver showed that rats fed SPI+SB diet had the highest $(P=0.03)$ cyst obstruction. Rats fed SPI+SB diet also had the highest $(P<0.001)$ interstitial portal inflammation. Gene expression by real time quantitative polymerase chain reaction (RT-qPCR) showed no significant differences in inflammation factors. Female pck rats fed SPI and/or n-3 PUFAs showed no significant differences in histological evidence of fibrosis or gene expression of liver fibrosis. However, rats fed SPI + SB diet had the highest liver total lipid $(P<0.001)$ and steatosis $(P=0.003)$ indicating fatty liver. Based in the results, none of the dietary treatments attenuated disease progression. Furthermore, the supplementation of SPI +SB diet increased PLD liver steatosis and inflammation.

Keywords: polycystic liver disease, n-3 fatty acids, soy protein, diet therapy 


\subsection{Introduction}

Polycystic liver disease (PLD) is a genetic disorder characterized by the presence of multiple benign cysts that accumulate on the epithelial lining of the liver as a complication of either autosomal dominant or autosomal recessive polycystic kidney disease (PKD). ${ }^{1}$ In PKD, there are genetic mutations in the $\mathrm{PKD}_{1}, \mathrm{PKD}_{2}$, or $\mathrm{PKHD}_{1}$ genes, which cause cyst growth and progression in the kidneys and liver. Female patients with advanced PKD exhibit greater liver cyst progression and severity compared to males. ${ }^{1}$ While the initial stages of PLD are asymptomatic, clinical symptoms associated with PLD include abdominal pain/swelling, bleeding into cysts, cyst infection, and jaundice due to bile duct obstruction. ${ }^{2}$ Furthermore, cyst accumulation may alter metabolism in the liver. ${ }^{3}$ Currently, there are no gene therapy or efficacious pharmaceutical treatment for PLD. Surgical aspiration of cysts is the main short-term treatment used to alleviate pressure due to cysts. ${ }^{4}$

Dietary treatment is a potentially safe, cost-effective, and non-invasive option that may benefit PLD patients. Studies have investigated the role of diet therapy in PKD which is commonly associated with PLD. ${ }^{5}$ Feeding soy protein isolate (SPI) in female PKD animal models has been shown to decrease cystic growth and overall cyst proliferation. ${ }^{6,7}$ Feeding SPI also decreased inflammation as indicated by decreased renal cyclooxygenase (COX-2) enzyme activity. ${ }^{7}$ Increasing omega-3 polyunsaturated fatty acids (n-3 PUFAs) is another dietary component with the potential to decrease inflammation and attenuate disease progression.

Dietary n-3 PUFAs have been reported to have anti-inflammatory actions by altering tissue fatty acid composition, eicosanoid production, transcription factors, and gene expression. ${ }^{8,9}$ Several studies have reported that feeding PKD rodent models diets supplemented with n-3 PUFAs significantly reduced renal inflammation and cystic damage. ${ }^{10,11}$ Since cyst pathogenesis in the 
liver is similar to PKD these diet components may attenuate PLD. To our knowledge, no studies have examined the role of soy protein isolate or n-3 PUFAs on PLD progression and severity. Few PKD animal models exhibit characteristics of PLD despite liver cysts being the most common extra-renal manifestation of PKD. ${ }^{12}$ The pck rat model resembles a slow progression ADPKD and PLD. ${ }^{13}$ The pck rat model shows cystogenesis, cyst enlargement and liver bile duct dilation within one week of age. ${ }^{12}$ Therefore, making the pck rat an attractive model to determine the potential for dietary intervention. Females are at higher risk for developing PLD than males, ${ }^{1}$ therefore it is important to examine dietary treatments in female rodent models. The objective of this study was to determine the role of soy protein and/or n-3 PUFAs on PLD progression and severity in female pck rats.

\subsection{Methods}

\section{Animals and diets}

All animal procedures performed in this study were conducted in accordance with the National Research Council for the Care and Use of Laboratory Animals Guidelines ${ }^{14}$ and were approved by the Animal Care and Use Committee at West Virginia University. Young (age 28 day) female pck rats were purchased from Charles River Laboratories (Wilmington, MA). All rats were individually caged and maintained in a room kept at $21^{\circ} \mathrm{C}$ with a 12 hour light/dark cycle throughout the 12 week study period. Following acclimation, animals were randomly assigned ( $\mathrm{n}=12$ rats/group) to different experimental diets based on the American Institute of Nutrition-93G (AIN-93 G) diet. A standard diet consisting of purified ingredients and formulated to meet all the nutritional requirements for growing rats as defined by the National Research Council. ${ }^{14}$ Diet ingredients and fatty acid composition are provided below. 


\begin{tabular}{lcccc}
\hline \multicolumn{1}{c}{ Ingredient (g/kg diet) ${ }^{\mathbf{1}}$} & Casein + CO & Casein + SO & SPI + SO & SPI + SB \\
\hline Casein & & & & \\
Soy protein isolate & 200.0 & 200.0 & 0.0 & 0.0 \\
L-Cystine & 0.0 & 0.0 & 200.0 & 200.0 \\
Corn Starch & 3.0 & 3.0 & 1.3 & 1.3 \\
Maltodextrin & 397.5 & 397.5 & 397.5 & 397.5 \\
Sucrose & 132.0 & 132.0 & 132.0 & 132.0 \\
Soybean Oil & 100.0 & 100.0 & 100.0 & 100.0 \\
Corn Oil & 70.0 & 0.0 & 70.0 & 35.0 \\
Salmon Oil & 0.0 & 70.0 & 0.0 & 0.0 \\
Cellulose & 0.0 & 0.0 & 0.0 & 35.0 \\
Mineral Mix ${ }^{2}$ & 50.0 & 50.0 & 50.0 & 50.0 \\
Vitamin Mix & 35.0 & 35.0 & 35.0 & 35.0 \\
Choline bitartrate & 10.0 & 10.0 & 10.0 & 10.0 \\
TBHQ, antioxidant & 2.5 & 2.5 & 2.5 & 2.5 \\
Calories & 0.014 & 0.014 & 0.014 & 0.014
\end{tabular}

\section{Fatty acids $(\%)$}

n-3 PUFAs

Alpha-linolenic acid (ALA, 18:3n-3)

Eicosapentaenoic acid (EPA, 20:5n-3)

$\begin{array}{cccc}0.59 \pm 0.18 \mathrm{c} & 7.69 \pm 0.02 \mathrm{a} & 7.68 \pm 0.04 \mathrm{a} & 4.85 \pm 0.01 \mathrm{~b} \\ \mathrm{ND} & \mathrm{ND} & \text { ND } & 7.4 \pm 0.03 \\ \text { ND } & \text { ND } & \text { ND } & 3.9 \pm 0.1\end{array}$

n-6 PUFAs

Linoleic acid (LA, 18:2n-6)

$52.93 \pm 2.68 \mathrm{a} \quad 55.78 \pm 0.07 \mathrm{a} \quad 56.09 \pm 0.09 \mathrm{a} \quad 35.19 \pm 0.06 \mathrm{~b}$

Arachidonic acid (ARA, 20:4n-6)

$1.10 \pm 0.04 \mathrm{a} \quad 0.16+0.005 \mathrm{c} \quad 0.21 \pm 0.01 \mathrm{c} \quad 0.41+0.007 \mathrm{~b}$

${ }^{1}$ All ingredients are from Harlan Teklad except for SPI from DuPont Nutrition and Health (St. Louis, MO) and salmon oil from Jedwards International (Quincy, MA).

${ }^{2}$ Based on the AIN-93G vitamin and mineral mixes. Different superscript letters a, b, c within the same rows indicate significant differences at $P<0.05$ by one-way ANOVA followed by Tukey's test. Abbreviations are CO, corn oil; SO, soybean oil; SPI, soy protein isolate; SB, 1:1 soybean oil:salmon oil blend; TBHQ, tertiary butylhydroquinone; ND, not detectable.

The protein sources consisting of $200 \mathrm{~g} / \mathrm{kg}$ diet as either casein or soy protein isolate (SPI). SPI was generously provided by DuPont Nutrition and Health (St. Louis, MO). The lipid sources consisted of $70 \mathrm{~g} / \mathrm{kg}$ diet as either corn oil which is low in n-3 PUFAs, soybean oil which contains the essential fatty acids linoleic acid (LA, 18:2n-6) and alpha-linolenic acid (ALA, 18:3n-3) or salmon oil which is rich in the long-chain n-3 PUFAs, eicosapentaenoic (EPA, 20:5n-3) and docosahexaenoic acid (DHA, 22:6n-3) as a 1:1 soybean oil + salmon oil blend. Salmon oil was purchased from Jedwards International Inc (Quincy, MA). The experimental 
diets consisted of: casein + corn oil $($ Casein $+\mathrm{CO})$, casein + soybean oil $($ Casein $+\mathrm{SO})$, soy protein isolate + soybean oil $(\mathrm{SPI}+\mathrm{SO})$ or soy protein isolate $+1: 1$ soybean/salmon oil $(\mathrm{SPI}+$ $\mathrm{SB})$.

Rats were provided free access to water and diet. To prevent variability in food intake, rats were provided $15 \pm 2 \mathrm{~g}$ of powdered diet daily based on previous studies showing growing female rats consume $\sim 15 \mathrm{~g}$ powdered diet/d (Tou et al 2011). ${ }^{15}$ All diets were kept at $-20^{\circ} \mathrm{C}$ until fed. Fresh diet was provided daily. At the end of the 12-week feeding study, rats were euthanized by $\mathrm{CO}_{2}$ inhalation. Liver was excised, weighed, immediately frozen in liquid nitrogen, and stored at $-80{ }^{\circ} \mathrm{C}$ for fatty acid and molecular analysis. The left lateral liver lobes were immediately fixed in a $10 \%$ formalin solution for histological evaluation.

\section{Histological evaluation of liver morphometry}

The left lateral liver lobes $(\mathrm{n}=11-12)$ were dehydrated through a series of increasing ethanol concentrations $\left(70-100 \%\right.$ in $\left.\mathrm{ddH}_{2} \mathrm{O}\right)$ then placed in xylene. The tissues were embedded in paraffin and serially cut to $8 \mu \mathrm{m}$ thick sections using a microtome (American Optical Company, NY). The paraffin embedded sections were placed on glass slides for mounting. Mounted sections were then de-paraffinized in xylene, and rehydrated through a series of decreasing ethanol concentrations (100-70\%) prior to staining. Tissue slides were stained with hematoxylin and eosin to analyze renal cyst number and size $(0.3-1.0 \mathrm{~mm})$ and structural abnormalities. All slides were analyzed using a Nikon TE 2000-S light microscope (Nikon Instruments, NY) at $4 \mathrm{X}$ magnification by a pathologist blinded to the dietary treatments. Images were captured using a PC interfaced with Q-Capture imaging software (Quantitative Imaging Corporation, BC, Canada).

Analysis of liver fatty acid composition 
Total lipid was extracted from snap frozen liver tissue according to a modified method of Bligh and Dyer. ${ }^{16}$ Briefly, frozen liver tissue $(\sim 400 \mathrm{mg})$ was homogenized in Tris/EDTA buffer (pH 7.4) and nonadecenoic (19:1) added as an internal standard. Hepatic tissue was homogenized in chloroform: methanol:acetic acid (2:1:0.15 v/v/v) solution, centrifugation at 900 $g$ for $10 \mathrm{~min}$ at $10^{\circ} \mathrm{C}$, and the bottom chloroform layer was collected. The collected chloroform was filtered through 1-phase separation filters and then dried under nitrogen gas.

The extracted lipid samples were transmethylated according to Fritsche and Johnston. ${ }^{17}$ Briefly, extracted fatty acids were methylated by adding $4 \% \mathrm{H}_{2} \mathrm{SO}_{4}$ in anhydrous methanol to the dried extracted lipid samples followed by incubation in a $90^{\circ} \mathrm{C}$ water bath for $60 \mathrm{~min}$. Samples were cooled to room temperature and $3 \mathrm{~mL}$ of $\mathrm{ddH}_{2} \mathrm{O}$ was added. Chloroform was added to the methylated samples and centrifuged at $900 \mathrm{~g}$ for $10 \mathrm{~min}$ at $10^{\circ} \mathrm{C}$, the chloroform layer was collected, and filtered through anhydrous $\mathrm{Na}_{2} \mathrm{SO}_{4}$. Samples were dried under nitrogen gas and diluted in iso-octane.

Fatty acid methyl esters (FAME) samples were analyzed by gas chromatography (CP3800 , Varian, CA) using an initial temperature of $140^{\circ} \mathrm{C}$ held for 5 minutes and then increased $1^{\circ} \mathrm{C}$ per minute to a final temperature of $220^{\circ} \mathrm{C}$. A wall-coated open tubular fused silica capillary column (Varian Inc., Walnut Creek, CA) was used to separate FAMEs with CP-Sil 88 as the stationary phase. Nitrogen was used as the carrier gas and total separation time was 110 min. Quantitative 37 Component FAME Sigma Mix (Supelco, Bellefonte, PA) was be used as a standard to identify fatty acids. Fatty acids were quantified using peak area counts and retention time. All samples were performed in duplicate and reported as \% total fatty acids. RNA isolation and gene expression analysis 
Total renal RNA was extracted from $\sim 100 \mathrm{mg}$ of frozen liver tissue following the Total RNA Isolation procedure of the mirVana miRNA Isolation Kit (Ambion, TX). Isolated RNA integrity was visualized on a $1.5 \%$ agarose gel and isolated RNA concentration was quantified by spectrophotometry (Thermo Scientific, DE). After DNase treatment of the isolated RNA (Applied Biosystems, CA), total mRNA was amplified using the Superscript III First Strand Synthesis assay with oligo dT primers (Invitrogen, CA).

Primer efficiencies were determined on pooled RNA samples serially diluted in $\mathrm{ddH}_{2} \mathrm{O}$ up to 1:10000. PCR consisted of $2.5 \mu 1$ of SYBR ${ }^{\circledR}$ Green Master Mix (Applied Biosystems, CA), $1 \mu \mathrm{l}$ of cDNA, $1 \mu \mathrm{l}$ of respective forward and reverse primers, and $0.5 \mu \mathrm{l}$ of $\mathrm{ddH}_{2} \mathrm{O}$ for a total reaction volume of $5 \mu 1$. The thermal profile consisted of $50^{\circ} \mathrm{C}$ for 2 minutes, $95^{\circ} \mathrm{C}$ for 10 minutes, and then 40 cycles of $95^{\circ} \mathrm{C}$ for 15 seconds and $60^{\circ} \mathrm{C}$ for 1 minute. Primers were designed for rat cyclooxygenase -2 (COX-2), mammalian target of rapamycin (mTOR), mitogenactivated protein kinase (MapK), peroxisome proliferator-activated receptor gamma (PPAR $\gamma$ ), transforming growth factor beta 1 (Tgf 1 1), epidermal growth factor (Egf), somatostatin receptor 3 (Sstr3), nuclear factor, erythroid derived 2, like 2 (Nrf2), cystic fibrosis transmembrane conductase regulator (Cftr), angiotensin II (At1), nuclear factor of kappa light polypeptide gene enhancer in B-cells inhibitor, alpha (Ikb $\alpha)$, tumor necrosis factor alpha (TNF $\alpha)$ and the housekeeping gene beta actin (ActB) using the Primer3 program (Howard Hughes Medical Institute) and respective mRNA sequences obtained from NCBI. Forward and reverse primers for genes were: 


\begin{tabular}{|c|c|c|}
\hline Gene & Forward Primer & Reverse Primer \\
\hline $\mathrm{COX}-2$ & 5' CGGAGGAGAAGTGGGTTTTAG 3' & 5' TGAAAGAGGCAAAGGGACAC 3' \\
\hline mTOR & 5' GGCTTCAACAGCAAGGACAC 3' & 5' ACGGGTGAGGTAACAGGATG 3' \\
\hline mapK & 5’CGTTCAGATGTCGGTGTCC 3’' & 5'CGGCTCAAAGGAGTCAAGAG 3' \\
\hline $\operatorname{PPAR} \gamma$ & 5' TGGAGCCTAAGTTTGAGTTTGC 3' & 5’CAGCAGGTTGTCTTGGATGTC 3’' \\
\hline $\operatorname{Tgf} \beta 1$ & 5' TGGAGCCTGGACACACAGTA 3' & 5' GTAGTAGACGATGGGCAGTGG 3' \\
\hline Egf & 5' TGGTGTCTGTCTGTGTGGTG 3' & 5’ GGGCTGTTGGTGTTCCTCTA 3’' \\
\hline Sstr3 & 5' СТTCСТCTCCTACCGCTTCA 3' & 5' CCTCCTCCTCCGTCTTCTCT 3' \\
\hline Nrf2 & 5' TGACTCGGAAATGGAAGAGC 3' & 5' TGTGTTGGCTGTGCTTTAGG 3' \\
\hline Cftr & 5' ACACGCACACGCACACTAAT 3' & 5' GCTTTCACGGGCATAGGTAG 3' \\
\hline At1 & 5' TTGAGGTGGAGTGACAGGTTC 3' & 5' ATGGTCCTTTGGTCGTAAGC 3' \\
\hline $\mathrm{I} \kappa \mathrm{b} \alpha$ & 5' CTGGTCTCGCTCCTGTTGA 3' & 5' GCCCTGGTAGGTTACTCTGTTG 3' \\
\hline $\operatorname{Tnf} \alpha$ & 5' CACAAGGCTGAAGATGT 3' & 5' GAGGGAAGGAAGGAAGGAAG 3' \\
\hline $\operatorname{Act} \beta$ & 5' TTGCTGACAGGATGCAGAAG 3' & 5' CAGTGAGGCCAGGATAGAGC 3' \\
\hline
\end{tabular}

All primers were normalized to beta actin.

Serum clinical markers of liver function

Rats were euthanized by $\mathrm{CO}_{2}$ inhalation and blood collected by aorta puncture. Blood was centrifuged at $1,500 \mathrm{~g}$ for $10 \mathrm{~min}$ at $4{ }^{\circ} \mathrm{C}$ to obtain serum. Serum measures of liver function included: gamma-glutamyl transferase, alanine aminotransferase, albumin, cholesterol, total protein, and triglycerides. Values were determined enzymatically using a commercially available Vet-16 rotor and quantified by a Hemagen Analyst automated spectrophotometer (Hemagen Diagnostics Inc., Columbia, MD).

\section{Statistical analysis}

Results are expressed as means \pm standard error of the mean (SEM). One-way analysis of variance (ANOVA) was used to determine differences among treatment groups. Post-hoc multiple comparisons were performed using Tukey's test. Differences were considered significant at $P<0.05$. All statistical analyses were performed using SigmaStat 3.1 statistical software program (Systat Software Inc., San Jose, CA). Relative gene expression was calculated according to methods by Bari et al, ${ }^{18}$ with values obtained by calculating 40-DCt. DCt was 
calculated as the difference in threshold cycle $(\mathrm{Ct})$ of the gene of interest and the reference gene (ActB) while the number 40 was selected because it represents the highest $\mathrm{Ct}$ value. Following the 40-DCt calculation, gene expression was analyzed using a one way ANOVA.

\subsection{Results}

Body weight and liver mass

There were no significant differences in body weight gain for rats fed Casein $+\mathrm{CO}$ $(184.25 \pm 6.36 \mathrm{~g})$, Casein $+\mathrm{SO}(184.42 \pm 4.92 \mathrm{~g}), \mathrm{SPI}+\mathrm{SO}(175.58 \pm 4.84 \mathrm{~g})$ and SPI+SB diets $(186.00 \pm 13.15 \mathrm{~g})$. There were also no significant differences in final body weight for rats fed Casein+CO $(271.25 \pm 2.03 \mathrm{~g})$, Casein $+\mathrm{SO}(270.50 \pm 2.82 \mathrm{~g}), \mathrm{SPI}+\mathrm{SO}(281.45 \pm 9.42 \mathrm{~g})$ and SPI+SB $(269.0 \pm 3.63 \mathrm{~g})$ diets. There were no significant differences in absolute or relative liver weights (Table 2).

\section{Liver histology}

Figure $2 \mathrm{~A}-\mathrm{C}$ are representative $\mathrm{H} \& \mathrm{E}$ staining of liver cysts, inflammation, and steatosis. Although cyst effacement was observed in all groups, there were no significant differences among the dietary treatments (Table 1). Rats fed SPI + SB diet had significantly higher cyst obstruction compared to rats fed Casein $+\mathrm{CO}$ or SPI + SO diet. Cyst obstruction was not observed in rats fed Casein + SO diet. Steatosis was highest $(P<0.03)$ in rats fed SPI + SB diet. Rats fed Casein + SO and SPI + SO diet had significantly higher steatosis than rats fed Casein + $\mathrm{CO}$ diet. Although no differences were seen in portal fibrosis among the treatment groups, portal inflammation was highest $(P<0.03)$ in rats fed SPI + SB diet.

\section{Hepatic tissue fatty acid composition}

Total lipid content was highest $(P<0.05)$ in rats fed SPI + SB diet. Rats fed Casein $+\mathrm{SO}$, SPI + SO, and SPI + SB diets had higher $(P<0.001)$ hepatic tissue ALA content than rats fed 
Casein + CO diet. Hepatic tissue EPA content was highest $(P<0.001)$ in rats fed SPI + SB diet. Rats fed SPI + SB diet had the highest $(P<0.001)$ hepatic DHA content. Rats fed SO as the lipid source had similar hepatic DHA content regardless of the protein source. Rats fed Casein + CO diet had the lowest $(P<0.001)$ renal DHA content (Table 2$)$. There were no significant differences in tissue renal linoleic acid (LA, 18:2n-6) content among the diet treatment groups. Hepatic arachidonic acid (AA, 20:4n-6) content was lowest $(P<0.001)$ in rats fed the SPI + SO $\operatorname{diet}($ Table 2).

\section{Hepatic gene expression analysis}

There were no significant differences hepatic relative gene expression between rats fed the different diets (Table 4).

\section{Biomarkers of liver function}

There were no significant differences in liver function measurements of gamma-glutamyl transferase, alanine aminotransferase, albumin, or total protein among the diet treatment groups (Table 3). Rats fed the Casein + CO diet had the highest $(P<0.001)$ serum cholesterol concentration, while rats fed $\mathrm{SO}$ as a lipid source had similar serum cholesterol levels. Rats fed the SPI + SB diet had the lowest $(P<0.01)$ serum cholesterol levels. Serum triglycerides were below detected levels.

\subsection{Discussion}

PLD patients are mostly asymptomatic, but as the disease progresses, multiple cyst formation eventually leads to a loss of liver structure, function, and altered metabolism. ${ }^{3}$

Increases in tissue size are often indicative of increased cyst formation and progression. ${ }^{19}$ In the present study, absolute and relative liver weights were similar among the dietary treatment groups. Histological evaluation showed all rats had liver cyst accumulation regardless of the 
dietary treatment group. Although, no significant differences were observed in cyst effacement, rats fed SPI + SB diet had significantly increased cyst obstruction compared to the other dietary treatment groups. Cyst obstruction may prevent transport of lipids from the liver into the circulation. In the present study, rats fed SPI + SB diet had significantly higher hepatic total lipid content than the rats fed other dietary treatments. Histological evaluation showed that rats fed the SPI + SB diet had significantly increased steatosis compared to all other dietary treatments. The development of hepatic steatosis results from an imbalance in the rates of entry, synthesis, or clearance of lipids from the liver. ${ }^{27}$

Rats fed SPI + SB diet consisting of a 7\% wt lipids as a 1:1 soybean oil: fish oil blend also had reduced serum cholesterol $(P<0.001)$ compared to other dietary treatments. Similarly, M-Shirazi et $\mathrm{al}^{20}$ showing that female Wistar rats fed $7 \% \mathrm{wt}$ fish oil exhibited significantly increased hepatic steatosis and decreased serum cholesterol compared to rats fed soybean oil. These results indicate that fish oil may not be fully metabolized in the liver thus, inducing hepatic steatosis. In female $\mathrm{LDLR}^{-/-}$mice, the inclusion of fish oil dose resulted in increased cholesterol storage capacity within the liver. ${ }^{21}$ This may explain lower serum cholesterol on a fish oil diet and higher total lipid content and liver steatosis.

Studies have suggested that EPA and DHA are beneficial for the treatment of liver inflammation associated with hepatic lipid accumulation. ${ }^{22}$ In a recent study by Depner et $\mathrm{al}^{23}$ male $\mathrm{Ldlr}^{-/-}$mice, a model nonalcoholic fatty liver disease, fed diets rich in DHA had significantly reduced hepatic inflammation and fibrosis compared to mice fed diets rich in olive oil and EPA. The authors suggested that n-3 PUFAs could be used as dietary treatment for individuals with altered lipid metabolism disorders by attenuating inflammation and fibrosis. ${ }^{23}$ In the present study, rats fed Casein $+\mathrm{SO}, \mathrm{SPI}+\mathrm{SO}$, and SPI $+\mathrm{SB}$ diets had similar $(P<0.001)$ 
hepatic ALA content. ALA can be converted to the long chain omega-3 fatty acids EPA and DHA, however conversion in mammals is low. ${ }^{24}$ Therefore, rats fed SPI + SB diet containing pre-formed EPA and DHA had the highest $(P<0.001)$ EPA and DHA hepatic content. The increase in hepatic omega-3 (EPA and DHA) content replaces tissue n-6 fatty acids. Rats fed SPI+SB diet had the lowest $(P<0.001)$ hepatic ARA content. The COX-2 enzyme converts ARA to eicosanoids with pro-inflammatory properties; therefore, reducing tissue ARA content may reduce inflammation. ${ }^{25}$ However, relative gene expression of COX-2 was not significantly different among the dietary treatment groups.

$\mathrm{Nf}-\mathrm{kB}$ is a major transcription factor of the inflammation pathway. Various studies have shown that the omega-3 fatty acid EPA inhibits the phosphorylation of IkBa, preventing its degradation and thus, promoting NF-kB inhibition. ${ }^{26}$ Rather than reduced inflammation, in our study, histological evaluation showed that rats fed SPI + SB diet also had significantly increased portal chronic inflammation compared to other dietary treatment groups. These results are consistent with those by Polavarapu et $\mathrm{al}^{27}$ showing male Wistar rats fed fish oil significantly increased inflammation compared to feeding corn oil or palm oil. The authors stated that feeding fish oil increased lipid peroxidation which increases susceptibility to oxidative damage and worsen liver injury. ${ }^{27}$ The n-3 PUFAs have also been shown to have anti-oxidant effects. Supplementation of fish oil in male C57BL/6 mice significantly up-regulated hepatic genetic expression levels of $\mathrm{Nrf2}$, a transcription factor in antioxidant response, compared to mice fed soybean oil and safflower oil. ${ }^{28}$ In our study Nrf2 expression was not significantly affected by dietary intake in the present study.

It is well known that females with PKD have a higher risk of developing advanced PLD compared to males. Arnold and Harrison ${ }^{29}$ suggested this could be due a result of hormonal 
effects created by estrogen. Soy protein contains phytoestrogens which have weak estrogenic or anti-estrogen action. Therefore, SPI may reduce liver cysts by acting as an anti-estrogen. Rat fed SPI as a soybean oil and fish oil blend, but not soybean oil alone showed greater cyst obstruction and inflammation. The results suggested that greater cyst obstruction was due to the fish oil inclusion. This is unexpected since dietary n-3 PUFA consumption has been shown to have antiinflammatory properties in the tissue. However, male Wistar rats (alcohol liver disease) fed fish oil experienced significantly increased fatty liver presence, necrosis, and inflammation compared to rats fed corn oil and palm oil. ${ }^{27}$ These results suggest that n-PUFA supplementation may increase oxidative damage in injured hepatic tissue.

In the current study there were no histological differences in portal chronic fibrosis among the dietary treatment groups. Although no significant differences were seen in any fibrosis gene expression in the current study, n-3 PUFAs have been shown to inhibit mTOR expression. ${ }^{30}$ Fibrosis indicates extensive damage. It is possible that the rats in this study did not progress to the phase of liver fibrosis. Furthermore, there were no differences in liver function biomarkers of serum gamma-glutamyl transferase, alanine aminotransferase, albumin, or total protein among the dietary treatments

In conclusion, feeding SPI and/or n-3 PUFAs did not attenuate disease progression or severity in female pck rats with PLD. Female pck rats fed SPI + SB diet resulted in higher hepatic n-3 PUFA content, but did not decrease inflammation or fibrosis. Furthermore, feeding SPI + SB increased cyst obstruction, portal inflammation, and steatosis suggesting possible detrimental effect in female pck rats with PLD. 


\subsection{References}

1. Gabow PA, Johnson AM, Kaehny WD, Manco-Johnson ML, Duley IT, Everson GT. Risk factors for the development of hepatic cysts in autosomal dominant polycystic kidney disease. Hepatology. 1990;11(6):1033-1037.

2. Qian Q, Li A, King BF, et al. Clinical profile of autosomal dominant polycystic liver disease. Hepatology. 2003;37(1):164-171. doi: 10.1053/jhep.2003.50006.

3. Andreasen PB, Ranek L, Statland BE, Tygstrup N. Clearance of antipyrine-dependence of quantitative liver function. Eur J Clin Invest. 1974;4(2):129-134.

4. Saini S, Mueller PR, Ferrucci JT,Jr, Simeone JF, Wittenberg J, Butch RJ. Percutaneous aspiration of hepatic cysts does not provide definitive therapy. AJR Am J Roentgenol. 1983;141(3):559-560. doi: 10.2214/ajr.141.3.559.

5. Maditz KH, Gigliotti JC, Tou JC. Evidence for a role of proteins, lipids, and phytochemicals in the prevention of polycystic kidney disease progression and severity. Nutr Rev. 2013;71(12):802-814. doi: 10.1111/nure.12085; 10.1111/nure.12085.

6. Aukema HM, Housini I, Rawling JM. Dietary soy protein effects on inherited polycystic kidney disease are influenced by gender and protein level. J Am Soc Nephrol. 1999;10(2):300308. 
7. Peng CY, Sankaran D, Ogborn MR, Aukema HM. Dietary soy protein selectively reduces renal prostanoids and cyclooxygenases in polycystic kidney disease. Exp Biol Med (Maywood). 2009;234(7):737-743. doi: 10.3181/0811-RM-315; 10.3181/0811-RM-315.

8. Clandinin MT, Jumpsen J, Suh M. Relationship between fatty acid accretion, membrane composition, and biologic functions. J Pediatr. 1994;125(5 Pt 2):S25-32.

9. Kiecolt-Glaser JK, Belury MA, Porter K, Beversdorf DQ, Lemeshow S, Glaser R. Depressive symptoms, omega-6:Omega-3 fatty acids, and inflammation in older adults. Psychosom Med. 2007;69(3):217-224. doi: 10.1097/PSY.0b013e3180313a45.

10. An WS, Kim HJ, Cho KH, Vaziri ND. Omega-3 fatty acid supplementation attenuates oxidative stress, inflammation, and tubulointerstitial fibrosis in the remnant kidney. Am J Physiol Renal Physiol. 2009;297(4):F895-903. doi: 10.1152/ajprenal.00217.2009;

10.1152/ajprenal.00217.2009.

11. Ogborn MR, Nitschmann E, Weiler H, Leswick D, Bankovic-Calic N. Flaxseed ameliorates interstitial nephritis in rat polycystic kidney disease. Kidney Int. 1999;55(2):417-423. doi: 10.1046/j.1523-1755.1999.00287.x.

12. Lager DJ, Qian Q, Bengal RJ, Ishibashi M, Torres VE. The pck rat: A new model that resembles human autosomal dominant polycystic kidney and liver disease. Kidney Int. 2001;59(1):126-136. doi: 10.1046/j.1523-1755.2001.00473.x. 
13. Torres VE, Harris PC. Polycystic kidney disease: Genes, proteins, animal models, disease mechanisms and therapeutic opportunities. J Intern Med. 2007;261(1):17-31. doi: 10.1111/j.1365-2796.2006.01743.x.

14. National Research Council. Nutrient requirements of laboratory animals. Fourth Revised Edition ed. Washington, DC: The National Academies Press; 1995.

15. Tou JC, Altman SN, Gigliotti JC, Benedito VA, Cordonier EL. Different sources of omega-3 polyunsaturated fatty acids affects apparent digestibility, tissue deposition, and tissue oxidative stability in growing female rats. Lipids Health Dis. 2011;10:179-511X-10-179. doi: 10.1186/1476-511X-10-179; 10.1186/1476-511X-10-179.

16. BLIGH EG, DYER WJ. A rapid method of total lipid extraction and purification. Can J Biochem Physiol. 1959;37(8):911-917.

17. Fritsche KL, Johnston PV. Effect of dietary alpha-linolenic acid on growth, metastasis, fatty acid profile and prostaglandin production of two murine mammary adenocarcinomas. J Nutr. 1990;120(12):1601-1609.

18. Bari R, Datt Pant B, Stitt M, Scheible WR. PHO2, microRNA399, and PHR1 define a phosphate-signaling pathway in plants. Plant Physiol. 2006;141(3):988-999. doi: 10.1104/pp.106.079707.

19. Igarashi P, Somlo S. Genetics and pathogenesis of polycystic kidney disease. J Am Soc Nephrol. 2002;13(9):2384-2398. 
20. M-Shirazi M, Taleban FA, Abadi AR, Sabetkasaei M. Fish oil increases atherosclerosis and hepatic steatosis, although decreases serum cholesterol in wistar rat. J Res Med Sci. 2011;16(5):583-590.

21. Saraswathi V, Gao L, Morrow JD, Chait A, Niswender KD, Hasty AH. Fish oil increases cholesterol storage in white adipose tissue with concomitant decreases in inflammation, hepatic steatosis, and atherosclerosis in mice. J Nutr. 2007;137(7):1776-1782.

22. El-Badry AM, Graf R, Clavien PA. Omega 3 - omega 6: What is right for the liver? J Hepatol. 2007;47(5):718-725. doi: 10.1016/j.jhep.2007.08.005.

23. Depner CM, Traber MG, Bobe G, et al. A metabolomic analysis of omega-3 fatty acidmediated attenuation of western diet-induced nonalcoholic steatohepatitis in LDLR-/- mice. PLoS One. 2013;8(12):e83756. doi: 10.1371/journal.pone.0083756;

10.1371/journal.pone.0083756.

24. Calder PC. Fatty acids and immune function: Relevance to inflammatory bowel diseases. Int Rev Immunol. 2009;28(6):506-534. doi: 10.3109/08830180903197480;

10.3109/08830180903197480.

25. Calder PC. N-3 polyunsaturated fatty acids, inflammation, and inflammatory diseases. Am J Clin Nutr. 2006;83(6 Suppl):1505S-1519S.

26. Huang F, Wei H, Luo H, Jiang S, Peng J. EPA inhibits the inhibitor of kappaBalpha (IkappaBalpha)/NF-kappaB/muscle RING finger 1 pathway in C2C12 myotubes in a 
PPARgamma-dependent manner. Br J Nutr. 2011;105(3):348-356. doi:

10.1017/S0007114510003703; 10.1017/S0007114510003703.

27. Polavarapu R, Spitz DR, Sim JE, et al. Increased lipid peroxidation and impaired antioxidant enzyme function is associated with pathological liver injury in experimental alcoholic liver disease in rats fed diets high in corn oil and fish oil. Hepatology. 1998;27(5):1317-1323. doi: 10.1002/hep.510270518.

28. Nakagawa F, Morino K, Ugi S, et al. 4-hydroxy hexenal derived from dietary n-3 polyunsaturated fatty acids induces anti-oxidative enzyme heme oxygenase-1 in multiple organs. Biochem Biophys Res Commun. 2014;443(3):991-996. doi: 10.1016/j.bbrc.2013.12.085; 10.1016/j.bbrc.2013.12.085.

29. Arnold HL, Harrison SA. New advances in evaluation and management of patients with polycystic liver disease. Am J Gastroenterol. 2005;100(11):2569-2582. doi: 10.1111/j.15720241.2005.00263.x.

30. Friedrichs W, Ruparel SB, Marciniak RA, deGraffenried L. Omega-3 fatty acid inhibition of prostate cancer progression to hormone independence is associated with suppression of mTOR signaling and androgen receptor expression. Nutr Cancer. 2011;63(5):771-777. doi: 10.1080/01635581.2011.570892; 10.1080/01635581.2011.570892. 


\section{Acknowledgements}

We thank Dr. Barbara Mickelson for her expertise in formulating and manufacturing the diet, and DuPont Nutrition and Health for generously donating the SPI to our laboratory. Also, we thank Jonathan Dehlin for his assistance in creating the figures for this manuscript. Funding for this project was provided by the United Soybean Board Soybean Health Incentive Grant, West Virginia University PSCoR 10008736.6-11-NT10055R, West Virginia University Agriculture and Forestry Experimental Station Hatch Grant WVAA00665, and West Virginia University summer SURE program. 
Table 1. Liver histology of female pck rats fed various protein and lipid sources.

\begin{tabular}{lccccc}
\hline \multicolumn{1}{c}{ Measurements } & Casein + CO & Casein + SO & SPI + SO & SPI + SB & P-value \\
\hline Cyst effacement & $1.82 \pm 0.23$ & $2.00 \pm 0.19$ & $2.08 \pm 0.29$ & $2.46 \pm 0.25$ & 0.33 \\
Cyst obstruction & $0.27 \pm 0.14 \mathrm{~b}$ & 0 & $0.58 \pm 0.40 \mathrm{~b}$ & $1.36 \pm 0.49 \mathrm{a}$ & 0.03 \\
Steatosis & $1.91 \pm 0.32 \mathrm{c}$ & $2.46 \pm 0.21 \mathrm{~b}$ & $1.83 \pm 0.17 \mathrm{~b}$ & $3.00 \pm 0.23 \mathrm{a}$ & 0.003 \\
Portal chronic inflammation & $0.18 \pm 0.12 \mathrm{~b}$ & $0.09 \pm 0.09 \mathrm{~b}$ & $0.50 \pm 0.34 \mathrm{~b}$ & $1.27 \pm 0.45 \mathrm{a}$ & 0.03 \\
Portal fibrosis & 0 & $0.36 \pm 0.20$ & $0.58 \pm 0.29$ & $0.67 \pm 0.20$ & 0.27 \\
\hline
\end{tabular}

Values are the mean \pm SEM of $n=11-12$ rats/group. Abbreviations are CO, corn oil; SO, soybean oil; SPI, soy protein isolate; SB, 1:1 soybean oil:salmon oil blend. 
Table 2. Hepatic tissue fatty acid composition in female pck rats fed various protein and lipid sources.

\begin{tabular}{|c|c|c|c|c|c|}
\hline Measurements & Casein + CO & Casein + SO & $\mathrm{SPI}+\mathrm{SO}$ & SPI + SB & $P$-value \\
\hline Absolute liver weight & $9.955 \pm 0.20$ & $10.538 \pm 0.25$ & $12.606 \pm 2.01$ & $13.902 \pm 1.60$ & 0.14 \\
\hline Relative liver weight & $36.71 \pm 0.73$ & $38.98 \pm 0.91$ & $46.66 \pm 7.39$ & $49.27 \pm 5.24$ & 0.17 \\
\hline Total Lipid (g lipid/g liver) & $0.31 \pm 0.03 b$ & $0.29 \pm 0.06 b$ & $0.31 \pm 0.05 b$ & $0.41 \pm 0.03 \mathrm{a}$ & $<0.05$ \\
\hline n-3 PUFAs & & & & & \\
\hline Alpha-linolenic acid (18:3) & $0.21 \pm 0.03 \mathrm{~b}$ & $1.14 \pm 0.13 \mathrm{a}$ & $1.25 \pm 0.24 \mathrm{a}$ & $1.30 \pm 0.06 \mathrm{a}$ & $<0.001$ \\
\hline Eicosapentaenoic acid (20:5) & $0.26 \pm 0.05 b$ & $0.33 \pm 0.03 b$ & $0.44 \pm 0.06 \mathrm{~b}$ & $3.34 \pm 0.23 \mathrm{a}$ & $<0.001$ \\
\hline Docosahexaenoic acid (22:6) & $2.18 \pm 0.22 \mathrm{c}$ & $4.83 \pm 0.49 b$ & $4.08 \pm 0.85 b c$ & $12.62 \pm 0.26 \mathrm{a}$ & $<0.001$ \\
\hline \multicolumn{6}{|l|}{ n-6 PUFAs } \\
\hline Linoleic acid (18:2) & $18.83 \pm 1.27$ & $19.67 \pm 1.11$ & $21.61 \pm 1.38$ & $18.55 \pm 0.63$ & 0.28 \\
\hline Arachadonic acid (20:4) & $11.57 \pm 1.22 \mathrm{a}$ & $10.06 \pm 1.20 \mathrm{a}$ & $13.34 \pm 1.19 \mathrm{a}$ & $4.61 \pm 1.24 b$ & $<0.001$ \\
\hline
\end{tabular}

Values are the mean $\pm \mathrm{SEM}$ of $\mathrm{n}=11-12$ rats/group. Different superscript letters $\mathrm{a}, \mathrm{b}, \mathrm{c}$ within the same rows indicate significant differences at $P<0.05$ by one-way ANOVA followed by Tukey's test. Abbreviations are CO, corn oil; SO, soybean oil; SPI, soy protein isolate; SB, 1:1 soybean oil:salmon oil blend; n-6 PUFAs, omega-6 polyunsaturated fatty acids; n-3 PUFAs, omega-3 polyunsaturated fatty acids. 
Table 3. Liver serum measurements in female pck rats fed various protein and lipid sources.

\begin{tabular}{|c|c|c|c|c|c|}
\hline Measurements & Casein + CO & Casein + SO & SPI + SO & SPI + SB & $P$-value \\
\hline $\begin{array}{l}\text { Gamma-glutamyl transferase } \\
\text { (U/L) }\end{array}$ & $3.10 \pm 0.84$ & $3.00 \pm 0.45$ & $2.50 \pm 0.96$ & $4.33 \pm 1.02$ & 0.59 \\
\hline $\begin{array}{l}\text { Alanine Aminotransferase } \\
(\mathrm{U} / \mathrm{L})\end{array}$ & $91.82 \pm 7.30$ & $102.80 \pm 14.72$ & $101.55 \pm 13.03$ & $89.60 \pm 8.81$ & 0.79 \\
\hline Albumin $(\mathrm{g} / \mathrm{dL})$ & $3.80 \pm 0.15$ & $3.76 \pm 0.10$ & $3.56 \pm 0.23$ & $3.52 \pm 0.16$ & 0.55 \\
\hline Cholesterol (mg/dL) & $144.55 \pm 8.74 \mathrm{a}$ & $130.40 \pm 5.96 b$ & $124.09 \pm 6.33 b$ & $77.73 \pm 5.80 \mathrm{c}$ & $<0.001$ \\
\hline Total Protein $(\mathrm{g} / \mathrm{dL})$ & $6.18 \pm 0.35$ & $6.36 \pm 0.26$ & $6.52 \pm 0.41$ & $6.36 \pm 0.33$ & 0.92 \\
\hline
\end{tabular}

Values are the mean \pm SEM of $n=11-12$ rats/group. Different superscript letters $a, b, c$ within the same rows indicate significant differences at $P<0.05$ by one-way ANOVA. Abbreviations are CO, corn oil; SO, soybean oil; SPI, soy protein isolate; SB, 1:1 soybean oil:salmon oil blend. 
Table 4. Hepatic relative genetic expression levels of various genes in relation to dietary treatments of pck female rats.

\begin{tabular}{cccccc}
\hline Gene & Casein + CO & Casein + SO & SPI + SO & SPI + SB & P-value \\
\hline COX-2 & $27.87 \pm 0.28$ & $28.88 \pm 0.70$ & $29.60 \pm 0.58$ & $28.07 \pm 0.47$ & 0.11 \\
mTor & $30.96 \pm 0.26$ & $30.84 \pm 0.32$ & $31.54 \pm 0.72$ & $31.62 \pm 0.65$ & 0.69 \\
MapK & $31.55 \pm 0.32$ & $31.74 \pm 0.30$ & $31.83 \pm 0.16$ & $31.82 \pm 0.24$ & 0.24 \\
PPAR $\gamma$ & $25.66 \pm 0.74$ & $26.09 \pm 0.89$ & $26.09 \pm 0.33$ & $26.82 \pm 0.19$ & 0.54 \\
Tgfb1 & $32.17 \pm 0.34$ & $32.31 \pm 0.26$ & $32.70 \pm 0.16$ & $32.91 \pm 0.14$ & 0.12 \\
Egf & $31.22 \pm 0.46$ & $31.39 \pm 0.34$ & $31.08 \pm 0.70$ & $31.19 \pm 0.43$ & 0.98 \\
Sstr3 & $25.14 \pm 0.43$ & $25.10 \pm 0.38$ & $25.89 \pm 0.51$ & $26.20 \pm 0.40$ & 0.24 \\
Nrf2 & $36.57 \pm 0.32$ & $36.41 \pm 0.34$ & $36.38 \pm 0.41$ & 36.450 .30 & 0.98 \\
Cftr & $31.01 \pm 1.49$ & $30.88 \pm 0.89$ & $28.76 \pm 0.46$ & 30.83 & 0.28 \\
At1 & $35.99 \pm 0.33$ & $35.36 \pm 0.50$ & $35.39 \pm 0.59$ & $35.46 \pm 0.19$ & 0.73 \\
Ikb & $34.75 \pm 0.30$ & $35.61 \pm 1.01$ & $35.96 \pm 0.89$ & $35.52 \pm 0.49$ & 0.73 \\
TNF $\alpha$ & $27.89 \pm 0.78$ & $29.23 \pm 0.61$ & $29.60 \pm 0.68$ & $28.76 \pm 0.31$ & 0.13 \\
\hline
\end{tabular}

Values are the mean \pm SEM of $n=11-12$ rats/group. Different superscript letters $a, b, c$ within the same rows indicate significant differences at $P<0.05$ by one-way ANOVA followed by Tukey's test. Abbreviations are CO, corn oil; SO, soybean oil; SPI, soy protein isolate; $\mathrm{SB}, 1: 1$ soybean oil:salmon oil blend. 
Figure 1 A-C. Histological evaluation by H\&E staining of livers from female pck rats fed various dietary treatments.

A)

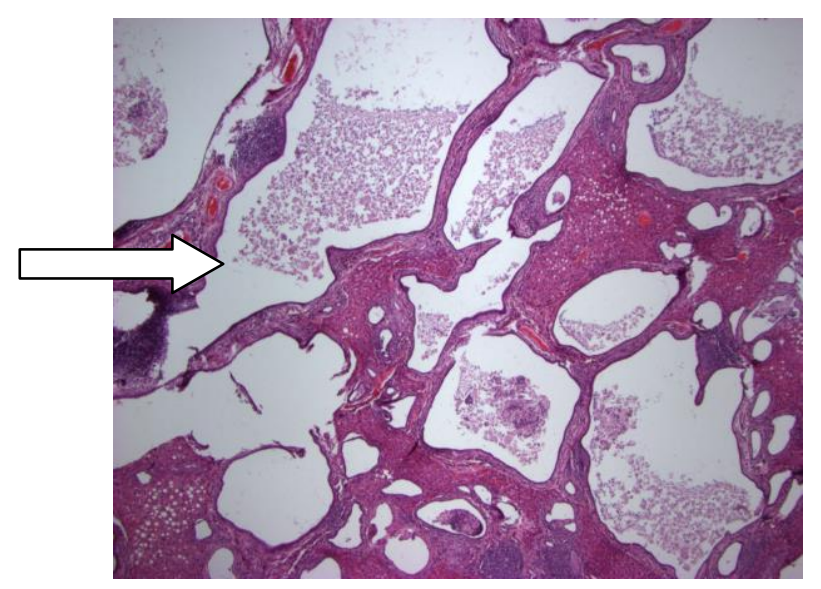

B)

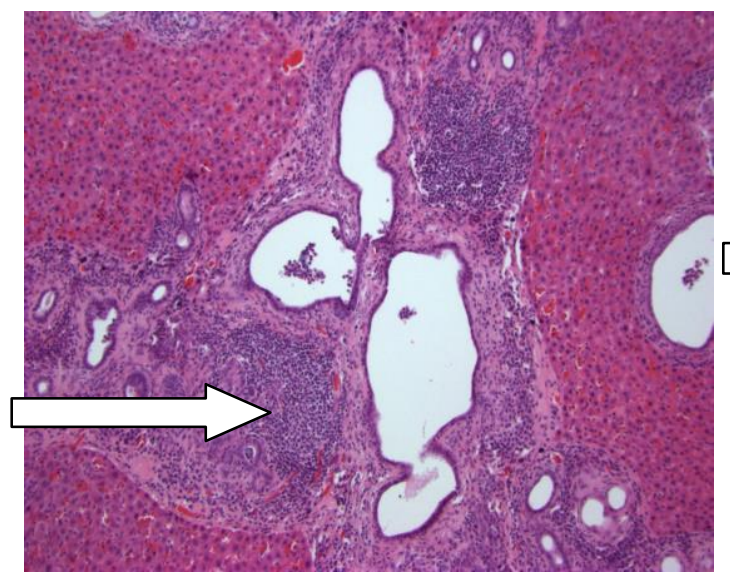

C)

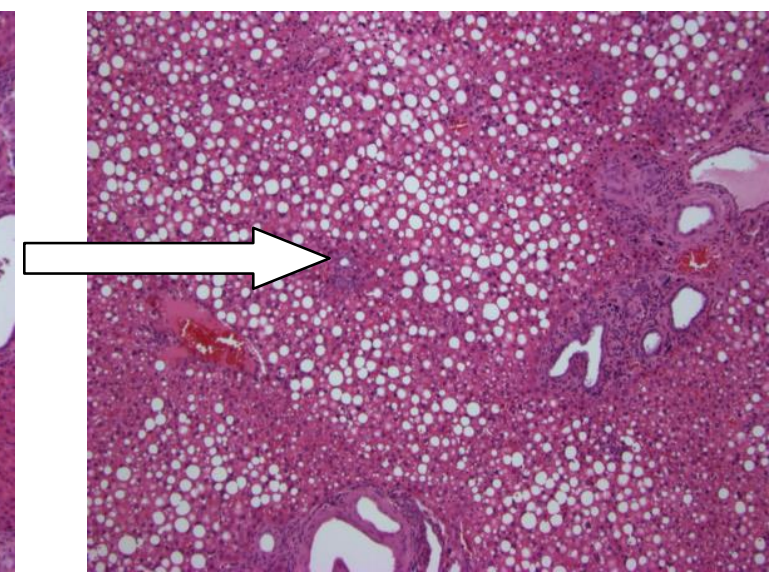

Slides depict (left to right) (A) cysts, (B) inflammation, and (C) steatosis at 100x magnification. 


\subsection{Summary and Conclusion}

The negative implications and poor prognoses associated with PKD patients, demands the need for sound nutrition research that will improve patient quality of life. Three studies were performed in this dissertation to address the role of the bioactive dietary compounds SPI and/or n-3 PUFA to attenuation PKD progression, severity, and PKD-related complications using a female pck rat model. The studies concluded:

1. Study 1 , female pck rats fed SPI+SO or SPI+SB diet had higher renal DHA tissue content than rats fed Casein+SO and Casein $+\mathrm{CO}$, but had no significant effect on expression of transcription factors and genes regulating proliferation or inflammation.

2. Study 1 , female pck rats fed SPI+SB diet with the highest renal DHA content and resulted in significantly higher cyst obstruction and decreased renal function.

3. Study 2 , female pck rats fed the SPI+SB diet had significantly higher Ca and P retention. However, bone growth, mineralization, microarchitecture, and strength was not significantly enhanced.

4. Study 3, all female pck rats had liver cysts regardless of diet. Of the dietary treatments, rats fed SPI + SB diet had the highest hepatic cyst obstruction, portal inflammation, and steatosis.

Overall, results from the studies indicated that SPI and/or n-3 PUFA did not delay PKD progression, improve bone health or PLD. Furthermore, the addition of EPA and DHA in the 
SPI + SB diet led to reduced renal function, and liver steatosis and inflammation. It is possible that in injured renal and hepatic tissue, n-3 fatty acid supplementation may increase oxidation and overall PKD severity as shown in the study by Polavarapu et al 1998.

In the absence of large human clinical trials that include dietary intervention for PKD, recommendations for PKD patients must rely on evidence from animal studies. Most dietary studies have used the Han:SPRD-cy rat, a non-orthologous genetic model of ADPKD. Also, the majority of the animal studies have focused on males, despite the existence of gender differences in PKD progression and nutrient metabolism. Therefore, the novel information regarding the effects and potential role of dietary components on molecular mechanisms obtained from studies in this thesis using the pck rat models of PKD can benefit human PKD patients by providing a better understanding of pathways to target in order to inhibit cyst pathogenesis that will allow clinicians to better treat PKD patients. 


\subsection{Future Studies}

Due to the novelty of this research, it is not surprising that the results raises many new questions. One potential area that could be further investigated is dietary lipid and protein dosages. Although, lipid and protein doses in the present studies were consistent with past studies, it is may not be physiologically relevant to humans. For example, most animal studies have use $7 \%$ to $20 \%$ (wt) diet of pure oil, which is unlikely to occur in the human diet. Furthermore, in renal failure, patients are often advised to reduce protein intake to minimize nitrogenous load on the renal system. A future study could determine multiple lipid and protein doses in PKD models to determine optimal doses for beneficial results. Another potential study would be performing RNA-seq on the renal and hepatic tissues which will allow global assessment of which genes and pathways were up-regulated or down-regulated due to dietary components. Since the full pathophysiology of PKD is unknown, this would provide vital information for understanding PKD and potential role of diet in the treatment of this genetic disease. However, rat tissues from the current study may not provide the best representation of up/down-regulated pathways. It may be beneficial to conduct RNA-seq on rat tissues at various points during a new feeding study. Also, to determine if diet truly is beneficial, it would helpful to examine a feeding study comparing both healthy (control) and diseased (experimental) animals. Due to the extensive damage associated with PKD and its related complications, it is quite possible that diet therapy alone may not reverse the disease process. Therefore, it may be beneficial to examine the effects of diet in addition to a pharmalogical agent to maximize beneficial results. Lastly, although most dietary treatments are successful when administered at weaning, it may be beneficial to conduct a study examining dietary treatment in utero since PKD manifests early, particularly ADPKD which has infantile onset. It also may be beneficial to examine the role of diet directly after birth, to maximize results. 